\title{
Impact of a tailored intervention on coaches' attitudes and use of sport psychology services
}

\author{
Rebecca Zakrajsek \\ West Virginia University
}

Follow this and additional works at: https://researchrepository.wvu.edu/etd

\section{Recommended Citation}

Zakrajsek, Rebecca, "Impact of a tailored intervention on coaches' attitudes and use of sport psychology services" (2007). Graduate Theses, Dissertations, and Problem Reports. 4353.

https://researchrepository.wvu.edu/etd/4353

This Dissertation is protected by copyright and/or related rights. It has been brought to you by the The Research Repository @ WVU with permission from the rights-holder(s). You are free to use this Dissertation in any way that is permitted by the copyright and related rights legislation that applies to your use. For other uses you must obtain permission from the rights-holder(s) directly, unless additional rights are indicated by a Creative Commons license in the record and/ or on the work itself. This Dissertation has been accepted for inclusion in WVU Graduate Theses, Dissertations, and Problem Reports collection by an authorized administrator of The Research Repository @ WVU.

For more information, please contact researchrepository@mail.wvu.edu. 


\title{
Impact of a Tailored Intervention on Coaches' Attitudes and Use of Sport Psychology Services
}

Rebecca Zakrajsek, M.S.

\author{
Dissertation submitted to the \\ School of Physical Education \\ at West Virginia University \\ in partial fulfillment of the requirements \\ for the degree of
}

\author{
Doctor of Philosophy \\ in \\ Kinesiology \\ (Major in Sport and Exercise Psychology) \\ Sam J. Zizzi, Ed.D., Chair \\ Jack C. Watson II, Ph.D. \\ Edward E. Jacobs, Ph.D. \\ Kristen D. Dieffenbach, Ph.D. \\ Dallas D. Branch, Jr., Ph.D. \\ Department of Physical Education
}

Morgantown, WV

2007

Keywords: Coaches, perceptions, attitude, expectations, gender, sport psychology consultation, stage of change

Copyright 2007 Rebecca Zakrajsek 


\section{ABSTRACT \\ Impact of a Tailored Intervention on Coaches' Attitudes and Use of Sport Psychology Services}

\section{Rebecca Zakrajsek, M.S.}

This study examined (1) coaches' attitudes and stage of change for sport psychology (SP) service use immediately following a tailored workshop and (2) the impact of a stagematched intervention on coaches' attitudes, stage of change, and behavioral usage patterns during a one-month follow-up. Ninety swim coaches participated in the SP workshop and a total of 53 swim coaches (30 in the stage-matched group and 23 in the control group) completed the one-month follow-up. Eleven tennis coaches participated in the SP workshop and none of the tennis coaches completed the follow-up. Some evidence supported the impact of a tailored SP workshop on stage of change, with approximately $13 \%$ of swim coaches and $18 \%$ of tennis coaches experiencing positive cognitive shifts from precontemplation to contemplation immediately post-workshop. Although, several two-way mixed ANOVAs did not reveal significant interactions (group x time), main effects for TIME found that swim coaches' personal openness, perceived barriers, selfefficacy and intentions to use SP services significantly increased while perceived barriers significantly decreased immediately following the SP workshop. Furthermore, swim coaches' perceived barriers, perceived behavioral control, and self-efficacy were maintained one month following the SP workshop while personal openness and intentions returned close to their pre-workshop means. Lastly, no differences were found between the stage-matched and control group with regard to behavioral SP usage patterns (e.g., contacting a SP consultant, seeking out more information about SP). However, approximately $30 \%$ to $40 \%$ of tennis and swim coaches accessed the website during the four-week follow-up. The appropriateness of the transtheoretical model of behavior change applied to SP service use with coaches and the use of stage-matched interventions will be discussed. 


\section{Dedication}

This dissertation is dedicated to family and loved ones.

Linda Zakrajsek - Thank you for your never ending support and interest in what I do. Your constant thirst for knowledge inspires me to continue to grow and strive to be a better person and professional. I admire your strength and unconditional love and I am proud that you are my mother. I love you.

Daniel, Kim, John, Angela, Kim, Rich, Amy, and Kelly Zakrajsek - Thank you for your love, support, and making me laugh when I needed it most. I can't tell you how much I appreciate you all and how much you have helped me throughout this process. I love you and am grateful that I have such a strong and caring family.

Abby Henry, Jace Hatcher, Sarah Almos - I can't imagine what this process would have been like without you. Thank you for your unconditional support and love. You cheered me on when I needed it most I appreciate and thoroughly enjoyed the many road trips you took to Morgantown. Thank you and I love you. 


\section{Acknowledgements}

Dr. Sam Zizzi, my dissertation chair, thank you for your guidance, expertise, and wonderful ability to be concise. I am grateful that you have been my mentor and advisor over the past five and a half years. I can't thank you enough for the amount of time and energy that you have spent with me starting with my thesis and now dissertation. You're encouragement and support throughout this process has been very much appreciated. I have very much enjoyed working with you and learning from you.

Dr. Jack Watson, thank you for your help and expertise with my thesis and now my dissertation. Thank you for showing your support and belief in me as an individual and professional. That has truly meant a lot to me.

Dr. Kristen Dieffenbach, I thank you and have valued your expertise and support throughout the past year and a half. I am grateful for every moment you set aside time to speak with me regarding my dissertation and coaching education programs. Also, thank you for getting me "out of the office" to go for a run. It helped to keep me sane. I have truly appreciated you taking an interest in this project and putting in your time and effort.

Dr. Dallas Branch, thank you for your help during the dissertation process. I appreciate the time you have put into this project as well as your suggestions and support throughout the past year and a half.

Dr. Ed Jacobs, thank you for your help and support throughout my thesis and dissertation. I have appreciated your words of encouragement, not only during my thesis and dissertation but also during class and internship in the counseling program. Thank you for putting your time into helping me during the past five and half years.

I would like to acknowledge Sue Davis and the Central States Swim Clinic, Jeff Cohen and the USPTA Florida Division, and Rudy Zimmermann and the National Soccer Coaches Association of America. Thank you for allowing me to attend the conference, present a workshop, and gather participants for my dissertation. Thank you for your support as well as your help in recruiting participants. I greatly appreciate it.

Stacey Marple, thank you for the time and dedication that you put into my dissertation. You exceeded my expectations as a research assistant and it was enjoyable to work with you.

I would like to express my heartfelt gratitude to all the vendors that donated items and sponsored my dissertation: Dolfin, FINIS, Nike, and TYR. Thank you. 


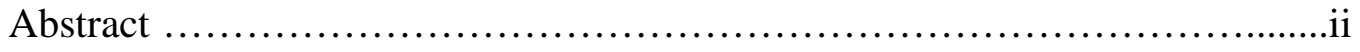

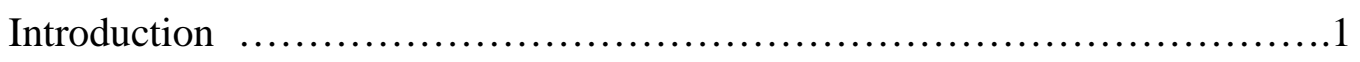

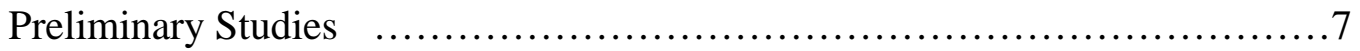

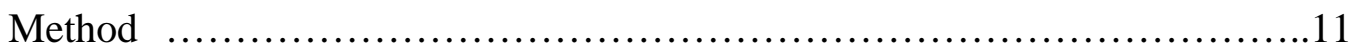

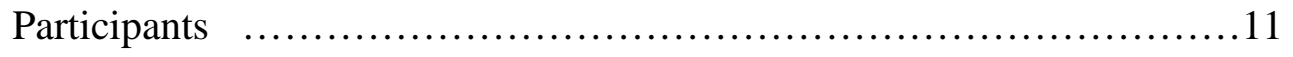

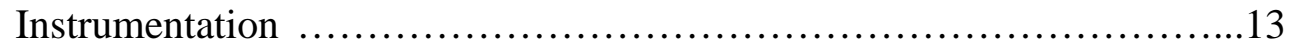

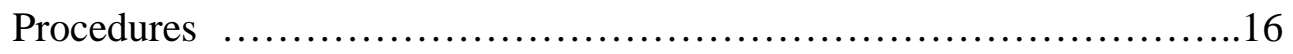

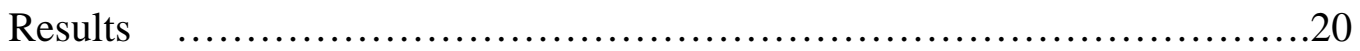

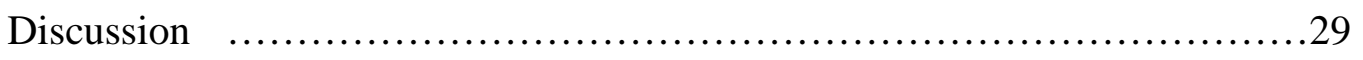

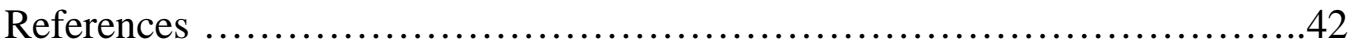

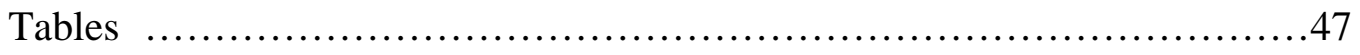

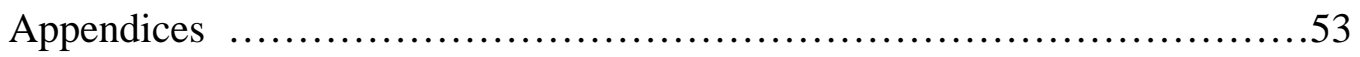

Appendix A. Supporting Materials for Preliminary Studies ..............53

Appendix B. Coaches Survey Packet Pre and Post-Workshop ............79

Appendix C. Coaches One-Month Follow-Up Survey Packet ...........88

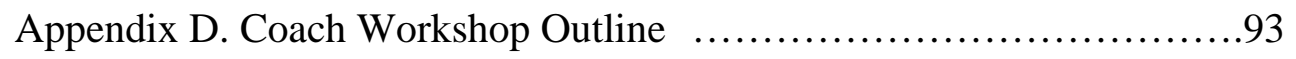

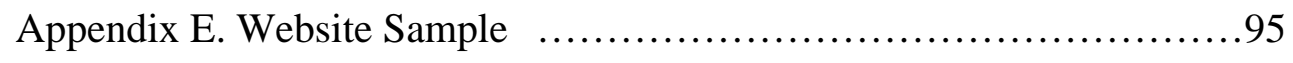

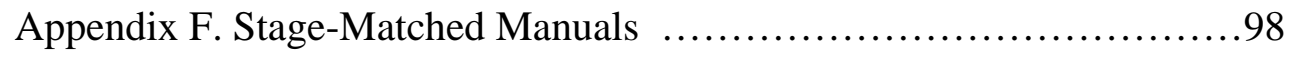

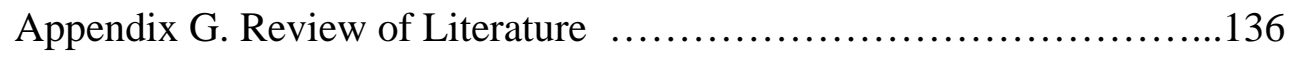


List of Tables

Page \#

Table 1: Swimming Coaches Scores on SPARC-2 Subscales

Over Time

Table 2: Swimming Coaches Scores on Dependent Variables

Over Time

Table 3: Swimming Coaches Barriers Pre-Workshop and

Post-Workshop

Table 4: Swimming Coaches Self-Reported Behavioral Usage

Patterns

Table 5: Swimming Coaches Website and Email Tracking

Table 6: Tennis Coaches Scores on Dependent Variables Pre-

Workshop to Post-workshop .52 


\section{Introduction}

As the field of sport psychology (SP) continues to grow, the literature consistently reports that many coaches have an interest and willingness to use SP services and agree that psychological skills are important to athletic success (Kimiecik \& Gould, 1987; Partington \& Orlick, 1987; Rice, 1996; Sullivan \& Hodge 1991; Wrisberg, 1990; Zakrajsek \& Zizzi, 2007). However, researchers also have found that only about 20\% of coaches sampled use some form of SP services (Rice; Zakrajsek \& Zizzi), even though at least $40 \%$ report having access. It is clear that the field of SP is becoming more visible to coaches, yet a gap continues to exist in which some coaches have not made the shift from willingness and interest to actual implementation of SP into training.

There are several possible reasons as to why some coaches do not utilize SP services. Lack of funding and time constraints have been consistently reported in the literature as some of the most common reasons why coaches and university athletic departments do not utilize mental skills training or SP services (Anshel, 1989; Gould, Medberry, Damarjian, \& Lauer, 1999; Gould, Tammen, Murphy, \& May, 1989; Haslam, 2004; Kremer \& Marchant, 2001; Pain \& Harwood, 2004; Voight \& Callaghan, 2001). Access has also been identified as a barrier in which $34 \%$ of elite level coaches sampled reported not knowing how they would go about identifying and accessing a SP consultant (Scully \& Hume, 1995). Sport psychology and mental skills training are not a traditional aspect of coaching in the U.S. and the coaching literature has recognized the need to develop coach education programs that balance technical and tactical knowledge with other areas such as SP (Cale \& Crisfield, 1994; Cassidy, Potrac, \& McKenzie, 2006). Currently, there is no standardization in coaching education programs in the U.S. and the 
programs that are in existence vary in content and requirements (McMillin \& Reffner, 1999). Because SP is often not viewed as a traditional aspect of sport training and because coaches may perceive the benefits of SP in terms of actual performance difficult to prove (Gould et al., 1999; Pain \& Harwood, 2004), some coaches and university athletic departments may not consider SP beneficial (Voight \& Callaghan, 2001; Haslam, 2004). Unless SP is integrated into sport and seen as a natural part of the athletic environment, some coaches may be hesitant to implement SP into practice and may hold misconceptions about how SP works.

Negative connotations associated with the discipline of SP continue to be reported by coaches and identified as a barrier to SP service use (Kremer \& Merchant, 2002; Pain \& Harwood, 2004). Some coaches still hold the misconception, for example, that SP is for problem athletes only and are aware that athletes could be ridiculed for seeing a SP consultant due to the term "psychology" within the title. Other coaches have expressed a fear that SP would make their athletes think too much about their game and negatively impact performance (Haslam, 2004). Next, expectations may influence willingness to seek SP consultation (Martin et al., 2001). For instance, coaches may expect the SP consultant to openly discuss an athlete’s problems (Zakrajsek \& Zizzi, 2007). Within the athletic environment, coaches often talk among themselves with regard to athletes' problems (Speed, Andersen, \& Simons, 2005) and the perceived lack of feedback and not knowing what is happening may be viewed by some coaches as limiting the value of SP (Pain \& Harwood). Therefore, if coaches and SP consultants begin a consultation with conflicting expectations of how SP services will be delivered, dissatisfaction and termination of services may occur. Sport psychology professionals need to clarify 
expectations prior to the start of a consultation as well as explain why certain expectations within service use (e.g. confidentiality) are important to maintain.

Although these factors have not been linked directly to actual service use, researchers have more recently made the link between attitudes, expectations, and confidence to overcome perceived barriers with athletes and coaches' intentions to use SP services. Anderson, Hodge, Lavallee, and Martin (2004) investigated the relationship between 112 elite athletes' attitudes toward SP and intentions to use SP services within the Theory of Reasoned Action and Theory of Planned Behavior. Results of a regression analysis revealed that confidence, subjective norm, and perceived behavioral control accounted for $39.7 \%$ of the variance in athletes' intentions. Predicting intentions to use SP services with 374 track and swimming coaches, Zakrajsek and Zizzi (2007) found that confidence, stigma tolerance, and expectations accounted for $38 \%$ of the total variance in coaches' intentions. However, confidence in SP consultation controlled substantially more variance (34\%) in predicting coaches' intentions compared to stigma tolerance (3\%), and expectations (1\%).

It appears that coaches and athletes consider several factors (e.g. perceived gains, losses, and barriers) when weighing the decision to use SP services. Some coaches may be aware of the benefits of using SP services but the perceived barriers (e.g. stigma, access, time, money, lack of knowledge, expectations, confidence in SP) continue to inhibit motivational readiness to integrate SP into training. Thus, in order to increase service use, professionals should seek to address coaches' attitudes, beliefs, and motivational readiness to use SP services within a theoretical framework. Applying the Transtheoretical Model to Mental Skills Training 
Within the transtheoretical model (TTM), behavior change is viewed as a process with predictable stages: precontemplation; contemplation; preparation; action; and maintenance (Prochaska \& DiClemente, 1983). Ten strategies to initiate or modify change in behavior, cognition, or affect have been incorporated within the five stages of change, in which certain processes used earlier in the stages (e.g. cognitive and affective activity) have been found to lay the groundwork for future action (Perz, DiClemente, \& Carbonari, 1996; Prochaska \& DiClemente). Lastly, core constructs of Janis and Mann’s (1977) decision making model have been integrated into the TTM, in which literature consistently reports that before action is taken, a crossover effect occurs where the pros of changing the behavior outweigh the cons (Prochaska et al., 1994).

Applying the TTM with athletes, Leffingwell and colleagues (2001) surveyed 308 NCAA Division I athletes and found stage of change to be related to subsequent participation in SP consultation, with athletes later in the stages of change (action) to be most likely to initiate individual consultation. Similar to the literature with problem and healthy behaviors, a crossover in pros and cons occurred before action was taken. Being able to identify an athletes’ stage and the crossover in pros and cons appears to be valuable information toward predicting SP consultation. Furthermore, three of the nine decisional balance items addressed athletes concerns of being stigmatized which may be an area to devote attention in the early stages of readiness and facilitate use of SP services.

Researchers have used measures within the TTM to evaluate the effectiveness of a mental skills training program and SP workshop. Traditionally, mental skills training programs have been assessed in a dichotomous manner (e.g. using or not using SP 
services), which assumes that changes related to the program will be dramatic, obvious, or immediate (Grove, Norton, Van Raalte, \& Brewer, 1999). The TTM assumes that more subtle changes (e.g. changes in attitudes such as pros and cons) will precede more obvious ones (e.g. regular use of SP services). For example, Grove and colleagues (1999) found that integrating a six-week mental skills training program with elite youth baseball athletes facilitated movement toward regular implementation of SP into practice. Prior to the intervention, $40 \%$ of the athletes in the mental skills training group identified being in the action or maintenance stage. Immediately following the program, athletes in the maintenance stage increased to $90 \%$ and dropped slightly to $75 \%$ three months later. This movement was not evident with the control group. These results support that a mental skills intervention may have a positive impact on stage of change; however, caution must be noted because athletes were required to attend the six-week training program so these changes may not be reflected in programs with voluntary attendance.

Zizzi and Perna (2003) examined the initial impact of a 45-minute SP workshop with 220 college and high school athletes on 14 teams. Results revealed a significant impact in stage of change profiles immediately following the workshop. From pre-post workshop, contemplation and pros scores increased, precontemplation and con scores decreased, and no change was observed in action scores. Seventy one athletes (32\%) were found to shift between stages, in which 24 athletes moved from precontemplation to contemplation and 11 moved from contemplation to action. Interestingly, 36 moved from action or contemplation to a lower stage. Despite not having a control group, the changes observed in pros and cons and stage of change is encouraging. For athletes in the early stages of change, Zizzi and Perna provided some support that a SP workshop and 
addressing the stigma associated with SP can have an impact on athletes' pros and cons and attitudes toward SP services. These results are supported by Leffingwell et al. (2001) who suggested that stigma may be an important factor to address in the early stages of change.

In addition to using stage of change as a measure of program impact, researchers within SP have suggested using the TTM as a form of intake for interventions (Grove et al., 1999; Zizzi \& Perna, 2003). Distinguishing between those who are not thinking about using SP services, are intending to use SP services in the near future, have made some attempts at using SP services, and have actively integrated SP into training may be useful toward developing interventions that maximize impact and facilitate change from precontemplation to action. This pre-intervention assessment may also help identify which athletes or coaches are most ready to use SP services and how to tailor interventions to meet different needs and levels of readiness.

Because research has found that approximately $80 \%$ of coaches surveyed do not use SP services (Rice 1996; Zakrajsek \& Zizzi, 2007), standard workshops and interventions geared toward action may not be addressing the needs of the majority of coaches. Most coaches are in the early stages of readiness; therefore, if we are interested in increasing service use in SP it would make sense to develop educational programs targeting attitudinal and behavior change.

Based upon the review of the literature and using the TTM as a framework, this study had two primary purposes. The first purpose was to examine the initial impact of a brief SP workshop on coaches' attitudes and readiness to use SP services. More specifically, it was hypothesized that coaches' confidence in SP consultation, belief in 
their ability to access SP services (e.g. perceived behavioral control), and intentions to use SP services would increase immediately following the SP workshop. Coaches' stigma tolerance and perceived barriers to SP service use were expected to decrease immediately following the workshop. Lastly, it was hypothesized that there would be an increase in the number of coaches in contemplation, decrease in the number of coaches in precontemplation, and no change with regard to preparation or action stage assignments immediately following the workshop.

The second purpose of the study was to examine the impact of a stage-matched intervention on coaches' attitudes, readiness to use SP services, and actual behavioral SP usage patterns one month following the workshop. It was hypothesized that coaches in the stage-matched group would have a further increase in their intentions to use SP services and a further decrease in perceived barriers at the one-month follow-up. Coaches in the stage-matched group were expected to have more coaches that moved forward in their stage of change profile compared to coaches in the control group at the one-month follow-up. And lastly, coaches in the stage-matched group were hypothesized to show more behavioral changes with regard to SP usage patterns (e.g. contacting a SP consultant, seeking out more SP information, referring athletes for personal or performance problems, accessing a SP website, and using SP services) compared to coaches in the control group at the one-month follow-up.

\section{Preliminary Studies}

The preliminary studies were conducted to strengthen the development of the SPA-RC (Zakrajsek \& Zizzi, 2007) questionnaire and to learn more about coaches’ perceptions and use of SP services. 
Interviews. Interviews were conducted with eight NCAA Division I head $(n=5)$ and assistant $(n=3)$ coaches. Based on the interview data, slight modifications of the existing SPA-RC items were made, and a total of 11 items were added. Three items were added to the personal openness subscale and eight items for the cultural preference subscale. Additionally, several themes emerged from the interviews regarding coaches’ expectations and barriers to service use, which facilitated the development of items in the survey packet for the current study. Refer to Appendix A to review an example of the coach's script, theme tree, and the SPA-RC modifications.

SPARC-2. Coaches attending the 2006 national convention of the Texas High School Coaches Association (THSCA) were included as participants for the purpose of improving the instrument. A total of 304 coaches participated in the study, in which 232 coached football and a total of 267 worked at the high school level. Exploratory factor analysis revealed a four-factor solution accounting for $52.5 \%$ of the total response variance. The SPA-RC was revised to the Sport Psychology Attitudes Revised Coaches-2 (SPARC-2) questionnaire, a 26-item assessment of coaches’ attitudes toward SP consulting on four factors: stigma tolerance (7 items); confidence in SP consultation (8 items); personal openness (5 items); and cultural preference (6 items). Internal consistency (Cronbach’s alpha) for the SPARC-2 was .84 (stigma tolerance), .83 (cultural preference), .79 (confidence in SP consulting), and .64 (personal openness). Refer to Appendix A (see Table 1) for the final factor structure of the SPARC-2.

In order to have a quick and practical means of gauging coaches’ attitudes toward SP consulting, a shortened version of the SPARC-2 was developed by means of reliability checks as items were removed from each subscale. The brief form of the 
SPARC-2 contains 15 items and four subscales: stigma tolerance (5 items), cultural preference (3 items), confidence in SP consultation (4 items), and personal openness (3 items). Internal consistency (Chronbach’s alpha) estimates were .81 (stigma tolerance), .81 (cultural preference), .75 (confidence in SP consultation), and .69 (personal openness).

Workshop. Coaches who attended the 2007 convention of the National Soccer Coaches Association of American were included as participants for the purpose of refining the survey packet and workshop methods. A total of 28 soccer coaches at various levels (Division I, Division II, NAIA, High School, Youth, and Club) participated in the 45-minute workshop designed to address attitudes, expectations, and barriers toward SP services. Refer to Appendix A for the pre-workshop and post-workshop survey packet.

The shortened version of the SPARC-2 was used successfully in the workshop. Internal consistency (Chronbach’s alpha) estimates were .79 (stigma tolerance), .74 (cultural preference), .70 (confidence in SP consultation), and .64 (personal openness).

Dependent samples t-tests revealed the following results. Coaches' confidence in SP consulting scores significantly increased following the workshop, $t(27)=-2.61, p=$ $.015, d=-.42$, revealing a moderate effect. A large significant increase was found in coaches' perceptions of their ability to access a SP professional for the upcoming season following the workshop, $t(27)=4.5, p<.001, d=1$.12. Coaches' perception of barriers to using SP services significantly decreased following the workshop, $t(26)=4.423, p<$ $.001, d=.7$. Lastly, each of the following also significantly increased immediately postworkshop: coaches intentions of using SP services in the next month and next season, $t(26)=-3.05, p=.05, d=-.51$ and $t(25)=-5.13, p<.001, d=-.78$; coaches' likelihood 
of referring an athlete to a SP consultant for personal concerns and performance problems, $t(26)=-2.29, p<.05, d=-.22$ and $t(26)=-2.64, p<.05, d=-.49$; and coaches' likelihood of seeking out more information about SP in the next month, $t(26)=$ -2.45, $p<.05, d=-.37$. Refer to Appendix A (see Tables 2 and 3) for individual item means and standard deviations for perceived behavioral control, subjective norm, and barriers.

Prior to the workshop, 22 (78.6\%) of the coaches identified themselves in precontemplation, 2 (7.1\%) in contemplation, and $4(14.3 \%)$ in preparation. None of the coaches were in action or maintenance. Immediately following the workshop, 20 (71.4\%) of coaches were in precontemplation, 5 (17.9\%) were in contemplation, and 3 (10.7) were in preparation. It appears that two coaches moved forward while one coach reported a negative cognitive shift. On the 6-point manipulation check item, the large majority of coaches reported that the workshop had a positive impact on their impression of SP services (one coach reported a negative response; $M=5.14$; $S D=1.15$ ).

In conclusion, the pilot workshop data showed some support for assessing changes in attitudes, intentions, and readiness to use SP services as a means for evaluating the impact of a brief SP workshop. Although the vast majority of coaches did not shift in their readiness to use SP services, the changes in attitude, barriers, perceived behavioral control, and intentions are encouraging. Additionally, most coaches were in precontemplation, which provided some support for developing workshops targeted toward attitudinal change. However, it is unclear as to how long these changes will last. 
Method

\section{Participants}

Swimming coaches. Approximately 347 swimming coaches attended the Central States Swim Clinic (CSSC) and 103 participated in the workshop, representing a 29.68\% response rate. However, due to incomplete or questionable data, 13 questionnaires were eliminated resulting in a subsample of 90 swimming coaches.

The sample included 44 male and 41 female swimming coaches. Five respondents did not specify their gender. The ages of the respondents fell into one of the following categories: 21-29 $(n=32)$; 30-39 $(n=21)$; 40-49 $(n=26)$; and 50+ years $(n=10)$. Of the 90 swimming coaches, 85 were Caucasian, one was African American, one was Latino, and one specified "N/A." The sample included the following levels of swim coaches: High School ( $n=38)$; Age-Group $(n=23)$; Division I $(n=5)$; Division II $(n=$ 2); Division III ( $n=2)$; NAIA ( $n=1)$; and other (i.e., club, masters, USS, and YMCA) $(n=16)$. Fifteen swimming coaches specified coaching an additional team (i.e., AgeGroup, Club, High School, Middle School, USA, YMCA, and Division I). The sample included head swimming coaches $(n=57)$, assistant coaches $(n=29)$, and three coaches specified “other” (i.e., graduate assistant and age-group coach). Participants had a mean of 9.65 years $(S D=7.88)$ of coaching experience, ranging from less than one year to 35 years of coaching. Forty-eight swimming coaches were currently in season while 41 were not currently in season. Fifty-seven participants were actively coaching swimming at the time of the workshop while 32 were not actively coaching. Fifty of the participants coached teams, one coached individuals, and 38 coached both teams and individual athletes. The majority of coaches $(n=78)$ worked with both male and female swimmers, 
10 coached female swimmers, and two coached male swimmers. Nine (10\%) swimming coaches had access to SP services and two (2.2\%) of the coaches sampled had a SP consultant currently working with their team. Fourteen (15.6\%) of the swimming coaches sampled had heard of AASP certification for SP. Some coaches did not provide responses to demographic questions (e.g. gender, age, ethnicity, level of coaching, or job title) resulting in missing data.

Tennis coaches. Approximately 285 tennis coaches attended the United States Professional Tennis Association (USPTA) Florida Division convention and 15 participated in the workshop, resulting in a 5.2\% response rate. However, due to incomplete data, four questionnaires were eliminated resulting in a subsample of 11 tennis coaches.

The sample included 10 males and one female tennis coach. Ages were grouped into the following categories: 21-20 $(n=3)$; 30-39 $(n=1)$; 40-49 $(n=3)$; and 50+ years $(n=4)$. Of the 11 tennis coaches, 8 were Caucasian, one was Hispanic, one was American Indian, and one was Brazilian. The sample included the following levels of tennis coaches: Club $(n=5)$; Juniors $(n=2)$; High School $(n=1)$; and other (i.e., Tennis Pro Coach, Sport Facility) $(n=2)$. Two tennis coaches specified coaching additional athletes (i.e., middle school and adults). The sample included head tennis coaches ( $n=$ 5), an assistant coach ( $n=1)$, and five coaches specified “other” (i.e., country club pro, director, USPTA pro, and tennis pro). Participants had a mean of 14.2 years $(S D=10.71)$ of coaching experience, ranging from three years to 36 years of coaching. Six tennis coaches were currently in season and four coaches were currently not in season. Nine coaches were actively coaching tennis at the time of the workshop and one was not 
actively coaching. Two participants coached individual athletes while nine specified coaching both team and individual athletes. The majority of coaches $(n=10)$ worked with both male and female tennis players, while one coach specified working with only female tennis players. Four (36.4\%) tennis coaches had access to SP services and none of the coaches currently had a SP consultant working with their athletes. One (9.1\%) tennis coach had heard of AASP certification for SP. Some coaches did not provide responses to demographic questions resulting in missing data.

\section{Instrumentation}

Attitudes. The shortened version of the Sport Psychology Attitudes Revised Coaches-2 (SPARC-2; see Appendix B; pre-workshop survey part 2) questionnaire contains 15 items assessing coaches’ attitudes toward SP consulting on four subscales: stigma tolerance (5 items); cultural preference (3 items); confidence in SP consultation (4 items); and personal openness (3 items). A six-point Likert-type scale, from 1 (strongly disagree) to 6 (strongly agree), was used. Interpretation and scores on the shortened version of the SPARC-2 were obtained by averaging the responses within each subscale. Higher scores (closer to 6) indicate a more negative attitude toward seeking SP consultation (stigma tolerance), a belief that SP consultation and mental training is useful (confidence in SP consultation), an unwillingness to be involved in SP consultation and mental training (personal openness), and a strong identity to nationality, ethnicity, culture, or race (cultural preference). Internal consistency (Chronbach’s alpha) estimates for the subsample of swimming coaches were .90 (stigma tolerance), .87 (confidence in SP consultation), .82 (cultural preference) and .79 (personal openness). 
Stage of change. Coaches' readiness to use SP services was assessed using a single-item ladder, which has been supported by previous literature with athletes (Grove et al., 1999) and coaches (Zakrajsek \& Zizzi, 2005). The stage of change measure focused on the five stages of behavior change: precontemplation, contemplation, preparation, action, and maintenance. Regular use of SP services was defined as using SP services consistently two to four times per month. Sport psychology services included consulting with a SP professional, having a SP professional meet with the team/athletes, having a SP professional meet with the coach or coaching staff, and referring athletes for performance enhancement or counseling. The single-item ladder stage of change question may be viewed in Part 3 of the survey packet (see Appendix B; pre-workshop survey). The number of swimming coaches who identified currently not working with a SP consultant $(n=83)$ closely resembled the number of coaches in precontemplation and contemplation ( $n=86)$, which provided some validity toward the stage of change assessment measure.

Expectations and barriers of SP service use. Ten items were used to assess coaches' expectations and perceived barriers of using SP services (see Appendix B; preworkshop survey part 5). Items were developed using interview data from the preliminary study as well as recent literature on barriers to using SP (Haslam, 2004; Pain \& Harwood, 2004; Voight \& Callaghan, 2001). Coaches rated their level of agreement on a Likerttype scale ranging from 1 (strongly disagree) to 6 (strongly agree). A total barriers score was obtained by averaging the responses of the 10 items. Higher scores reflect higher perceived barriers to using SP services. 
Perceived behavioral control, self-efficacy, and subjective norm. Six items were used to assess coaches' perceived behavioral control, self-efficacy, and subjective norm (see Appendix B; pre-workshop survey part 4). Coaches’ perceived behavioral control assessed coaches' confidence in their ability to access and use SP services. The item used to assess perceived behavioral control was "If the coaching staff wanted to, we could easily access and use sport psychology services for the upcoming season” and was modified from a question used in previous research with athletes (Anderson et al., 2004). Ajzen (2002) suggested including self-efficacy in the initial scale of perceived behavioral control. Therefore, a second item was developed to measure coaches' self-efficacy and included "I would not know how to access a sport psychology professional for the upcoming season." Subjective norm has a total of four items. As suggested by Ajzen, items were included to assess how important others approve or disapprove of the desired behavior as well as if important others themselves perform the desired behavior. A sample item of each includes "I feel pressure from people who are important to me to not access and use sport psychology services with our athletes" and "the coaches whose opinions I respect use sport psychology services with their athletes.” Item 26 (subjective norm) is reverse scored and was modified from previous literature with athletes (Anderson et al.). Coaches rated each statement on a Likert-type scale from 1 (strongly disagree) to 6 (strongly agree). Higher scores (closer to 6) reflect higher perceived behavioral control, lower self-efficacy in accessing and using SP services, and a stronger norm for using SP services.

Intentions. A total of five items were included to measure coaches' intentions (see Appendix B; pre-workshop survey part 6). Four items (40a, 40b, 41a, 41b) were included 
to measure coaches' intentions to use SP services or refer athletes and have been used successfully in previous literature (Zakrajsek \& Zizzi, 2007). Item 42 was included to measure coaches' intentions to seek out more information about SP in the next month. All items were on a Likert-type scale ranging from 1 (not at all likely) to 6 (very likely). Higher scores (closer to 6) reflect higher intentions to use SP services and higher scores on item 42 reflect higher intentions to seek out more information about SP.

Usage patterns. Several coach behaviors were assessed one-month following the workshop through both a self-report follow-up survey as well as web and email tracking. Self-report items included information regarding contacting a SP consultant, contacting the researcher, using a SP consultant, gathering information about SP and SP services, referring athletes to a SP consultant, and accessing the website provided by the researcher. Refer to Appendix C (follow-up survey packet, part 1 and part 6) for specific questions. Web and email tracking was also used to assess coach behavior (e.g. how many times coaches accessed the web site or emailed the consultant).

\section{Procedures}

Approval from the Institutional Review Board for the Protection of Human Subjects was obtained for the study. In addition, permission was obtained from the clinic coordinator of the CSSC and the vice president of the USPTA Florida division for the primary investigator to attend each convention, recruit coaches for participation, and present a workshop. The procedures in the present study occurred in two phases.

Phase I. The researcher attended two coaches’ conventions (CSSC and USPTA) to present a workshop. The researcher presented two workshops at the CSSC convention and one workshop at the USPTA convention. The workshop itself was 30-minutes in 
length and followed an outline (see Appendix D). The workshop focused on coaches' attitudes, expectations, barriers, and access to SP services.

During the first 10-15 minutes of the session, the researcher provided a brief explanation of the study and instructions regarding the consent form and questionnaire packet. Each coach received a survey packet containing the pre-workshop survey, a contact information sheet, and the post-workshop survey. The pre-workshop survey (see Appendix B) was completed during this time. Each coach also provided contact information that included their initials and email address (contact method for follow-up intervention). Contact information was paired with an ID number in order to track prepost and follow-up data. Coaches' email addresses were used for the one-month followup described later in this section. The contact information page also informed coaches to stop completing the survey packet and wait until the end of the workshop to complete the post-workshop survey.

Immediately following the workshop and during the last 10-15 minutes of the time allotted during the session, coaches completed the post-workshop survey (see Appendix B). The post-workshop survey was the same as the pre-workshop survey, except it included a manipulation check item. The post-workshop survey packet also contained an ID number that corresponded to the coaches' pre-workshop ID number and contact information. Coaches were thanked for their time and given a handout with the researchers contact information and a web-site that each coach had access to for the next month (http://www.wvu.edu/ physed/coachingtools/). The web-site contained information about SP services, news article links, and links to other SP resources. The information on the website changed each week (for four weeks) in order to provide 
coaches with new information and an incentive to consistently access the website. The researcher was also available via e-mail for any questions that the coaches had about SP services during the month following the workshop. See Appendix E for a sample of the website.

Phase II. Following the workshop, coaches were randomly assigned to either a stage-matched group or control group. Out of the 90 swimming coaches, 45 were randomly assigned to the stage-matched group and 45 to the control group. Out of the 11 tennis coaches, 6 were randomly assigned to the stage-matched group and 5 to the control group. During the month following the workshop, the stage-matched group received information via email, which was tailored toward their stage of change. The control group did not receive any additional information or intervention. Coaches in both the stage-matched and control groups all received email prompts once a week to access the website and to contact the researcher with any questions.

The stage-matched intervention consisted of tailored self-help packets that were focused on the five stages of change and were delivered through email as pdf file attachments. Coaches in precontemplation received a packet of information entitled “Why Mental Skills Training?” which focused on increasing awareness of the benefits of SP services. Anecdotal and empirical evidence of the value of SP consulting was also included. Lastly, information addressed misperceptions and concerns of the stigma associated with SP consulting. Coaches in contemplation received information entitled “Give it a try” which discussed the benefits and barriers to using SP services (pros and cons). Information regarding perceived behavioral control was also included. Coaches in preparation received information entitled "Getting Started” which focused on reviewing 
the benefits of using SP services. Obstacles to regular use of SP services (e.g. access, time, money) were addressed. Importance was placed on making a commitment to mental skills training and using SP services regularly. A discussion of the process of SP consulting, the role of a SP consultant and coach, who is considered qualified, and how to initiate contact and set up a program was also included. There were no coaches in the current sample that identified being in the action or maintenance stage of change; therefore, manuals were not sent that addressed the later stages of change. Refer to Appendix F for a sample of the stage-matched manuals.

One month following the workshop, coaches were sent an email to complete the follow-up survey packet (see Appendix C). The follow-up survey was completed online through simple forms and coaches were reminded to complete the survey through email. The follow-up survey contained actual usage patterns which included questions about seeking out SP information, contacting a SP professional, and actual use of SP services. The follow-up survey packet also contained the shortened version of the SPARC-2, and items addressing stage of change, subjective norm, perceived behavioral control, expectations and barriers of using SP services, and intentions. In addition to the followup survey, web and email tracking (i.e., how many times coaches accessed the website and/or emailed the researcher) were used to assess coaching behaviors.

In order to ensure confidentiality, the researcher was blind to coaches contact information (i.e., initials and email address). A master “contact” sheet was created, which matched the ID numbers on the survey packets to the coaches' initials and email address. A research assistant was responsible for the master "contact” sheet. The researcher prompted the research assistant to email coaches the weekly reminders to check the 
website. The researcher also used the ID numbers to prompt the research assistant to email the stage matched interventions to the appropriate coach as well as to email coaches regarding the follow-up survey. A separate email account was created by the researcher for coaches to contact with questions. The research assistant was also responsible for checking the email account and referring questions to the researcher without identifying the coaches. Any identifiable information was removed prior to entering and analyzing the data.

\section{Results}

\section{Swimming Coaches}

Fifty-three swimming coaches completed all three data points (pre-workshop, post-workshop, and follow-up), representing a $41.1 \%$ attrition rate from post-workshop to the follow-up. Out of the 53 swimming coaches, 30 were in the stage-matched group and 23 were in the control group resulting in an attrition rate of $33.3 \%$ and $56.6 \%$ respectively. Two-way mixed ANOVAs were performed to test the study's hypotheses with one between group independent variable (group- two levels), one repeated measures independent variable (time- three levels) and nine dependent variables (stigma tolerance, confidence in SP consultation, cultural preference, personal openness, subjective norm, perceived behavioral control, self-efficacy, perceived barriers, and intentions). Therefore, the significance level was adjusted to .01 to control for Type I error. Adjusted F’s (Greenhouse-Geisser) were reported for three variables (stigma tolerance, cultural preference, and subjective norm) because the assumptions of sphericity were violated. With regard to attitudes toward SP consultation, results of the two-way mixed ANOVAs revealed no significant interactions (group $\mathrm{x}$ time) on stigma tolerance, $F(1.6$, 
$96)=.11, p=.86, \eta^{2}=.002$, confidence in SP consultation, $F(2,98)=1.11, p=.33, \eta^{2}$ $=.022$, personal openness, $F(2,98)=.96, p=.39, \eta^{2}=.019$, and cultural preference, $F(1.7,98)=.35, p=.66, \eta^{2}=.007$ (refer to Table 1$)$. However, a significant main effect for TIME was found for the dependent variable personal openness, $F(2,98)=7.04, p<$ $.01, \eta^{2}=.126$, revealing a moderate effect. Multiple comparisons revealed that swimming coaches in both the stage-matched and control groups became more open from pre-workshop to post-workshop, $p<.01$ and less open from post-workshop to the followup, $p<.05$. Refer to Table 1 for means and standard deviations on SPARC-2 subscales over time.

The two-way mixed ANOVAs revealed no significant interactions (group x time) on subjective norm, $F(1.7,86)=2.87, p=.07, \eta^{2}=.063$, perceived behavioral control, $F(2,98)=.81, p=.45, \eta^{2}=.016$, and self-efficacy $F(2,100)=.05, p=.97, \eta^{2}=.001$. However, a significant main effect for TIME was found for the dependent variables perceived behavioral control, $F(2,98)=10.5, p<.001, \eta^{2}=.176$, and self-efficacy, $F(2$, 100) $=44.77, p<.001, \eta^{2}=.472$, revealing moderate to large effects. Multiple comparisons revealed that swimming coaches perceived higher behavioral control from pre-workshop to post-workshop, $p<.001$. Swimming coaches in both the stage-matched and control groups perceived higher behavioral control from pre-workshop to the followup, $p<.05$. With regards to self-efficacy, post-hoc testing revealed that both groups reported significantly higher self-efficacy from pre-workshop to post-workshop, $p<.001$ and from pre-workshop to follow-up, $p<.001$.

The two-way mixed ANOVA revealed no significant interaction (group x time) on perceived barriers, $F(2,100)=.180, p=.84, \eta^{2}=.004$. However, a significant main 
effect for TIME was found on the dependent variable perceived barriers, $F(2,100)=$ 20.56, $p<.001, \eta^{2}=.291$, with a large effect. Pairwise comparisons revealed that swimming coaches in both the stage-matched and control groups perceived barriers significantly decreased from pre-workshop to post-workshop, $p<.001$ as well as from pre-workshop to the follow-up, $p<.001$. Refer to Table 2 for means and standard deviations on the dependent variables subjective norm, perceived behavioral control, and barriers over time. In addition, when looking at individual barrier items, money and time were consistently reported as the highest barriers to service use. Refer to Table 3 for individual barrier item means and standard deviations pre-workshop and post-workshop.

The two-way mixed ANOVA revealed no significant interaction (group x time) on intentions, $F(2,92)=1.2, p=.31, \eta^{2}=.025$ (refer to Table 2). However, a significant main effect for TIME was found on the dependent variable intentions, $F(2,92)=15.58, p$ $<.001, \eta^{2}=.253$, with a large effect. Post-hoc testing revealed that swimming coaches in both the stage-matched and control groups increased their intentions significantly from pre-workshop to post-workshop, $p<.001$. Intentions returned close to baseline at the follow-up in which there was a significant decrease in the mean intentions score from post-workshop to the follow-up, $p<.001$.

Stage of change. It was hypothesized that there would be an increase in the number of coaches in contemplation and a decrease in number of coaches in precontemplation from pre to post-workshop. Due to several cell frequencies being one or less, stage of change frequencies pre-workshop and post-workshop could not be analyzed with a two-way chi square analysis because assumptions of the test would have been violated. However, stage of change frequencies pre-workshop and post-workshop 
are reported below. Prior to the workshop, 66 (73.3\%) of the swimming coaches identified themselves in precontemplation, 20 (22.2\%) in contemplation and 4 (4.4\%) in preparation. Immediately following the workshop, 54 (60.7\%) of the swimming coaches were in precontemplation, 32 (36\%) were in contemplation, and 3 (3.4\%) were in preparation. Overall, there was an increase in contemplation and decrease in precontemplation from pre to post-workshop. When looking further at the data, 12 (13.3\%) coaches had positive cognitive shifts from precontemplation to contemplation. One (1.1\%) coach who identified being in preparation prior to the workshop had a negative cognitive shift, moving to precontemplation immediately following the workshop. In addition, 1 (1.1\%) coach who identified being in precontmplation prior to the workshop did not answer the stage of change question in the post-workshop survey. On the 6-point manipulation check item ranging from 1 (very negative impact) to 6 (very positive impact), coaches reported that the workshop had a positive impact on their impression of SP services $(M=4.78, S D=1.05)$.

It was further hypothesized that coaches in the stage-matched group would have more coaches who moved forward in their stage of change profile compared to coaches in the control group at the one-month follow-up. Thirty coaches completed the follow-up in the stage-matched group. Of the 30 coaches, 19 (63.3\%) were in precontemplation, 10 (33.3\%) were in contemplation, and 1 (3.3\%) was in preparation at the one-month followup. When looking further at the data, 3 (10\%) coaches had positive cognitive shifts moving from preceontemplation to contemplation, and 5 (16.6\%) coaches had negative cognitive shifts moving from contemplation to precontemplation. Twenty-three coaches completed the follow-up in the control group. Of the 23 coaches, 13 (56.5\%) were in 
precontemplation and 10 (43.5\%) were in contemplation at the one-month follow-up. One (4.3\%) coach had a positive cognitive shift moving from precontemplation to contemplation and no coaches had a negative cognitive shift.

Self-Reported Behaviors. It was hypothesized that coaches in the stage-matched group would have more behavioral SP usage patterns (accessing the website, contacting a SP consultant, seeking out more information, contacting the researcher, referring athletes, and using SP services) compared to coaches in the control group at the one-month follow-up.

The results of a two-way chi square analysis revealed no significant difference in the number of coaches who accessed the website between the stage-matched and control groups, $\chi^{2}(1, n=53)=.007, p=.933, \phi^{2}=.012$. Overall, a total of $28(52.8 \%)$ coaches reported accessing the website over the four-week time period. More specifically, 16 (53.3\%) coaches from the stage-matched group and 12 (52.2\%) coaches from the control group reported accessing the website. Independent samples t-test revealed no significant difference, $t(25)=-.71, p=.49, d=-.26$, in the mean number of times coaches in the stage-matched $(M=2.38, S D=1.45)$ and control group $(M=2.91, S D=2.47)$ accessed the website.

The results of a two-way chi square analysis revealed no significant difference in the number of coaches that sought out more information about SP between the stagematched and control groups, $\chi^{2}(1, n=53)=.058, p=.81, \phi^{2}=.033$. Overall, ten (18.9\%) coaches reported seeking out more information about SP: six (20.0\%) coaches in the stage-matched group and four (17.4\%) coaches in the control group. 
Due to several cell frequencies being one or less, the remainder of the selfreported behaviors could not be analyzed with a two-way chi square analysis. However, frequencies will be reported for each behavior. One coach (4.3\%) in the control group and no coaches in the stage-matched group reported contacting the researcher with a question or to inquire about SP services. The coach reported contacting the researcher a total of two times during the four-weeks. One coach (4.3\%) in the control group and no coaches in the stage-matched group reported contacting a SP consultant to inquire about services. Overall, two (3.8\%) coaches reported referring an athlete to a SP consultant during the four-week time period: one (3.3\%) coach from the stage matched group and one (4.3\%) coach from the control group. The coach in the stage-matched group referred one athlete for performance related concerns and the coach in the control group referred one athlete for personal and performance related concerns. Refer to Table 4 for frequencies and percentages regarding swimming coaches self-reported behavioral usage patterns.

Website Tracking. Website tracking was used to record the number of times individuals entered the website provided over a period of four weeks. Overall, 69 hits were recorded, in which 38 (55.07\%) of those hits were from participants in the stagematched group and 31 (44.93\%) of the website hits were from participants in the control group. Out of the 38 website hits in the stage-matched group, 11 (28.95\%) website hits were made by coaches in precontemplation while 27 (71.05\%) website hits were made by coaches in contemplation. Out of the 31 website hits in the control group, 19 (61.29\%) website hits were made by coaches in precontemplation while 12 (38.71\%) website hits were made by coaches in contemplation. Overall 38 individual swimming coaches 
accessed the website. A total of 19 individual coaches in the stage-matched group accessed the website: eight coaches in precontemplation and 11 coaches in contemplation. Coaches in precontemplation accessed the website between one to three times over the course of four weeks. Coaches in contemplation accessed the website between one to five times over the course of four weeks. A total of 19 individual coaches in the control group accessed the website: 12 coaches in precontemplation and seven coaches in contemplation. Coaches in precontemplation accessed the website between one to four times over the course of four weeks. Coaches in contemplation accessed the website between one to three times over the four-week time period. On a Likert-type scale from 1 (not at all) to 6 (very), coaches rated the helpfulness of the website near the midpoint $(M=3.40, S D=1.20)$. Refer to Table 5 for website tracking over the fourweek time period.

Email Tracking. A total of two coaches emailed the researcher over the four-week time period. One coach in the control group, who was in precontemplation, contacted the researcher to inquire about SP services in the area. One coach in the stage-matched group, who was in precontemplation, contacted the researcher because he/she was unable to open the stage-matched manual and wanted a copy in Microsoft Word format.

\section{Tennis Coaches}

A total of 11 tennis coaches completed the pre-test and post-test in which six tennis coaches were randomly assigned to the stage-matched group and five to the control group. None of the tennis coaches completed all three data points (pre-workshop, postworkshop, and follow-up), representing a 100\% attrition rate from post-workshop to the follow-up. Therefore, analyses investigated pre-workshop and post-workshop data with 
emphasis placed on interpreting effect size estimates (cohen's d) due to the small sample size.

With regard to attitudes, dependent samples t-tests revealed no significant difference pre-workshop to post-workshop in tennis coaches' stigma tolerance, $t(8)=$ $1.42, p=.19, d=-.45$, confidence in SP consultation, $t(9)=.71, p=.50, d=.24$, cultural preference, $t(9)=-1.5, p=.17, d=-.22$, and personal openness, $t(8)=.79, p=$ $.45, d=.20$, revealing a moderate effect in the unexpected direction for stigma tolerance.

Dependent samples t-tests revealed no significant difference pre-workshop to post-workshop in tennis coaches' subjective norm, $t(6)=-.15, p=.89, d=-.04$, perceived behavioral control, $t(8)=-1.00, p=.35, d=-.41$, self-efficacy, $t(9)=1.81, p$ $=.10, d=.53$, perceived barriers, $t(8)=-.22, p=.84, d=-.07$, and intentions to use SP services, $t(10)=-1.81, p=.10, d=-.36$, revealing moderate effects in the expected direction for perceived behavioral control and self-efficacy. Refer to Table 6 for means and standard deviations of dependent variables pre-workshop to post-workshop.

Stages of Change. It was hypothesized that there would be an increase in the number of coaches in contemplation and a decrease in number of coaches in precontemplation from pre to post-workshop. Due to several cell frequencies being one or less, stage of change frequencies pre-workshop and post-workshop could not be analyzed with a two-way chi square analysis. However, stage of change frequencies preworkshop and post-workshop was reported. Prior to the workshop, seven (63.6\%) tennis coaches identified themselves in precontemplation and four (35.4\%) in contemplation. Immediately following the workshop, three (30.0\%) tennis coaches were in precontemplation, six (54.5\%) were in contemplation, one (9.1\%) identified being in 
preparation, and one (9.1\%) did not respond. Overall, there was an increase in contemplation and decrease in precontemplation from pre to post-workshop. In addition, there was a slight increase in preparation in which one coach identified being in preparation following the workshop. When looking further at the data, three (27.27\%) tennis coaches had positive cognitive shifts in which two (18.18\%) tennis coaches moved from precontemplation to contemplation and one (9.1\%) moved from precontemplation to preparation. One (9.1\%) tennis coach who identified being in precontemplation prior to the workshop did not answer the stage of change question in the post-workshop survey. On a 6-point manipulation check item ranging from 1 (very negative impact) to 6 (very positive impact), coaches reported that the workshop had a positive impact on their impression of SP services $(M=5.7, S D=.48)$.

Self-reported behavioral usage patterns. It was hypothesized that coaches in the stage-matched group would show more behavioral SP usage patterns (accessing the website, contacting a SP consultant, seeking out more information, contacting the researcher, referring athletes, and using SP services) compared to coaches in the control group at the one-month follow-up. However, self-reported behavioral usage patterns could not be assessed since the follow-up survey was not completed by tennis coaches.

Website Tracking. Although coaches did not complete the follow-up survey, website tracking recorded the number of times individuals entered the website provided by the researcher over a period of four weeks. A total of three tennis coaches accessed the website. One tennis coach was in precontemplation and the other two were in contemplation. Overall, nine hits were recorded, in which one (11.11\%) of those hits 
were from participants in precontemplation and eight (88.89\%) were from participants in contemplation.

Out of the nine total website hits, eight (88.89\%) of those hits came from participants in the stage-matched group. From the stage-matched group, one tennis coach, in precontemplation accessed the website a total of one time while one tennis coach in contemplation accessed the website seven times over four weeks. Out of the nine total website hits, one (11.11\%) hit came from the control group.

Email Tracking. No tennis coaches contacted the researcher through email.

\section{Discussion}

Using the TTM as a framework, the current study examined swimming and tennis coaches with regard to (1) their attitudes and readiness to use SP services immediately following a tailored workshop and (2) the impact of a stage-matched intervention on attitudes, readiness to use SP services, and behavioral usage patterns at the one-month follow-up. Because of the small sample size of the tennis coaches and the lack of followup data in this sub-sample, swimming coaches' attitudes, readiness to use SP services and behavioral usage patterns will be the primary focus of the discussion. The discussion will highlight important findings with specific attention toward coaches' attitudes, stage of change profiles, and potential reasons for poor compliance with the intervention and low usage patterns during the follow-up. Lastly, the limitations and practical implications for SP professionals will be addressed.

The current study provided some evidence of the impact of a tailored workshop on coaches' stage of change profiles, in which $13.3 \%$ of swimming coaches and $18.18 \%$ of tennis coaches experienced positive cognitive shifts from precontemplation to 
contemplation. This percentage is relatively close to previous literature in which, $16 \%$ of athletes experienced positive cognitive shifts after a SP workshop (Zizzi \& Perna, 2003). This suggests that a one-time SP workshop can be expected to impact roughly $13 \%$ to $18 \%$ of the sample's stage of change profile in a positive direction. It appears that the effect the current workshop had on increasing swimming coaches perceived behavioral control, self-efficacy, personal openness, and intentions, and decreasing perceived barriers may have shifted some from not thinking about using services (precontemplation) to thinking about using SP services for the upcoming season (contemplation). This is consistent within the TTM, as it would be unrealistic to expect a coach to jump into action after a 45-minute workshop; therefore, it makes sense to see more subtle changes with the greatest impact on shifting coaches from precontemplation to contemplation.

At the one-month follow-up, three (10\%) swim coaches in the stage matched group and one (4.3\%) in the control group experienced positive cognitive shifts from precontemplation to contemplation. Five (16.6\%) swim coaches in the stage-matched group experienced negative cognitive shifts from contemplation to precontemplation. This finding is contradictory to the idea of maximizing impact with tailored self-help interventions, in which previous literature has found stage-appropriate self-help interventions to be more effective and successful in facilitating forward movement in stage of change profiles for physical activity behaviors (Marcus et al., 1998).

Furthermore, the majority of coaches were in precontemplation and contemplation and previous literature has found stage-matched self-help interventions to be particularly useful for individuals in the earlier stages of change (Marcus et al.). It appears that the 
workshop had a positive impact on stage of change profiles; however, it is clear that this impact was not sustained over time or further impacted by the stage appropriate intervention. Similarly, swim coaches’ intentions were impacted positively by the workshop; however they remained relatively low $(M=3.2, S D=1.22)$ and regressed to the pre-workshop mean at the follow-up. Again, this is contradictory to maximizing impact with stage-appropriate interventions and suggests that if intentions are not acted on quickly they will mostly likely regress. As the first attempt at developing stageappropriate interventions with coaches, much research is still needed with regard to the appropriateness and effectiveness of self-help interventions as a strategy to impact coaches’ readiness and intentions to use SP services. Furthermore, previous TTM literature has assessed the impact of tailored interventions on physical activity behaviors for up to seven months (Cardinal \& Sachs, 1995; Marcus et al). According to the TTM, one month may not have been long enough for participants to move into action and future research would benefit from assessing the impact of tailored interventions over a longer period of time.

Much of the previous literature has primarily focused on attitudes and addressing confidence and stigma tolerance with coaches and athletes in order to help increase service use (Anderson et al., 2004; Leffingwell, et al., 2001; Zakrajsek \& Zizzi, 2007). Interestingly, the current sample of swimming and tennis coaches entered the workshop with low stigma tolerance scores and high scores on confidence. Therefore, a ceiling effect may have limited the amount of impact the workshop could have on coaches’ confidence and stigma tolerance. Swim coaches' were generally open to using SP services prior to the workshop but openness may have had more room for improvement 
in comparison to the other SPARC-2 variables. Although swim coaches became more willing to use SP services, the effect $(d=$.39) should not be over-interpreted since the gains were not maintained at the one-month follow-up. With swim coaches' overall attitudes toward SP consulting being positive (ceiling effect), the information on the website or in the stage-matched manual may not have been able to further impact confidence, personal openness, stigma tolerance, or cultural preference. Thus, the intended impact of the tailored self-help materials may not have occurred for most coaches.

It is interesting that coaches' attitudes were so positive prior to entering the workshop given that only three coaches in the entire sample had previous experience with SP consultation. This is inconsistent with previous literature in which athletes who previously used SP services at least once were found to have higher confidence and lower stigma toward SP consultation compared to athletes without previous experience (Anderson et al., 2004; Martin, 2005). Zakrajsek and Zizzi (2007) reported similar findings in which previous experience was related to track and swimming coaches’ confidence and stigma tolerance. It is possible that perceptions and attitudes toward SP have become more favorable as the field has grown in visibility since the 1980's. In addition, Martin and colleagues (2004) found that type of sport may influence attitudes toward SP consultation. For instance, athletes in physical non-contact sports, such as swimming, held a more positive view of SP consulting compared to athletes in contact sports. Because coaches' hold a different role regarding SP service use, caution must be noted when translating athletes' attitudes to coaches' attitudes and use of SP services. Research regarding athletes' attitudes and use of SP is more developed compared to 
research with coaches. Therefore, in order to fully understand how coaches' previous experience and type of sport impact attitudes more research with coaches is needed. Lastly, perhaps coaches who decide to attend a SP workshop already have favorable attitudes toward SP consulting and differ in attitudes compared to those coaches who do not choose to attend a SP workshop. The overall positive attitude toward SP consulting (refer to Table 1 and Table 6) is encouraging and suggests that swimming and tennis coaches’ may be interested, receptive, and confident in using SP services.

The positive attitudes and interest in SP would suggest that many of these coaches would become consumers of SP services if they had access and the services were free or affordable. Interestingly, the sample of swimming coaches had positive attitudes towards SP consultation yet the vast majority was in the early stages of motivational readiness, had relatively low intentions, and had low behavioral usage patterns. A similar pattern emerged with tennis coaches in which they had positive attitudes but were in the early stages of change and had extremely low behavioral usage patterns. It is clear that the workshop and the stage-matched intervention did not have the intended effect on coaches’ behavioral usage patterns. This is interesting since seeking out more information, utilizing a free website and SP resource (e.g. the researcher), and talking to others to inquire about SP services would be some of the expected behaviors of someone with positive attitudes and thinking about using SP services for the upcoming season. Further research needs to explore if this mismatch between attitudes and readiness to use services as well as attitudes and behavioral usage patterns is consistent with various populations of coaches with and without previous SP experience. 
The mismatch between attitudes and readiness does not coincide with the framework of the TTM. For instance, coaches in the early stages of motivational readiness would be expected to have less favorable attitudes toward SP service use. It is possible that the TTM is not the most appropriate theoretical framework to use with coaches and SP service use. Although more research is needed with regard to the TTM and coaches' use of SP services, it may be beneficial to explore the appropriateness of other theories, such as the theory of planned behavior. According to the theory of planned behavior (Ajzen, 2002), an individual's perception of behavioral control influences the decision to carry out an intended behavior. Although swim coaches learned more about how to access a SP professional, coaches did not report high behavioral control. This suggests that swim coaches in the early stages of readiness may continue to be inhibited if they do not believe they have volitional control or can easily access and use SP services. Investigating the barriers identified by coaches may provide some insight into what factors may be perceived as out of their control and continue to inhibit SP service use. When looking at individual items addressing swim coaches barriers to service use prior to the workshop (refer to Table 3), money and time were among the highest along with familiarity with the role of a SP consultant, familiarity with why they should use SP services, and knowing enough about SP to feel comfortable with using services. Although swim coaches’ overall perceived barriers decreased at the post workshop, money and time remained relatively high and continued to be identified as a barrier to service use at the one-month follow-up. This is in line with previous literature which has consistently reported lack of funding and time constraints as common barriers to SP service use (Anshel, 1989; Gould, Medberry, Damarjian, \& Lauer, 1999; Gould, Tammen, Murphy, 
and May, 1989; Haslam, 2004; Kremer \& Marchant, 2001; Pain \& Harwood, 2004;

Voight \& Callaghan, 2001). In addition, coaches in the current study responded to an open ended question and identified several benefits (e.g. coping with stress and pressure, performance enhancement, personal development) to using SP services; however, several barriers such as money $(n=68)$, availability and access $(n=22)$, and time $(n=21)$ were consistently reported.

From the current sample, $10 \%$ of swimming coaches reported having access to SP services. The majority of the sample either coached at the High School $(n=38)$ or AgeGroup ( $n=23$ ) level and; therefore, may have limited access to SP services compared to higher levels of competition (e.g. collegiate and professional). It is possible that the overall budget allocated to the team is perceived as being outside the coaches' volitional control. In addition, High School or Age-Group coaches are likely to have a very restricted budget compared to their college or pro counterparts, making it more difficult to contract the services of a SP professional. For coaches in the early stages of readiness, the perceived degree of difficulty in executing the behavior (due to time, money, and access) may outweigh the effort that coaches are willing to put forth in creating opportunity and resources for SP service use regardless of having positive attitudes.

There may be several reasons for the unexpected findings and follow-up difficulties with this sample. Within the theory of planned behavior, Ajzen (2007) suggests that interventions need to be designed toward factors that have more room for change. Thus, if attitudes are already positive (e.g. a ceiling effect) then one would not expect an intervention designed to make attitudes more favorable to influence behavior. This may partially explain the low behavioral usage patterns and low intentions of 
swimming coaches. Therefore, other variables that had more room for change (e.g. perceived behavioral control and barriers) would more likely have a greater impact on intentions and behavioral usage patterns and would be more appropriate to address. It appears that the workshop was not effective in clearly addressing controllability and ease in accessing SP services and; therefore, the effect of the workshop was not strong enough to overcome the combined barriers to increase service use. This does not imply that attitudes are not important to service use. The fact that coaches consistently report the importance of mental skills and an interest and willingness to use SP services may be partially due to the positive attitudes toward SP. However, the current findings suggest that efforts of SP professionals and organizations may benefit from spending more time on the issue of perceived controllability as well as helping coaches understand why they should prioritize SP services.

Another interesting result worthy of discussion is that manuals tailored toward contemplation focused on decreasing the barriers commonly mentioned by coaches (e.g. time, money, access), which seems to have been a near exact match for the profile of many coaches in this sample. However, only thirteen (48\%) swim coaches in the stagematched group reported actually reading the manual. It is clear that over half of the swim coaches did not receive the intended intervention. Four of the eight swim coaches that responded to an open ended question said they had not read the manual due to not having the time. One swim coach responded "I have not had a chance to really look at the information, I'm sorry this has been a really busy month.” From this statement and the fact that 52\% of swimming coaches did not read the manual, it is clear the coaches did not make SP service use a priority and that no need was established after the workshop. 
It is possible that the tailored manuals did not differ enough from the information provided on the website, to which all coaches had access. Coaches who received the stage-matched manual were directed to answer an open ended question regarding what information they felt was most useful from the manual. Some swim coaches responded that they felt information about eating disorders and reading SP articles were helpful; however, this information came from links that were on the website and not the stagematched manuals. Unexpectedly, a large number of swimming coaches in the control group ( $n=15)$ reported receiving the stage-matched manual and five reported actually reading the manual. This finding is confusing given that coaches' in the control group were not emailed tailored manuals. All coaches did receive weekly reminders to check the website. Perhaps the question “did you receive an attachment (manual) through email one week following the workshop?” was interpreted by some swim coaches as the weekly reminders that were sent to check the website. Considering this information, the stage-matched intervention may not have differed enough from the website provided to all coaches. Lastly, and very plausible, the one-month follow-up may not have been enough time for coaches to change their behavior or stage of change profiles. Considering that the vast majority of coaches were in precontemplation or contemplation, one month would not have been enough time to expect coaches to shift into preparation or action.

\section{Limitations}

In addition to the follow-up difficulties previously mentioned, a few additional limitations warrant discussion. First, results of the current sample may not generalize to other coaches, sports, or levels of competition. The vast majority of swimming coaches were at the High School or Age-Group level and the vast majority of tennis coaches were 
at the club level. Findings may not generalize to other swimming or tennis coaches not present at the conference. And, there may be a difference between coaches who participated in and completed the study and coaches who did not. It would be worthwhile to study the impact of interventions with coaches at higher levels of competition that may have more access to SP professionals. Second, the current study did not have a true control group. All coaches received the SP workshop and had access to a SP website. Future research should consider comparing coaches’ perceptions, readiness, and use of SP services between those who received an intervention and those that received no intervention at all.

Third, the current study utilized coaching conferences to conduct the workshop. Although this is useful, coaches are away from their busy schedules and day to day activities. Once back in their environment, SP may not be prioritized since it may be viewed as a "luxury" component to training and is often not viewed as a traditional aspect of sport. Especially with High School and Age-Group coaches, it may be useful to go a step further and provide a series of workshops with hands on activities that coaches themselves can integrate within the sporting environment.

Lastly, the small sample size and attrition rate regarding the tennis coaches is a concern. Approximately 285 coaches attended the convention; however, only 11 tennis coaches attended the workshop. The workshop occurred on the last day and last time slot of the convention. It is possible that many coaches had already left the convention. It is also possible that tennis coaches at the convention were, overall, not interested in SP services. However, throughout the convention several coaches did approach the researcher with an interest in the mental side of sport. Additionally, coaches may have 
perceived that the workshop was about SP skills compared to learning about services. For instance, the speaker prior to the workshop made several comments that did not accurately represent the content of the researcher's workshop. Several comments were made that the workshop would cover how to motivate athletes or increase confidence. Many of those attending the speaker prior also attended the workshop. Therefore, the sample's perception of the content of the workshop may have been biased which may have influenced the impact of the workshop as well as the completion of the follow-up. Implications for Sport Psychology Professionals

From the current study, it is clear that establishing a need and prioritizing SP services is important during a workshop and intervention with coaches. Therefore, it would be beneficial for a practitioner to understand and tailor a workshop within the context (e.g. level of sport, type of sport, time of season, previous experience with SP, and if the coach works part time or full time) of their audience. For instance, the performance gains related to physical training and technique may be viewed as high and immediate at the high school and age-group level. Therefore, coaches may not see the immediate value or need of SP to their level of athletes. In addition, coaches need to believe they have the resources and opportunities to use SP services. Money was viewed as the number one barrier to service use with the current sample and has been repeatedly reported as a barrier throughout the SP literature. Especially with high school and youth programs, there may be other important sources (e.g. parents, boosters) willing to donate funding for mental skills training. Sport psychology professionals can educate coaches with restricted budgets regarding other possible sources for funding, offer services for free initially, or provide a variety of packages at different price points. 
As noted previously, coaches perceived having little control over the ease in accessing and using services. One suggestion to facilitate the ease for coaches to carry out intentions is to form an implementation intention (Gollwitzer, 1999) which focuses on formulating specific plans that identify when, where, and how the intended behavior will be carried out. Therefore, coaches that intend to seek out more information or use services can identify how and when they will access information or a SP professional. Planning may be a key skill to transfer learning from an applied SP workshop which may increase commitment and strengthen the link between intentions and behavior rather than regress and weaken the intention-behavior link.

Although behavioral usage patterns were overall low, it is encouraging that approximately $40 \%$ of the swim coaches that attended the SP workshop accessed the website during the four-week follow-up. Accessing a website may be the simplest behavior and least invasive approach to providing SP information. Perhaps there is a hierarchy of methods in terms of coaches' preference for gathering information about SP. Given that most coaches were in the early stages of readiness it makes sense that accessing a website was the most common behavior in this sample. This provides some incentive for SP professionals to develop and market useful and well-informed websites. Other methods, such as e-mail, phone, and in-person should also be explored and may be used by coaches that are ready to integrate SP services into training.

AASP, the largest organization of its kind in North America, has developed the Coaching Science- Special Interest Group (CS-SIG) to promote SP in coaching. Mental skills and SP may have increased in visibility; however, only $15.6 \%$ of swimming coaches and 9.1\% of tennis coaches had heard of AASP certification. Zakrajsek \& Zizzi 
(2007) suggested that attention within the profession needs to be directed toward increasing coaches’ access to competent consultants. During the annual AASP conference in 2007, members of the organization provided, for a small fee, an applied SP workshop for coaches within the local area. This is an encouraging step taken by AASP members and hands-on applied workshops need to continue to be marketed and offered to area coaches. For coaches that attended the workshop, it may be useful to provide contact information for qualified consultants within the area that are interested in working with teams, athletes, and coaches. Perhaps the CS-SIG and AASP would also be interested in partnering with coaching organizations in order to provide their member coaches access to applied SP techniques and strategies through a series of workshops. These approaches may be a useful foundation to build rapport and credibility, increase accessibility to competent SP professionals who are AASP certified, and work around the barriers of time and money that are so commonly cited by coaches.

Currently, this is the first attempt at studying the impact of a tailored self-help intervention on coaches' readiness and behavioral usage patterns. Further research with regards to the appropriateness of self-help interventions when trying to impact coaches’ readiness to use SP services is warranted. Given that coaches had positive attitudes despite being in the early stages of readiness, further research is needed regarding the applicability of the TTM with coaches and SP services. Coaches' low readiness most likely is impacted by perceived controllability in the ease of accessing services as well as barriers such as time and money. Therefore, future research needs to examine if the theory of planned behavior may be a more appropriate framework to use when understanding SP service use and developing interventions with coaches. 


\section{References}

Ajzen, I. (2002). Constructing a TPB questionnaire: Conceptual and methodological considerations. Retrieved October 3, 2006, from http://wwwunix.oit.umass.edu/ ajzen/tpb.html

Ajzen, I. (2007). Behavioral interventions based on the theory of planned behavior. Retrieved November 3, 2007 from http://www.people.umass.edu/aizen/pdf/tpb.intervention.pdf

Anderson, A. G., Hodge, K. P., Lavallee, D., \& Martin, S. (2004). New Zealand athletes’ attitudes towards seeking sport psychology consultation. New Zealand Journal of Psychology, 33, 129-136.

Anshel, M. H. (1989). Examination of a college football coach's receptivity to sport psychology consulting: A three-year case study. Journal of Applied Research in Coaching and Athletics, 4(3), 139-149.

Cale, A., \& Crisfield, P. (1994). Advances in British coach education: A sports psychology perspective. In F. I. Bell \& G. H. Van Gyn (Eds.), Proceedings for the $10^{\text {th }}$ Commonwealth \& International Scientific Congress: access to active living, University of Victoria, 560-564.

Cardinal, B. J., \& Sachs, M. L. (1995). Prospective analysis of stage-of-exercise movement following mail-delivered, self-instructional exercise packets. American Journal of Health Promotion, 9, 430-432.

Cassidy, T., Potrac, P., \& McKenzie, A. (2006). Evaluating and reflecting upon a coach education initiative: The CoDe of rugby. The Sport Psychologist, 20, 145-161. 
Gollwitzer, P. M. (1999). Implementation intentions: Strong effects of simple plans. American Psychologist, 54, 493-503.

Gould, D., Medberry, R., Damarjian, N., \& Lauer, L. (1999). A survey of mental skills training knowledge, opinion, and practices of junior tennis coaches. Journal of Applied Sport Psychology, 11, 28-50.

Gould, D., Tammen, V., Murphy, S., \& May, J. (1989). An examination of U.S. Olympic sport psychology consultants and the services they provide. The Sport Psychologist, 3, 300-312.

Grove, J. R., Norton, P. J., Van Raalte, J. L., \& Brewer, B. W. (1999). Stage of change as an outcome measure in the evaluation of mental skills training programs. The Sport Psychologist, 13, 107-116.

Haslam. I. R. (2004). Psychological skills training: A qualitative study of Singapore coaches. Journal of Physical Education \& Recreation, 10, 37-47.

Janis, I. L., \& Mann, L. (1977). Decision making: A psychological analysis of conflict, choice, and commitment. London: Cassel \& Collier Macmillan.

Kimiecik, J., \& Gould, D. (1987). Coaching psychology: The case of James “Doc” Counsilman. The Sport Psychologist, 1, 350-358.

Kremer, P. J., \& Marchant, D. B. (2002). Reflections and considerations of providing sport psychology services with professional football players. In W. Spinks (Ed.), Science and Football IV (pp.294-299). London: Routledge.

Leffingwell, T. R., Rider, S. P., \& Williams, J. M. (2001). Applications of the Transtheoretical model to psychological skills training. The Sport Psychologist, $15,168-187$. 
Marcus, B. H., Emmons, K. M., Simikin-Silverman, L. R., Linnan, L. A., Taylor, E. R., Bock, B. C., et al. (1998). Evaluation of motivationally tailored vs. standard selfhelp physical activity interventions at the workplace. American Journal of Health Promotion, 12, 246-253.

Martin, S. B. (2005). High school and college athletes’ attitudes toward sport psychology consulting. Journal of Applied Sport Psychology, 17, 127-139.

Martin, S. B., Akers, A., Jackson, A. W., Wrisberg, C. A., Nelson, L., Leslie, P. J., et al. (2001). Male and female athletes’ and nonathletes’ expectations about sport psychology consulting. Journal of Applied Sport Psychology, 13(1), 18-39.

Martin, S. B., Lavallee, D., Kellman, M., \& Page, S. J. (2004). Attitudes toward sport psychology consulting of adult athletes from the United States, United Kingdom, and Germany. International Journal of Sport and Exercise Psychology, 2, 146160.

McMillin, C. J., \& Reffner, C. (Eds.). (1999). Directory of college and university coaching education programs. Morgantown: Fitness Information Technology.

Pain, M. A., \& Harwood, C. G. (2004). Knowledge and perceptions of sport psychology within English soccer. Journal of Sports Sciences, 22, 813-826.

Partington, J., \& Orlick, T. (1987). The sport psychology consultant: Olympic coaches’ views. The Sport Psychologist, 1, 95-102.

Perz, C. A., DiClemente, C. C., \& Carbonari, J. P. (1996). Doing the right thing at the right time? The interaction of stages and processes of change in successful smoking cessation. Health Psychology, 15, 462-468. 
Prochaska, J. O., \& DiClemente, C. C. (1983). Stages and processes of self-change of smoking: toward an integrative model of change. Journal of Consulting and Clinical Psychology, 51, 390-395.

Prochaska, J. O., Velicer, W. F., Rossi, J. S., Goldstein, M. G., Marcus, B. H., Rakowski, W., Fiore, C., Harlow, L. L. et al. (1994). Stages of change and decisional balance for 12 problem behaviors. Health Psychology, 13, 39-46.

Rice, T. S. (1996). Should coaches administer psychological interventions to their athletes? Unpublished doctoral dissertation, West Virginia University, Morgantown.

Scully, D., \& Hume. A. (1995). Sport psychology: Status, knowledge and use among elite level coaches and performers in Ireland. The Irish Journal of Psychology, 16, 5266.

Speed, H. D., Andersen, M. B., \& Simons, J. (2005). The selling or the telling of sport psychology; presenting services to coaches. In M. B. Andersen (Ed.), Sport psychology in practice (pp. 1-16). Champaign, IL: Human Kinetics.

Sullivan, J., \& Hodge, K. P. (1991). A survey of coaches and athletes about sport psychology in New Zealand. The Sport Psychologist, 5, 140-151.

Voight, M., \& Callaghan, J. (2001). The use of sport psychology services at NCAA Division I Universities. The Sport Psychologist, 15, 91-102.

Wrisberg, C. A. (1990). An interview with Pat Head Summit. The Sport Psychologist, 4, 180-191. 
Zakrajsek, R. A., \& Zizzi, S. J. (2007). Factors influencing track and swimming coaches’ intentions to use sport psychology services. Athletic Insight: The Online Journal of Sport Psychology, 9(2). Retrieved September 29, 2007, from http://www.athleticinsight.com/Vol9Iss2/CoachesIntentions.htm

Zakrajsek, R. A., \& Zizzi, S. J. (2005, October). Coaches’ intentions to use sport psychology services and their preferences for different contact methods. Poster session presented at the annual meeting of the Association of the Advancement of Applied Sport Psychology, Vancouver, BC.

Zizzi, S. J., \& Perna, F. M. (2003). Impact of a brief workshop on stages of change profiles in athletes. Athletic Insight: The Online Journal of Sport Psychology, 5(4). Retrieved October, 24, 2004, from http://www.athleticinsight.com/Vol5Iss4/ImpactofBriefWorkshop.htm 
Table 1

Swimming Coaches Scores on SPARC-2 Subscales Over Time.

\begin{tabular}{|c|c|c|c|c|c|c|c|}
\hline & & \multicolumn{2}{|c|}{ Pre-Workshop } & \multicolumn{2}{|c|}{ Post-Workshop } & \multicolumn{2}{|c|}{ Follow-UP } \\
\hline & & $\underline{\text { MEAN }}$ & $\underline{\mathrm{SD}}$ & $\underline{\text { MEAN }}$ & $\underline{\mathrm{SD}}$ & MEAN & $\underline{\mathrm{SD}}$ \\
\hline & Stage-Matched & 1.65 & .68 & 1.59 & .72 & 1.58 & .77 \\
\hline \multirow[t]{3}{*}{ Stigma Tolerance } & Control & 1.60 & .69 & 1.56 & .72 & 1.60 & .65 \\
\hline & Total Sample & 1.62 & .68 & 1.58 & .71 & 1.59 & .71 \\
\hline & Stage-Matched & 5.12 & .85 & 5.15 & .76 & 4.87 & .81 \\
\hline \multirow{3}{*}{$\begin{array}{l}\text { Confidence in SP } \\
\text { Consultation }\end{array}$} & Control & 4.93 & .87 & 5.06 & .98 & 4.95 & .98 \\
\hline & Total Sample & 5.04 & .85 & 5.11 & .84 & 4.90 & .88 \\
\hline & Stage-Matched & 2.82 & 1.13 & 2.66 & 1.15 & 3.01 & 1.11 \\
\hline \multirow[t]{3}{*}{$\begin{array}{l}\text { Cultural } \\
\text { Preference }\end{array}$} & Control & 2.77 & 1.14 & 2.77 & 1.29 & 3.21 & 1.02 \\
\hline & Total Sample & 2.80 & 1.13 & 2.71 & 1.20 & 3.10 & 1.07 \\
\hline & Stage-Matched & 2.83 & 1.02 & 2.31 & 1.05 & 2.71 & 1.01 \\
\hline \multirow[t]{2}{*}{$\begin{array}{l}\text { Personal } \\
\text { Openness }\end{array}$} & Control & 3.02 & .90 & 2.79 & 1.06 & 3.00 & .95 \\
\hline & Total Sample & 2.91 & .97 & 2.51 & 1.07 & 2.83 & .99 \\
\hline
\end{tabular}

Note. Scores closer to 6 indicate higher stigma, confidence in SP consultation, lower personal openness, and a strong cultural preference. 
Table 2

Swimming Coaches Scores on Dependent Variables Over Time.

\begin{tabular}{|c|c|c|c|c|c|c|c|}
\hline & & \multicolumn{2}{|c|}{ Pre-Workshop } & \multicolumn{2}{|c|}{ Post-Workshop } & \multicolumn{2}{|c|}{ Follow-UP } \\
\hline & & MEAN & $\underline{\mathrm{SD}}$ & MEAN & $\underline{\mathrm{SD}}$ & MEAN & $\underline{\mathrm{SD}}$ \\
\hline & Stage-Matched & 3.80 & .790 & 4.02 & .86 & 4.01 & .75 \\
\hline \multirow[t]{3}{*}{ Subjective Norm } & Control & 4.15 & .86 & 4.45 & .84 & 4.00 & .80 \\
\hline & Total Sample & 3.96 & .83 & 4.22 & .87 & 4.01 & .77 \\
\hline & Stage-Matched & 2.46 & 1.17 & 3.14 & 1.32 & 2.89 & .96 \\
\hline \multirow{3}{*}{$\begin{array}{l}\text { Perceived } \\
\text { Behavioral } \\
\text { Control }\end{array}$} & Control & 1.87 & 1.25 & 3.04 & 1.49 & 2.70 & 1.58 \\
\hline & Total Sample & 2.20 & 1.23 & 3.10 & 1.39 & 2.80 & 1.27 \\
\hline & Stage-Matched & 4.41 & 1.32 & 2.62 & 1.05 & 2.62 & 1.08 \\
\hline \multirow[t]{3}{*}{ Self-Efficacy } & Control & 4.04 & 1.89 & 2.17 & 1.27 & 2.30 & 1.15 \\
\hline & Total Sample & 4.25 & 1.6 & 2.42 & 1.16 & 2.48 & 1.11 \\
\hline & Stage-Matched & 3.10 & .84 & 2.67 & .71 & 2.66 & .81 \\
\hline \multirow[t]{3}{*}{$\begin{array}{l}\text { Perceived } \\
\text { Barriers }\end{array}$} & Control & 3.05 & .98 & 2.51 & .73 & 2.53 & .67 \\
\hline & Total Sample & 3.08 & .90 & 2.60 & .71 & 2.60 & .75 \\
\hline & Stage-Matched & 2.53 & 1.14 & 3.07 & 1.06 & 2.57 & .89 \\
\hline \multirow[t]{2}{*}{ Intentions } & Control & 2.41 & 1.10 & 3.38 & 1.44 & 2.75 & 1.23 \\
\hline & Total Sample & 2.48 & 1.10 & 3.2 & 1.23 & 2.65 & 1.04 \\
\hline
\end{tabular}

Note. Scores closer to 6 indicate a stronger norm for using SP services, higher perceived behavioral control, lower self-efficacy, higher perceived barriers, and higher intentions to use SP services. 
Table 3

Swimming Coaches Barriers Pre-Workshop and Post-Workshop.

\begin{tabular}{|c|c|c|c|c|}
\hline & \multicolumn{2}{|c|}{ Pre-Workshop } & \multicolumn{2}{|c|}{ Post-Workshop } \\
\hline & MEAN & $\underline{\mathrm{SD}}$ & MEAN & $\underline{\mathrm{SD}}$ \\
\hline $\begin{array}{l}\text { I would struggle with not knowing what would } \\
\text { be said between the sport psychology consultant } \\
\text { and our athletes. }\end{array}$ & 2.59 & 1.45 & 2.35 & 1.26 \\
\hline $\begin{array}{l}\text { Our team does not have enough time to use } \\
\text { sport psychology services. }\end{array}$ & 3.69 & 1.30 & 3.55 & 1.35 \\
\hline $\begin{array}{l}\text { It would be difficult for me to trust a sport } \\
\text { psychology consultant to work with our } \\
\text { athletes. }\end{array}$ & 2.40 & 1.23 & 1.97 & .99 \\
\hline $\begin{array}{l}\text { Using a sport psychology services might make } \\
\text { our athletes' think too much during practice or } \\
\text { competition }\end{array}$ & 2.62 & 1.28 & 2.12 & 1.12 \\
\hline $\begin{array}{l}\text { We do not have the money in our budget to use } \\
\text { sport psychology services. }\end{array}$ & 5.21 & 1.21 & 4.70 & 1.28 \\
\hline $\begin{array}{l}\text { I am not familiar with why I should use sport } \\
\text { psychology services. }\end{array}$ & 3.24 & 1.58 & 2.20 & 1.19 \\
\hline $\begin{array}{l}\text { Using sport psychology services would be } \\
\text { counterproductive; athletes either have mental } \\
\text { skills or they don't }\end{array}$ & 1.76 & .96 & 1.79 & .94 \\
\hline $\begin{array}{l}\text { I do not know enough about sport psychology to } \\
\text { feel comfortable using sport psychology } \\
\text { services with my athletes. }\end{array}$ & 3.22 & 1.47 & 2.57 & 1.31 \\
\hline $\begin{array}{l}\text { I am not familiar with the role of a sport } \\
\text { psychology professional. }\end{array}$ & 3.48 & 1.46 & 2.36 & 1.20 \\
\hline $\begin{array}{l}\text { The benefits of sport psychology would be } \\
\text { difficult to prove. }\end{array}$ & 2.47 & 1.21 & 2.26 & 1.22 \\
\hline
\end{tabular}

Note. Scores closer to 6 indicate a higher perceived barrier to using SP services. 
Table 4

Swimming Coaches Self-Reported Behavioral Usage Patterns

\begin{tabular}{|c|c|c|c|c|c|c|}
\hline & \multicolumn{2}{|c|}{$\begin{array}{l}\text { Stage-Matched } \\
\qquad(n=30)\end{array}$} & \multicolumn{2}{|c|}{$\begin{array}{l}\text { Control } \\
(n=23)\end{array}$} & \multicolumn{2}{|c|}{$\begin{array}{c}\text { Total } \\
(N=53)\end{array}$} \\
\hline & Frequency & $\begin{array}{c}\text { Valid } \\
\text { Percent }\end{array}$ & Frequency & $\begin{array}{c}\text { Valid } \\
\text { Percent }\end{array}$ & Frequency & $\begin{array}{c}\text { Valid } \\
\text { Percent }\end{array}$ \\
\hline Accessed the Website & 16 & 53.33 & 12 & 52.17 & 28 & 52.83 \\
\hline $\begin{array}{l}\text { Sought out More Information } \\
\text { About SP }\end{array}$ & 6 & 20.0 & 4 & 17.39 & 10 & 18.87 \\
\hline Contacted Researcher & 0 & 0.0 & 1 & 4.35 & 1 & 1.89 \\
\hline Contacted a SPC & 0 & 0.0 & 1 & 4.35 & 1 & 1.89 \\
\hline Referred an Athlete & 1 & 3.33 & 1 & 4.35 & 2 & 3.77 \\
\hline
\end{tabular}


Table 5

Swimming Coaches Website and Email Tracking

\begin{tabular}{|c|c|c|}
\hline & \# of Website Hits & \# of Emails \\
\hline Total & 69 & 2 \\
\hline Stage-Matched & 38 & 1 \\
\hline Precontemplation & 11 & 1 \\
\hline Contemplation & 27 & 0 \\
\hline Control & 31 & 1 \\
\hline Precontemplation & 19 & 1 \\
\hline Contemplation & 12 & 0 \\
\hline
\end{tabular}

Note. A total of 38 swimming coaches accessed the website. Each individual coach in the stage-matched group that accessed the website did so between 1 to 5 times over four weeks. Each individual coach in the control group that accessed the website did so between 1 to 4 times over four weeks. 
Table 6

Tennis Coaches Scores on Dependent Variables Pre-Workshop to Post-workshop.

\begin{tabular}{|c|c|c|c|c|c|}
\hline & \multicolumn{2}{|c|}{ Pre-Workshop } & \multicolumn{2}{|c|}{ Post Workshop } & \multirow[b]{2}{*}{$\begin{array}{c}\text { EFFECT } \\
\text { SIZE }\end{array}$} \\
\hline & $\underline{\text { MEAN }}$ & $\underline{\mathrm{SD}}$ & $\underline{\text { MEAN }}$ & $\underline{\mathrm{SD}}$ & \\
\hline Stigma Tolerance & 1.33 & .64 & 1.71 & 1.02 & -.45 \\
\hline $\begin{array}{r}\text { Confidence in SP } \\
\text { Consultation }\end{array}$ & 5.53 & .53 & 5.38 & .73 & .24 \\
\hline Cultural Preference & 2.30 & 1.27 & 2.63 & 1.76 & -.22 \\
\hline Personal Openness & 2.78 & 1.29 & 2.52 & 1.37 & .20 \\
\hline Subjective Norm & 4.50 & .99 & 4.54 & .88 & -.04 \\
\hline $\begin{array}{r}\text { Perceived } \\
\text { Behavioral Control }\end{array}$ & 3.22 & 1.30 & 3.67 & .87 & -.41 \\
\hline Self-Efficacy & 2.40 & 1.71 & 1.60 & 1.26 & .53 \\
\hline Perceived Barriers & 2.01 & 1.01 & 2.07 & .79 & -.07 \\
\hline Intentions & 3.57 & .75 & 3.89 & 1.01 & -.36 \\
\hline
\end{tabular}

Note. Scores closer to 6 indicate higher stigma, confidence in SP consultation, lower personal openness, a strong cultural preference, a strong subjective norm for using SP services, higher perceived behavioral control, lower self-efficacy, higher perceived barriers, and higher intentions to use SP services. 
Tailored Coach Intervention 53

\section{Appendix A}

Supporting Materials for Preliminary Studies 
Table 1

Final Factor Solution of SPARC-2: THSCA Data $(n=304)$

\begin{tabular}{|c|c|c|c|c|c|}
\hline \multirow{2}{*}{\multicolumn{2}{|c|}{ Item \#, and Item }} & \multicolumn{4}{|c|}{ Factor } \\
\hline & & 1 & 2 & 3 & 4 \\
\hline \multicolumn{6}{|c|}{ Stigma Tolerance } \\
\hline 13 & Having seen a SPC is bad for an athlete's reputation. & .76 & -.03 & -.03 & .02 \\
\hline 9 & $\begin{array}{l}\text { I would feel uneasy having a SPC work with my athletes because some people would } \\
\text { disapprove. }\end{array}$ & .74 & -.11 & -.05 & .03 \\
\hline 19 & I would not want someone else to know about my athletes receiving help from a SPC. & .71 & .10 & .12 & -.06 \\
\hline 11 & $\begin{array}{l}\text { If I utilized a SPC to help me coach better, I would not want other coaches to know } \\
\text { about it. }\end{array}$ & .69 & -.20 & -.02 & .05 \\
\hline 22 & If my athletes worked with a SPC, I would not want other coaches to know about it. & .67 & .14 & .11 & .11 \\
\hline 4 & $\begin{array}{l}\text { I would not want a SPC working with my athletes because other coaches would think } \\
\text { less of me. }\end{array}$ & .64 & -.02 & .04 & -.01 \\
\hline 25 & I would think less of my athletes if they went to a SPC. & .62 & .14 & -.05 & -.008 \\
\hline \multicolumn{6}{|c|}{ Cultural Preference } \\
\hline 29 & An athlete may relate best to a SPC if he/she were the same race or ethnicity. & -.15 & .87 & .003 & .07 \\
\hline 23 & $\begin{array}{l}\text { My athletes would be more comfortable with a SPC if he/she were of the same race or } \\
\text { ethnicity as them. }\end{array}$ & -.12 & .79 & .08 & .06 \\
\hline 31 & $\begin{array}{l}\text { I would be more comfortable hiring a SPC if he/she were of the same cultural } \\
\text { background as my athletes. }\end{array}$ & -.001 & .74 & -.07 & -.04 \\
\hline 27 & $\begin{array}{l}\text { I would be more comfortable with a SPC if he/she were the same race or ethnicity as I } \\
\text { am. }\end{array}$ & .12 & .66 & -.07 & -.13 \\
\hline 20 & There are great differences between people of different races or ethnicities. & .06 & .60 & .15 & -.07 \\
\hline 16 & If I were to hire a SPC, I would take into account his/her race or ethnicity. & .31 & .44 & -.000 & -.08 \\
\hline \multicolumn{6}{|c|}{ Confidence in SPC } \\
\hline 18 & I think a SPC would help my athletes perform b & -.14 & .06 & .68 & .003 \\
\hline 8 & I would like to have the assistance of a SPC to help me better understand my athletes. & -.05 & -.03 & .66 & .02 \\
\hline 21 & A SPC could help my athletes fine-tune their performance. & -.08 & -.07 & .64 & .11 \\
\hline 15 & $\begin{array}{l}\text { If I was worried or upset about my athletes’ performance, I would want to get help } \\
\text { from a SPC. }\end{array}$ & .12 & .06 & .61 & .11 \\
\hline 24 & $\begin{array}{l}\text { At times I have felt lost and would have welcomed professional advice for a personal } \\
\text { problem. }\end{array}$ & .12 & .09 & .59 & -.08 \\
\hline 3 & $\begin{array}{l}\text { If an athlete on my team asked my advice about personal feelings of failure related to } \\
\text { sport, I might recommend that he/she see a SPC. }\end{array}$ & .26 & -.004 & .56 & -.10 \\
\hline 1 & A SPC can help athletes improve their mental toughness. & -.25 & .03 &. .55 & .11 \\
\hline 12 & $\begin{array}{l}\text { I feel that an athlete with emotional problems during sport performance would feel } \\
\text { most secure in receiving assistance from a SPC. }\end{array}$ & -.01 & .06 & .42 & .05 \\
\hline \multicolumn{6}{|c|}{ Personal Openness } \\
\hline 26 & Athletes with a strong character can get over mental conflicts by themselves. & -.07 & .10 & -.11 & .74 \\
\hline 7 & $\begin{array}{l}\text { A good idea for an athlete to avoid personal worries and concerns is to keep one’s } \\
\text { mind on the job }\end{array}$ & -.01 & -.06 & .11 & .45 \\
\hline 10 & $\begin{array}{l}\text { There is something respectable in the attitude of athletes who are willing to cope with } \\
\text { their conflicts and fears without resorting to professional help }\end{array}$ & .11 & -.17 & .25 & .47 \\
\hline 17 & Athletes with emotional difficulties tend to work themselves out in time. & .22 & .04 & -.16 & .41 \\
\hline 30 & Athletes should know how to handle problems without needing assistance from a SPC & .25 & .13 & -.11 & .39 \\
\hline \multicolumn{2}{|c|}{ Eigenvalues } & 6.78 & 2.23 & 2.17 & 1.48 \\
\hline \multicolumn{2}{|c|}{$\%$ of Variance } & 26.07 & 12.41 & 8.33 & 5.69 \\
\hline \multicolumn{2}{|c|}{ Factor Reliability } & .84 & .83 & .79 & .64 \\
\hline
\end{tabular}


Table 2

Perceived Behavioral Control and Subjective Norm Pre to Post-Workshop

\begin{tabular}{|c|c|c|c|c|}
\hline \multirow[t]{2}{*}{ Item } & \multicolumn{2}{|c|}{$\begin{array}{c}\text { Pre- } \\
\text { Workshop }\end{array}$} & \multicolumn{2}{|c|}{$\begin{array}{c}\text { Post- } \\
\text { Workshop }\end{array}$} \\
\hline & Mean & $\underline{\mathrm{SD}}$ & Mean & $\underline{\mathrm{SD}}$ \\
\hline $\begin{array}{l}\text { Other coaches on our staff would be supportive of using sport } \\
\text { psychology services with our athletes. }\end{array}$ & 4.57 & .92 & 4.71 & 1.08 \\
\hline $\begin{array}{l}\text { Other coaches at my level are using sport psychology services } \\
\text { with their athletes. }\end{array}$ & 2.77 & 1.46 & 3.14 & 1.43 \\
\hline $\begin{array}{l}\text { I feel pressure from people who are important to me to not } \\
\text { access and use sport psychology services with our athletes. }\end{array}$ & 1.29 & .46 & 1.43 & .69 \\
\hline $\begin{array}{l}\text { The coaches whose opinions I respect use sport psychology } \\
\text { services with their athletes. }\end{array}$ & 4.41 & 1.08 & 4.11 & 1.72 \\
\hline $\begin{array}{l}\text { If the coaching staff wanted to, we could easily access and use } \\
\text { sport psychology services for the upcoming season. }\end{array}$ & 2.81 & 1.96 & 3.48 & 1.53 \\
\hline $\begin{array}{l}\text { I would not know how to access a sport psychology } \\
\text { professional for the upcoming season. }\end{array}$ & $* * 3.43$ & 1.87 & $* * 1.71$ & 1.05 \\
\hline
\end{tabular}

Note. Items are on a 6-point Likert scale ranging from 1 (strongly disagree) to 6 (strongly

agree). **Dependent samples t-test is significant at the .001 level. 
Table 3

Perceived Barriers and Expectations Pre to Post-Workshop

\begin{tabular}{|c|c|c|c|c|}
\hline \multirow[t]{2}{*}{ Item } & \multicolumn{2}{|c|}{$\begin{array}{c}\text { Pre- } \\
\text { Workshop }\end{array}$} & \multicolumn{2}{|c|}{$\begin{array}{c}\text { Post- } \\
\text { Workshop }\end{array}$} \\
\hline & Mean & $\underline{\mathrm{SD}}$ & Mean & $\underline{\mathrm{SD}}$ \\
\hline $\begin{array}{l}\text { I would struggle with not knowing what would be said } \\
\text { between the sport psychology consultant and our athlete(s). }\end{array}$ & 2.21 & 1.23 & 1.79 & .99 \\
\hline $\begin{array}{l}\text { Our team does not have enough time to use sport psychology } \\
\text { services. }\end{array}$ & *3.18 & 1.44 & $* 2.71$ & 1.18 \\
\hline $\begin{array}{l}\text { It would be difficult for me to trust a sport psychology } \\
\text { consultant to work with our athletes. }\end{array}$ & 2.15 & 1.41 & 1.67 & .73 \\
\hline $\begin{array}{l}\text { Using sport psychology services might make our athletes } \\
\text { think too much during practice or competition. }\end{array}$ & $* 2.07$ & .94 & *1.68 & .67 \\
\hline $\begin{array}{l}\text { We do not have the money in our budget to use sport } \\
\text { psychology services. }\end{array}$ & $* 4.82$ & 1.68 & $* 4.00$ & 1.81 \\
\hline $\begin{array}{l}\text { I am not familiar with why I should use sport psychology } \\
\text { services. }\end{array}$ & $* * 2.46$ & 1.10 & $* * 1.64$ & .83 \\
\hline $\begin{array}{l}\text { Using sport psychology services would be counterproductive: } \\
\text { athletes either have mental skills or they don't. }\end{array}$ & 1.46 & .51 & 1.46 & .74 \\
\hline $\begin{array}{l}\text { I do not know enough about sport psychology to feel } \\
\text { comfortable using sport psychology services with my athletes. }\end{array}$ & $* 2.64$ & 1.19 & $* 2.00$ & .98 \\
\hline $\begin{array}{l}\text { I am not familiar with the role of a sport psychology } \\
\text { professional. }\end{array}$ & $* * 2.46$ & 1.26 & $* * 1.71$ & .85 \\
\hline The benefits of sport psychology would be difficult to prove. & 1.93 & .94 & 2.21 & 1.29 \\
\hline
\end{tabular}

Note. Items are on a 6-point Likert scale ranging from 1 (strongly disagree) to 6 (strongly agree). *Dependent samples t-test is significant at the .05 level. **Dependent samples t-test is significant at the .001 level. 


\section{Coaches Script}

Introduction (explain format for interview and what it is about)

$\Rightarrow$ Talking today about sport psychology consultation

$\Rightarrow$ Will be asking your opinion regarding different attitudes toward sport psychology consultations

$\Rightarrow$ Asking opinion regarding expectations toward process of SP consulting

$\Rightarrow$ No right or wrong answers

$\Rightarrow$ We are trying to get as many viewpoints as possible

$\Rightarrow$ All views are important

$\Rightarrow$ Anything you say is confidential. Names or answers will not be shared with anyone. Only a summary of what everyone being interviewed will be compiled.

$\Rightarrow$ I will be taping this discussion to make sure I don't miss any of your comments.

$\Rightarrow$ Try to speak up so the tape recorder picks up our conversation.

$\Rightarrow$ Approximate Time: 20-30 minutes

General Discussion regarding SP consulting...

1. How would you describe sport psychology (What do you think SPC is for)?

2. For what reasons can you think of that a coach would hire a SPC to work with his/her team?

Generally Discuss Coaches Experience...

1. Have you worked with a SPC (student or professional) in the past? For how long?

1a. do you currently?

1b. How did you and the SPC first make contact? Start?

2. If you had a question or wanted more information on mental skills or sport psychology, how would you get that information?

General Questions Regarding Coaches’ Attitudes...

1. What factors go into deciding of you will use or not use a SPC?

2. What characteristics are you looking for in an SPC? What should they be able to do? (to be useful to coaches)

3. What would make coaches reluctant to use a SPC?

4. Do you have a specific preference for a man or woman to work with your team as a SPC?

5. Is there an age range that you would be looking for in a consultant? (How old?) 
6. Do you have a preference regarding the race/ethnicity of the consultant working with your team?

7. Would you be open to an SPC working with your team? (Why/Why not?)

8. Would you recommend your athlete see a sport psychology consultant? For what issues would you refer (personal/sport performance)

9. What contributes to coaches' confidence in SPC?

-Why do you think some coaches are confident that SP works and others are not?

10. Would care if other coaches knew about your team working with an SPC?

General Questions Regarding Coaches’ Expectations...

1. What should a competent SPC be able to do?

2. What kind of training or certification would they have? How would you know if they were "qualified" for the job?

3. How would you expect to communicate with an SPC? How quickly? How regularly? Through what methods (phone, in person, email, etc)

4. How much time would you expect the SPC to spend with your team?

-time of year (in/out of season)

-weekly schedule

-how often meet / how often at practice for observation

-team sessions / individual sessions (team only/individuals only/both)

5. Would you expect the SPC to travel to away competitions? Separately or with the team?

6. If an SPC were working with an athlete or your team, how much information would you expect to know regarding their meetings?

-are they familiar with confidentiality in sport psychology

7. How much would you expect to pay for SP services, for example, per hour, or per semester)?

\section{Final Question...}

1. How long would you expect a SP consultation with your team would last? How who would it end?

2. Are there any other questions you have? 


\section{Theme Tree}

$\underline{\text { Main Categories }}$

$\underline{\text { Subcategories }}$

Performance Enhancement (5)

Treatment (1)

Psychology of Sport (2) $\underline{\text { Raw Data Themes }}$

Visualization (1)

Positive Thinking/Self-Talk (2)

Motivation (1)

Study/Change Behavior (2)

Positive Reinforcement (1)

Goals Setting (2)

Adjustment to Situations (1)

Confidence (2)

Team Building/Team Cohesion (2)

Preparation (2)

Outside Issue (1)

Team Issue (2)

Individual Psychological Aspects (1)

Struggling mentally w/game (1)

Team building/Team cohesion (1)

Confidence (1)

Goal setting (3)

Imagery (2)

Stress Management (1)

Mental preparation (2)

Sport is $50 \%, 80 \%, 90 \%$ mental (1)

Tap into mind (1)

Behavior change (1)

Win/Loss record (1)

Athletes buying into team concept (1)

Adjustment to Situations (1)

Process competition (1)

Someone other than coach for athlete to talk to/Outside person (3)

Coach is not trained to deal with mental aspect (3)

Coach already wears a lot of "hats" (2)

Male coach may not be comfortable dealing with female athlete issues (1)

Learn about individual athletes regarding their performance (1)

Educational background of coach (1)

Support service (1)

Mediator to Coach/Athlete problem (1) 


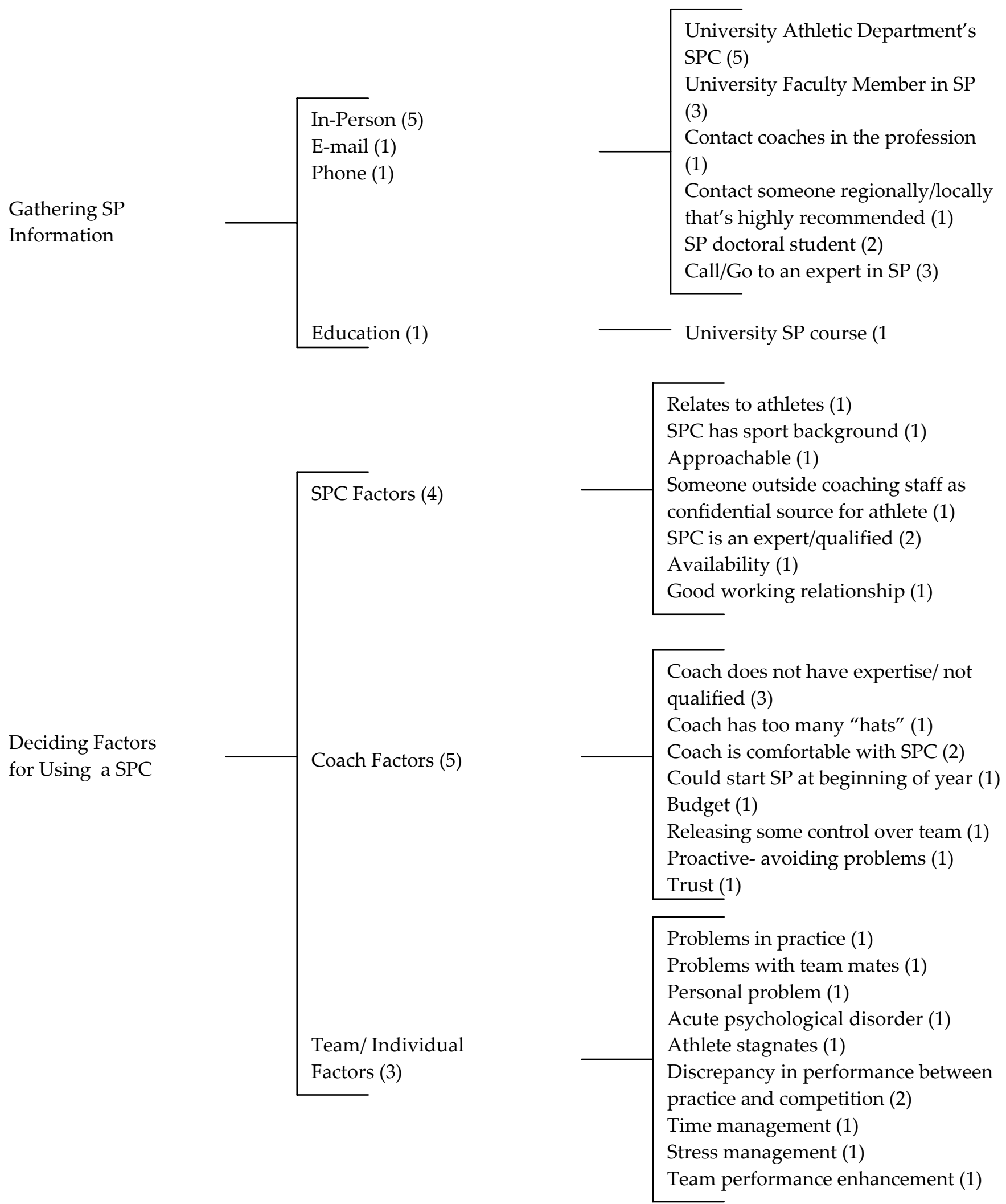




\section{$\underline{\text { Main Categories }}$}

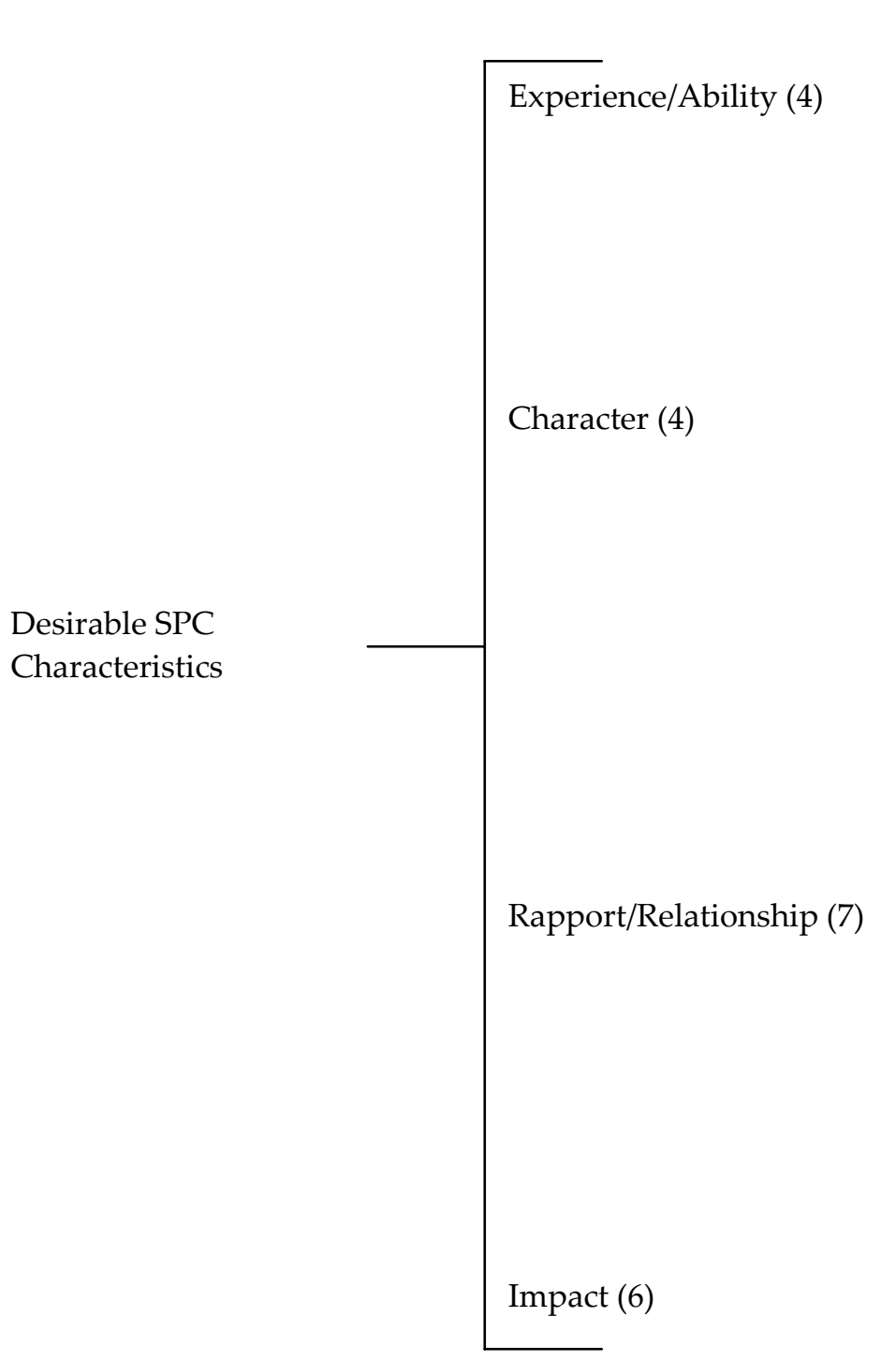

Raw Data Themes

Athletic experience (2)

Coaching experience (1)

Know their field/Education (2)

High moral character (1)

People skills/personable (2)

Positive/Enthusiastic (1)

Outgoing (1)

Empathetic (2)

Nurturing (1)

Approachable (1)

Passionate about field (3)

Outstanding work ethic (1)

Understands athlete/relates to athlete (5)

Athletes trust SPC/establish a bond (1)

Understands coach (1)

Communicates well (3)

Team is comfortable with SPC (1)

Consistently around (1)

Win coaches over (1)

On same page as coach (1)

Easy to work with (1)

Communicates so athletes understand (1)

Helpful (1)/ Be Effective (1)

Help us win/improve their development (1)

Gives athletes things to work on (1)

Has presence in front of group (1)

Present material in an interesting way

Put team out of comfort range (2)

Provide first hand (anectodal) experiences (1)

Putting ideas into athletes head/athletes over thinking things (3)

Athletes using SP as an excuse for not doing well (1)

Paranoia (1)

Not knowing what's being said (1)

Ignorance (1)

Insecurity (1)

Territorial/Control (1)

Outside person saying something to coach

don't want to hear (1)

Ego (1)

Not a good match between SPC and athlete (1)

Fear it will be counterproductive (1)

Coach's background/not knowledgeable about

SP (2)

Unfamiliarity with SP process (1)

Coach not comfortable with SP (2)

Coach thinks can do it him/herself (1)

Don't see a need for SP (1)

Stigma associated with SP (1)

Don't trust SPC (1) 
$\underline{\text { Main Categories }}$

Factors Contributing to Coach Openness to use SPC

Areas Coach would Refer Athletes to SPC

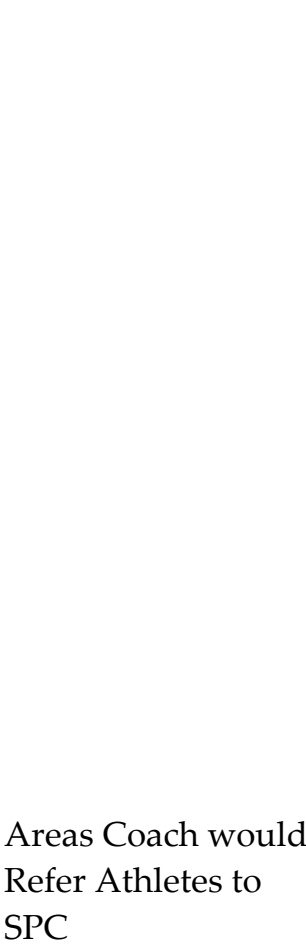

\section{Subcategories}

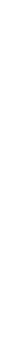

$\underline{\text { Subcategories }}$

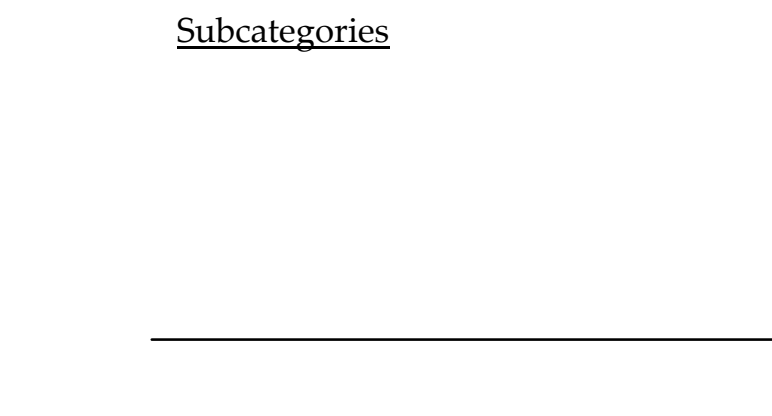

\section{$\underline{\text { Raw Data Themes }}$}

Benefits the team/Helpful (2)

Difficult due to limited time (1)

Wanting to win (1)

Any subtle gain would be worth using SPC (1)

Opportunity for athletes to go on own (1)

Availability of an SPC (1)

An SPC who knows dynamics of team \& individuals (1)

If parameters were set up early (1)

Not a strong area for coach (1)

Meeting/knowing the SPC (1)

Knowing SPC's plan (1)

Something interfering with performance/drop

off in performance (2)

Anything effecting workouts (1)

Confidence (1)

Self-esteem (2)

Relaxation techniques (1)

Visualization (2)

Behavioral Change (2)

Self-talk (1)

Team related issues (1)

In a slump (1)

Not able to do role on team (1)

Match preparation (1)

Life issues (2)

Eating Disorder (1)

Thoughts of personal injury (1)

Time Management (1)

Depression (1)

Nothing is going right/ feel defeated (1) 
$\underline{\text { Main Categories }}$

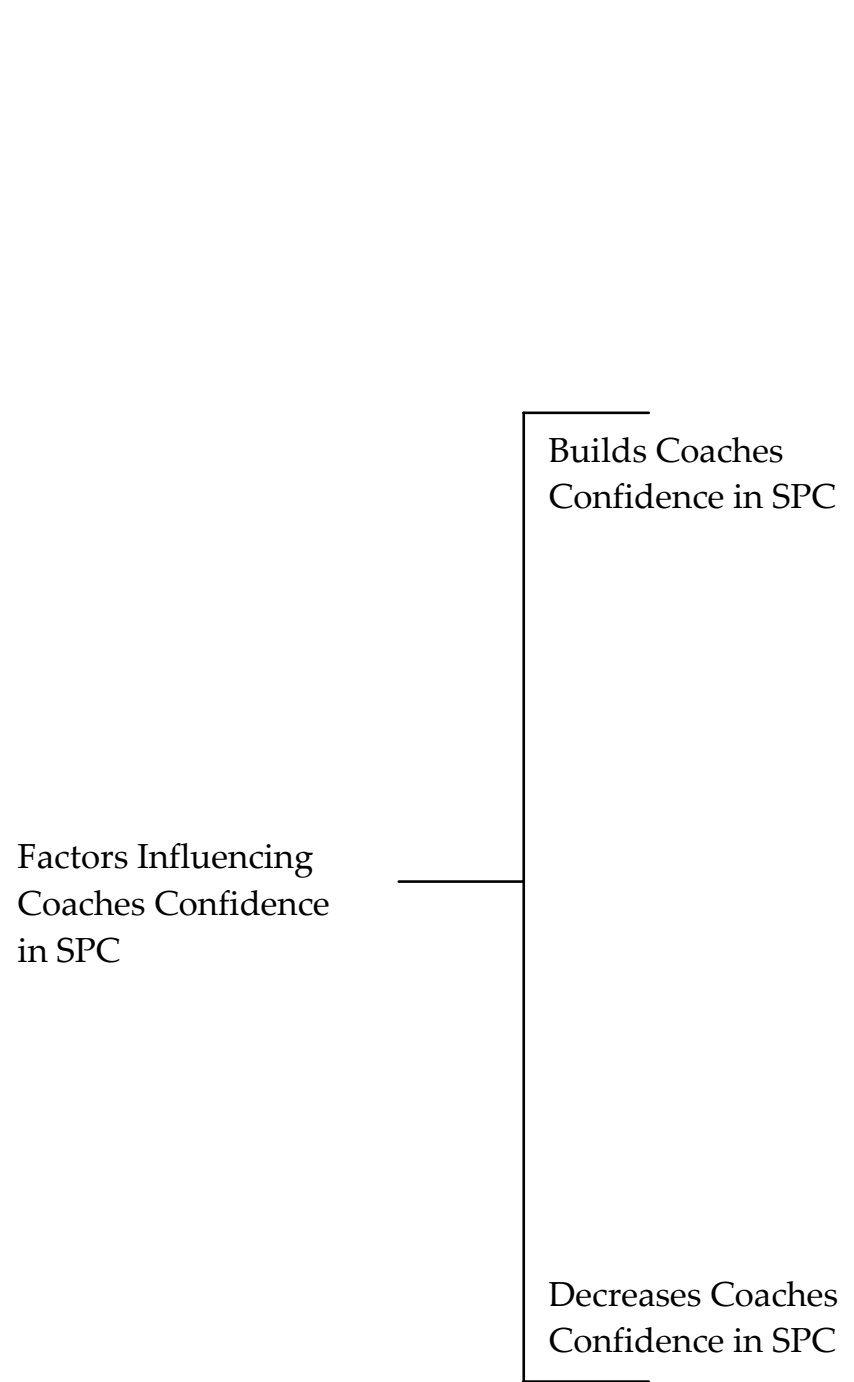

$\underline{\text { Subcategories }}$ $\underline{\text { Raw Data Themes }}$

Information/Coach education (1)

If coach feels SP is beneficial (1)

Coach is comfortable with it (2)

Good relationship between SPC and coach (1)

SPC fits well (1)

SPC's ability to pick up "red flags" (1)

Interpersonal relationships (1)

Communicates well (2)

Doesn't make people feel they are being

analyzed/questioned (1)

SPC knows the athletes (1)

SPC is good at what he/she does (1)

Character of SPC (1)

Recommendations (1)

Passionate (1)

High moral standard in community and as a

person (1)

Examples of professional/best athletes have used

SP (1)

Coach's personal experience (1)

SPC has personal experience as athlete (1)

SPC is available when needed (1)

Keeps coach informed (1)

If $\mathrm{SP}$ is new for coach (1)

Don't think they need it (1)

Lack of character (1)

Incompetence (1)

Coach not wanting athletes to depend on SPC (1)

If coach feels out of the loop (1) 
$\underline{\text { Main Categories }}$

Factors Relating to
Competence if SPC

Factors Relating to
Competence if SPC $\underline{\text { Subcategories }}$

Expected SPC

Qualifications $\underline{\text { Raw Data Themes }}$

SPC can get a hold of group on own (1)

Excited about what doing (2)

On top of details (1)

Team has respect for SPC (1)

Makes team comfortable (1)

Builds relationship with athlete \& coaches (3)

Good at reading athletes (1)

Athlete looks forward to seeing SPC (1)

Athlete feels getting something out of meetings

(2)

Change behavior when needed (1)

Raise self-esteem (1)

Enhances the environment when needed (1)

Have an impact on group (1)

Ability to identify individual's problem (1)

Give athlete exercises to work on problem (1)

Ability to listen (1)

Don't over simplify (1)

Works hand in hand with coaching staff (1)

Gives coaches his/her perspective (1)

Organized (1)

Conveys \& communicates principles easily (1)

Helpful (1)

Knows what's necessary to convey (1)

Relates to the sport (1)

Relates to what it means to be a student-athlete

(1)

Professional attitude (1)

Psychology \& sport oriented background (1)

Expert in field(1)

Continues to learn (1)

Advanced degree (2)

Have a degree (1)

Has gone through all appropriate training (1)

Previous athletic experience with the sport (1)

Experience working with team/group (2)

Experience working with individuals (1)

Experience (4)
Age difference between SPC and athlete/ Someone older (2)

Someone highly recommended (1)

Has worked as SPC for long time/experienced (1) 
$\underline{\text { Main Categories }}$

ication

Information coach would want to know $\underline{\text { Subcategories }}$

Preferred Method

Expected regularity of

Communication

between Coach and SPC

General Information

Serious Issues

Strategies
Raw Data Themes

Face-to-Face meetings- Preferred (6)

Phone to touch base (4)

Email to touch base (3)

Before/After SPC meets with team (2)

Set plan at beginning for meetings between coach \& SPC (1)

30 minutes once a week (1)

Couple times a week (1)

2-3 hour meeting before season starts \& touch up before Christmas break (1)

Every couple weeks during season (1)

Less frequent in off season (1)

If able to, would like to know what's going on/general feel for how athlete is doing (2)

As much as possibly can, don't have to know every detail but general idea of what's going on (1)

Having some sort of clue, which comes from a lot of trust of what person is telling you (1) Whatever SPC would feel appropriate (1) For sport performance issues want a little feedback to see how person's developing (1) Topics covered in meetings (i.e. confidence, leadership) (1)

Feedback regarding group meetings (1)

Traumatic situation with athlete (1)

Anything coach would need to worry about (1)

If athlete was having problem with coach \& could have mediator come in (1)

If athlete signed off then would expect clear and careful communication (1)

Hoping allowed to talk about strategies (1) Feedback/strategies to help athletes (1) Feedback to become better coach (i.e. better communication, better teacher) (1)

Know if anything coach could do to enhance development or improve it (1)

Aware of it and has complete respect for it/Very important when dealing with team (1)

Not fully aware of what allowed to talk about but assume can't talk about what is said in individual meetings (1)

Confidentiality is important between SPC and team to build confidence (1)

Aware of confidentiality (1)

For meetings about personal life, there has to be some confidentiality (1) 
Limited by NCAA rules- how many hours can spend with team per week/time is crucial (1) Depends on where at in season (1) Keep it short, limited on time (1)

$30 \mathrm{~min}$. to 1 hour a week sounds minimal but major chunk of time, max 1 hour (1)

Periodic team building (1)

5-10 minutes, maybe 30 minutes. It would be pushing it beyond that (1)

Weekly would be too much- willing to dedicate one practice a month, if there's a big problem, maybe twice a month (1) Mandatory group meetings every week for 2 months then phase out to individual during the season (1)

Once a week, 5-10 minutes before practice (1) Weekly, first two or three months before season. Work on a topic a day for maybe a month. 5 minutes or 5 hours initially (1)

Every two weeks, 30 minute meetings unless if it's important. Couple meetings during pre-season, couple times month during season (1)

Depends on frequency needed with the athlete (1) Available during the year (1) Individual sessions if needed (1) More hands off during season and have open door policy to come by individually (1)

The more SPC comes to practice the more will learn about team and individuals (1)

Observe minimum every other day (3-4 days a week) to get feel of what's going on (1)

Would be great to be at practice every day (1) Realistically- 2 days a week for an hour or 75 minutes when they are working hard (1)

Beneficial to come to some of the meets, be in hotel with team, have breakfast, figure out what their life's like (1)

If athlete doesn't mind SPC being at practice- could be there once or twice a week to implement what working on during practice (1)

Would like advice on what coach could do with team to implement into practice weekly/bi weekly (1) 
$\underline{\text { Main Categories }}$

Time of Year $\underline{\text { Subcategories }}$

Expect SPC to

travel to away

competitions?

If SPC did travel, would expect with

team or on own?
Raw Data Themes

Out of season more meetings, in season less meetings (1)

Pre-season (1)

In and out of season. Team deals with different issues in and out of season (1)

Beginning of the season in fall \& before season in spring (1) More pre-season, not a lot of time want to take out of practice during season (1)

Start out of season and maintain over both semesters (1)

Initially, set up in fall . As season progresses more hands off (1)

In and out of season. Mostly during season (1)

No, not necessarily. Think there's ample time to have impact without traveling with team. Could be assessable by phone or e-mail (1)

Would not expect it, would like to see them there for couple of key weekends (1)

If the relationship was there. If budget would allow it (1)

No, I don't think so, don't want an extra distraction at the race. If SPC wanted to watch from shore that's okay or give pre-race feedback to coach (1)

No, they would be welcome to where we don't fly. Could addcare enough to take time to come (1)

I don't think so, limited on number of players can take due to financial restrictions. If had unlimited budget, yea probably (1) First thought was no, as relationship blossomed \& everyone became more comfortable \& maybe was told by few kids the need was there- Yes (1)

No can't take everybody. It's nice if SPC does travel to a competition (1)

With the team (3)

With the team if they could do it, right now they would not let them do it (1)

Can, but not in budget. If had it in budget wouldn't be a problem (1)

Have no idea. Don't know what going rate is (2)

Would be different for different budgets. Depends on resources (1)

Don't know how much. Should probably be paid per semester. Would probably come out of the budget (1)

We have a resource here for us so I don't know. I would reckon it would be the same as going to see any other therapist or consultant (1)

Don't know, never had to come up with funds to pay and don't know how much budget would allocate to that area (1)

Don't know- would want to pay per session so could regulate sessions. If had unlimited budget then per season (1)

Don't have it in the budget. In perfect world, maybe similar to what assistants are making. Could see it as an hourly wage (1) 


\section{SPA-RC Modifications}

Please indicate your level of agreement with each of the following statements by circling the response that corresponds to your feelings toward each statement. Please respond to each statement as truthfully as you can.

$\begin{array}{cccccc}\text { SD } & \text { MD } & \text { D } & \text { A } & \text { MA } & \text { SA } \\ 1 & 2 & 3 & 4 & 5 & 6 \\ \text { Strongly } & \text { Moderately } & \text { Slightly } & \text { Slightly } & \text { Moderately } & \text { Strongly } \\ \text { Disagree } & \text { Disagree } & \text { Disagree } & \text { Agree } & \text { Agree } & \text { Agree }\end{array}$

\section{Question}

A MA SA

1. A sport psychology consultant (SPC) can help athletes improve their mental toughness.

$\begin{array}{lllllll}1 & 2 & 3 & 4 & 5 & 6 & \text { СО } \\ 1 & 2 & 3 & 4 & 5 & 6 & \text { СР }\end{array}$

3. If an athlete on my team asked my advice about personal feelings of failure related to sport, I might recommend that he/she see a SPC.

Modification: "If an athlete on my team asked my advice about personal feelings of failure related to sport, I would recommend that he/she see a SPC."

4. I would not want a SPC working with my team because other coaches would harass me.

Modification: "I would not want a SPC working with my athletes because other coaches would think less of me.”

5. There are certain problems that should not be discussed outside one's immediate family

Modification: "There are certain problems that athletes should not discuss outside their immediate family.”

6. The people I associate with most are of the same race or ethnicity as me.

Modification: "The coaches and athletes I associate with most are of

$\begin{array}{llllll}2 & 3 & 4 & 5 & 6 & \text { со }\end{array}$
the same race or ethnicity as me"

7. A good idea for avoiding personal worries and concerns is to keep one's mind on the job.

Modification: "A good idea for an athlete to avoid personal worries and concerns is to keep one's mind on the job."

8. I would like to have the assistance of a SPC to help me better understand my team.

Modification: "I would like to have the assistance of a SPC to help me better understand my athletes."

9. I would feel uneasy having a SPC work with my team because some people would disapprove.

Modification: I would feel uneasy having a SPC work with my athletes because some people would disapprove."

$\begin{array}{lllllll}1 & 2 & 3 & 4 & 5 & 6 & \text { вт }\end{array}$

$\begin{array}{lllllll}1 & 2 & 3 & 4 & 5 & 6 & \text { PО }\end{array}$

$\begin{array}{lllllll}1 & 2 & 3 & 4 & 5 & 6 & \text { СР }\end{array}$

$\begin{array}{lllllll}1 & 2 & 3 & 4 & 5 & 6 & \text { PO }\end{array}$

$\begin{array}{lllllll}1 & 2 & 3 & 4 & 5 & 6 & \text { со }\end{array}$

$\begin{array}{lllllll}1 & 2 & 3 & 4 & 5 & 6 & \text { sт }\end{array}$


10. There is something respectable in the attitude of athletes who are willing to cope with their conflicts and fears without resorting to professional help.

11. If I utilized a SPC to help me coach better, I would not want other coaches to know about it.

$\begin{array}{lllllll}1 & 2 & 3 & 4 & 5 & 6 & \text { sт }\end{array}$

12. An athlete with emotional problems during sport performance would feel most secure in receiving assistance from a SPC.

Modification: "I feel that an athlete with emotional problems during sport performance would feel most secure in receiving assistance from a SPC.

13. Having seen a SPC is bad for an athlete's reputation.

14. There are experiences in my life that I would not discuss with anyone.

Modification: “There are experiences in my athletes' lives that I

$\begin{array}{lllllll}1 & 2 & 3 & 4 & 5 & 6 & \text { PO }\end{array}$
believe they would not discuss with a SPC."

15. If I was worried or upset about my team's performance, I would want to get help from a SPC.

Modification: "If I was worried or upset about my athletes' performance, I would want to get help from a SPC."

16. Emotional difficulties tend to work themselves out in time.

Modification: "Athletes emotional difficulties tend to work themselves out in time."

17. I think a SPC would help my team perform better under pressure.

Modification: "It think a SPC would help my athletes perform better under pressure."

18. I would not want someone else to know about my team receiving help from a SPC.

Modification: "I would not want someone else to know about my athletes receiving help from a SPC.”

19. There are great differences between people of different races or ethnicities.

20. A SPC could help my team fine-tune their performance. Modification: "A SPC could help my athletes fine-tune their performance.”

$\begin{array}{lllllll}1 & 2 & 3 & 4 & 5 & 6 & \text { со }\end{array}$

$\begin{array}{lllllll}1 & 2 & 3 & 4 & 5 & 6 & \text { PO }\end{array}$

$\begin{array}{lllllll}1 & 2 & 3 & 4 & 5 & 6 & \text { со }\end{array}$

21. If my team worked with a SPC, I would not want other coaches to know about it.

Modification: "If my athletes worked with a SPC, I would not want

$\begin{array}{lllllll}1 & 2 & 3 & 4 & 5 & 6 & \text { sт }\end{array}$
other coaches to know about it."

22. At times I have felt lost and would have welcomed professional advice for a personal problem.

$\begin{array}{lllllll}1 & 2 & 3 & 4 & 5 & 6 & \text { со }\end{array}$


23. I would think less of my athletes if they went to a SPC. $\quad \begin{array}{llllllllll}1 & 2 & 3 & 4 & 5 & 6 & \text { ST }\end{array}$

24. Athletes with a strong character can get over mental conflicts by themselves.

$\begin{array}{lllllll}1 & 2 & 3 & 4 & 5 & 6 & \text { PO }\end{array}$

25. I would be more comfortable with a SPC if he/she were the same race or ethnicity as I am.

$\begin{array}{lllllll}1 & 2 & 3 & 4 & 5 & 6 & \text { СР }\end{array}$

\section{Items Added}

26. I am not willing to discuss concerns regarding my team with a sport psychology consultant.

$\begin{array}{lllllll}1 & 2 & 3 & 4 & 5 & 6 & \text { PO }\end{array}$

27. If I were to hire a SPC, I would take into account his/her race or ethnicity.

$\begin{array}{lllllll}1 & 2 & 3 & 4 & 5 & 6 & \text { СР }\end{array}$

28. My athletes would be more comfortable with a SPC if he/she were of the same race or ethnicity as them.

$\begin{array}{lllllll}1 & 2 & 3 & 4 & 5 & 6 & \text { СР }\end{array}$

29. I am open to hiring a SPC to work with my athletes.

$\begin{array}{lllllll}1 & 2 & 3 & 4 & 5 & 6 & \text { PO }\end{array}$

30. An athlete may relate best to a SPC if he/she were the same race or ethnicity.

$\begin{array}{lllllll}1 & 2 & 3 & 4 & 5 & 6 & \text { СР }\end{array}$

31. Athletes should know how to handle problems without needing assistance from a SPC.

$\begin{array}{lllllll}1 & 2 & 3 & 4 & 5 & 6 & \mathrm{PO}\end{array}$

32. I would be more comfortable hiring a SPC if he/she were from the same cultural background as my athletes.

$\begin{array}{lllllll}1 & 2 & 3 & 4 & 5 & 6 & \text { СР }\end{array}$


PART 1: Please circle or fill in the most appropriate answers below. There are no right or wrong answers, and all information will be kept confidential. We value your honest responses.

1. Sport that you primarily coach (please list only one):

a. What gender do you coach in your primary sport? Male Female Both

2. Have you heard of AAASP certification for sport psychology? Yes No

3. Do you have access to sport psychology services? Yes No

4. Do you currently have a sport psychology consultant (SPC) working with your team?

Yes $\quad$ No (if no, skip to question 5)

a. How satisfied are you with these services right now? Very Unsatisfied $1122 \quad 3 \quad 4 \quad 5 \quad 6$ Very Satisfied

5. In the past, have you previously had a SPC work with your team? Yes No (if no, skip to Part 2)

a. Please estimate the total number of seasons that a SPC has worked with your team(s):

b. Based on this previous experience, would you consider using services in the future? Yes No

PART 2: Please indicate your level of agreement with each of the following statements by circling the response that corresponds to your feelings toward each statement. Please respond to each statement as truthfully as you can.

$\begin{array}{cccccc}\text { SD } & \text { MD } & \text { D } & \text { A } & \text { MA } & \text { SA } \\ 1 & 2 & 3 & 4 & 5 & 6 \\ \text { Strongly } & \text { Moderately } & \text { Slightly } & \text { Slightly } & \text { Moderately } & \text { Strongly } \\ \text { Disagree } & \text { Disagree } & \text { Disagree } & \text { Agree } & \text { Agree } & \text { Agree }\end{array}$

Question (SPC= Sport Psychology Consultant)

1. A sport psychology consultant (SPC) can help athletes improve their mental toughness.

$\begin{array}{cccccc}\text { SD } & \text { MD } & \text { D } & \text { A } & \text { MA } & \text { SA } \\ 1 & 2 & 3 & 4 & 5 & 6 \\ 1 & 2 & 3 & 4 & 5 & 6 \\ 1 & 2 & 3 & 4 & 5 & 6 \\ 1 & 2 & 3 & 4 & 5 & 6 \\ 1 & 2 & 3 & 4 & 5 & 6 \\ 1 & 2 & 3 & 4 & 5 & 6 \\ 1 & 2 & 3 & 4 & 5 & 6 \\ 1 & 2 & 3 & 4 & 5 & 6\end{array}$

2. I would not want a SPC working with my athletes because other coaches would think less of me.

3. I would like to have the assistance of a SPC to help me better understand my athletes.

4. I would feel uneasy having a SPC work with my athletes because some people would disapprove.

5. Having seen a SPC is bad for an athlete's reputation.

6. Athletes emotional difficulties tend to work themselves out in time.

7. I think a SPC would help my athletes perform better under pressure.

8. A SPC could help my athletes fine-tune their performance. 


$\begin{array}{cccc}\text { SD } & \text { MD } & \text { D } & \text { A } \\ 1 & 2 & 3 & 4 \\ \text { Strongly } & \text { Moderately } & \text { Slightly } & \text { Slightly } \\ \text { Disagree } & \text { Disagree } & \text { Disagree } & \text { Agree }\end{array}$

\section{Question (SPC= Sport Psychology Consultant)}

9. If my athletes worked with a SPC, I would not want other coaches to know about it.

10. My athletes would be more comfortable with a SPC if he/she were of the same race or ethnicity as them.

11. I would think less of my athletes if they went to a SPC.

12. Athletes with a strong character can get over mental conflicts by themselves.

13. An athlete may relate best to a SPC if he/she were the same race or ethnicity.

14. Athletes should know how to handle problems without needing assistance from a SPC.

15. I would be more comfortable hiring a SPC if he/she were from the same cultural background as my athletes.

Tailored Coach Intervention 72 SA

Sightly

Agree

$\begin{array}{llllll}\text { SD } & \text { MD } & \text { D } & \text { A } & \text { MA } & \text { SA } \\ 1 & 2 & 3 & 4 & 5 & 6 \\ 1 & 2 & 3 & 4 & 5 & 6 \\ 1 & 2 & 3 & 4 & 5 & 6 \\ 1 & 2 & 3 & 4 & 5 & 6 \\ 1 & 2 & 3 & 4 & 5 & 6 \\ 1 & 2 & 3 & 4 & 5 & 6 \\ 1 & 2 & 3 & 4 & 5 & 6\end{array}$

PART 3: Use of mental skills and sport psychology services

1. Please circle the letter that best describes your team's current use of sport psychology services. Sport psychology services include consulting with a sport psychology professional, having a sport psychology professional meet with your team/athletes, having a sport psychology professional meet with the coach or coaching staff, and referring athletes for performance enhancement or counseling.

${ }^{*}$ Using sport psychology services consistently each week or every two weeks is considered regular.**

We currently do not use, and are not thinking of using sport psychology services as part of our athletes

A. overall training program.

B. We currently do not use sport psychology services as part of our athletes overall training program, but we are thinking about starting by the upcoming season.

C. We currently use sport psychology services as part of our athletes overall training program, but not regularly.

D. We regularly use sport psychology services as part of our athletes overall training program, but we have only begun doing so within the past season

E. We regularly use sport psychology services as part of our athletes overall training program and have done so for longer than one season

2. What are some of the reasons why you do or would use sport psychology services?

3. What are some reasons why you do not or would not use sport psychology services? 
PART 4: Please rate your level of agreement with the following statements.

\section{Question}

1. Other coaches on our staff would be supportive of using sport psychology services with our athletes.

2. Other coaches at my level are using sport psychology services with their athletes.

3. I feel pressure from people who are important to me to not access and use sport psychology services with our athletes.

4. The coaches whose opinions I respect use sport psychology services with their athletes.

5. If the coaching staff wanted to, we could easily access and use sport psychology services for the upcoming season.

6. I would not know how to access a sport psychology professional for the upcoming season.

\section{Strongly \\ Disagree}

$\begin{array}{llllll}1 & 2 & 3 & 4 & 5 & 6 \\ 1 & 2 & 3 & 4 & 5 & 6 \\ 1 & 2 & 3 & 4 & 5 & 6 \\ 1 & 2 & 3 & 4 & 5 & 6 \\ 1 & 2 & 3 & 4 & 5 & 6 \\ 1 & 2 & 3 & 4 & 5 & 6\end{array}$

\section{Strongly}

Agree

6

6

6

6

PART 5: Please rate your level of agreement with regards to expectations and barriers to using sport psychology services with your athletes right now?

\section{Question}

1. I would struggle with not knowing what would be said between the sport psychology consultant and our athlete(s).

2. Our team does not have enough time to use sport psychology services.

3. It would be difficult for me to trust a sport psychology consultant to work with our athletes.

4. Using sport psychology services might make our athletes' think too much during practice or competition.

5. We do not have the money in our budget to use sport psychology services.

6. I am not familiar with why I should use sport psychology services.

7. Using sport psychology services would be counterproductive: athletes either have mental skills or they don't.

8. I do not know enough about sport psychology to feel comfortable using sport psychology services with my athletes.

9. I am not familiar with the role of a sport psychology professional.

10.The benefits of sport psychology would be difficult to prove.

\section{Strongly \\ Disagree}

Strongly

Agree

$\begin{array}{llllll}1 & 2 & 3 & 4 & 5 & 6\end{array}$

1

2

3

4

5

6

1

2

3

4

5

6

1

2

3

4

5

6

1

2

3

$$
4
$$

5

6

1

1

1

12

2

3

$$
4
$$

5

12

3

4

5

12

3

4

5

6

1

2

3

4

5 
PART 6: This section contains questions about your intentions to use sport psychology services in the future.

1. How likely is it that you will use sport psychology services ...
a. In the next month (Not at all Likely) $1 \begin{array}{llllll}1 & 2 & 3 & 4 & 5 & 6\end{array}$ (Very Likely)

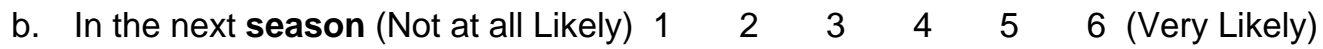

2. How likely is it that you would refer an athlete to a sport psychology consultant for ...
a. Personal concerns
$\begin{array}{lllllll}\text { or relationship problems (Not at all Likely) } & 1 & 2 & 3 & 4 & 5 & 6 \text { (Very Likely) }\end{array}$

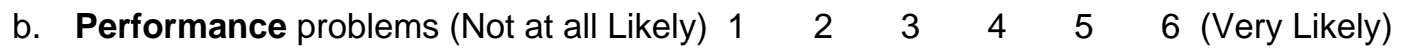

3. How likely is it that you will seek out more information about sport psychology in the next month?

$$
\text { (Not at all Likely) } 1 \quad 2 \quad 3 \quad 4 \quad 5 \quad 6 \text { (Very Likely) }
$$

PART 7: Please tell us a bit about who filled out this survey...

1. What is your Gender: Male Female

2. Age: 21-29years 30-39years 40-49years 50-59years 60+years

3. Ethnicity/Race: African-American Caucasian Hispanic American Indian

Asian or Pacific Islander Other (specify):

4. Highest Degree Completed: High School BA/BS MA/MS

$$
\text { EdD/PhD/PsyD Other Degree (specify): }
$$

5. Current Work Setting: Division I Division II Division III NAIA NJCAA NSCAA

$$
\text { Junior College High School Other (specify): }
$$

6. Current Job Title in Primary Sport: Head Coach Assistant Coach Other (specify):

Number of years at current position:

Total number of years of work experience as a coach:

7. Please list any certifications you currently hold related to coaching: 
THANK YOU FOR COMPLETING THIS QUESTIONNAIRE!

PLEASE STOP HERE AND WAIT UNTIL AFTER THE WORKSHOP TO FILL OUT THE REMAINDER OF THE SURVEY PACKET 


\section{COACHES POST-WORKSHOP SURVEY}

PART 1: Please indicate your level of agreement with each of the following statements by circling the response that corresponds to your feelings toward each statement. Please respond to each statement as truthfully as you can.

$\begin{array}{cccccc}\text { SD } & \text { MD } & \text { D } & \text { A } & \text { MA } & \text { SA } \\ 1 & 2 & 3 & 4 & 5 & 6 \\ \text { Strongly } & \text { Moderately } & \text { Slightly } & \text { Slightly } & \text { Moderately } & \text { Strongly } \\ \text { Disagree } & \text { Disagree } & \text { Disagree } & \text { Agree } & \text { Agree } & \text { Agree }\end{array}$

\section{Question (SPC= Sport Psychology Consultant)}

1. A sport psychology consultant (SPC) can help athletes improve their mental toughness.

2. I would not want a SPC working with my athletes because other coaches would think less of me.

3. I would like to have the assistance of a SPC to help me better understand my athletes.

4. I would feel uneasy having a SPC work with my athletes because some people would disapprove.

5. Having seen a SPC is bad for an athlete's reputation.

6. Athletes emotional difficulties tend to work themselves out in time.

7. I think a SPC would help my athletes perform better under pressure.

8. A SPC could help my athletes fine-tune their performance.

9. If my athletes worked with a SPC, I would not want other coaches to know about it.

10. My athletes would be more comfortable with a SPC if he/she were of the same race or ethnicity as them.

11. I would think less of my athletes if they went to a SPC.

12. Athletes with a strong character can get over mental conflicts by themselves.

13. An athlete may relate best to a SPC if he/she were the same race or ethnicity.

14. Athletes should know how to handle problems without needing assistance from a SPC.

15. I would be more comfortable hiring a SPC if he/she were from the same cultural background as my athletes.

\begin{tabular}{|c|c|c|c|c|c|}
\hline SD & MD & D & A & MA & SA \\
\hline 1 & 2 & 3 & 4 & 5 & 6 \\
\hline 1 & 2 & 3 & 4 & 5 & 6 \\
\hline 1 & 2 & 3 & 4 & 5 & 6 \\
\hline 1 & 2 & 3 & 4 & 5 & 6 \\
\hline 1 & 2 & 3 & 4 & 5 & 6 \\
\hline 1 & 2 & 3 & 4 & 5 & 6 \\
\hline 1 & 2 & 3 & 4 & 5 & 6 \\
\hline 1 & 2 & 3 & 4 & 5 & 6 \\
\hline 1 & 2 & 3 & 4 & 5 & 6 \\
\hline 1 & 2 & 3 & 4 & 5 & 6 \\
\hline 1 & 2 & 3 & 4 & 5 & 6 \\
\hline 1 & 2 & 3 & 4 & 5 & 6 \\
\hline 1 & 2 & 3 & 4 & 5 & 6 \\
\hline 1 & 2 & 3 & 4 & 5 & 6 \\
\hline 1 & 2 & 3 & 4 & 5 & 6 \\
\hline
\end{tabular}


PART 2: Use of mental skills and sport psychology services

1. Please circle the letter that best describes your team's current use of sport psychology services. Sport psychology services include consulting with a sport psychology professional, having a sport psychology professional meet with your team/athletes, having a sport psychology professional meet with the coach or coaching staff, and referring athletes for performance enhancement or counseling.

${ }^{\star *}$ Using sport psychology services consistently each week or every two weeks is considered regular. **

We currently do not use, and are not thinking of using sport psychology services as part of our athletes

A. overall training program.

B. We currently do not use sport psychology services as part of our athletes overall training program, but we are thinking about starting by the upcoming season.

C. We currently use sport psychology services as part of our athletes overall training program, but not regularly.

D. We regularly use sport psychology services as part of our athletes overall training program, but we have only begun doing so within the past season

E. We regularly use sport psychology services as part of our athletes overall training program and have done so for longer than one season

PART 3: Please rate your level of agreement with regards to expectations and barriers to using sport psychology services with your athletes right now?

\section{Question}

1. I would struggle with not knowing what would be said between the sport psychology consultant and our athlete(s).

2. Our team does not have enough time to use sport psychology services.

3. It would be difficult for me to trust a sport psychology consultant to work with our athletes.

4. Using sport psychology services might make our athletes' think too much during practice or competition.

5. We do not have the money in our budget to use sport psychology services.

6. I am not familiar with why I should use sport psychology services.

7. Using sport psychology services would be counterproductive: athletes either have mental skills or they don't.

8. I do not know enough about sport psychology to feel comfortable using sport psychology services with my athletes.

9. I am not familiar with the role of a sport psychology professional.

10.The benefits of sport psychology would be difficult to prove.

\section{Strongly \\ Disagree}

1

1

2

3

4

5

6

1

1

2

3

3

4

5

6

2

3

4

5

6

1

2

3

4

5

6

1

1

1

1

1

2

2

3

4

5

6 
PART 4: Please rate your level of agreement with the following statements.

\section{Question}

7. Other coaches on our staff would be supportive of using sport psychology services with our athletes.

8. Other coaches at my level are using sport psychology services with their athletes.

9. I feel pressure from people who are important to me to not access and use sport psychology services with our athletes.

10. The coaches whose opinions I respect use sport psychology services with their athletes.

11. If the coaching staff wanted to, we could easily access and use sport psychology services for the upcoming season.

12. I would not know how to access a sport psychology professional for the upcoming season.

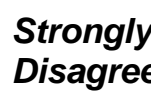

Strongly

Agree

$\begin{array}{llllll}1 & 2 & 3 & 4 & 5 & 6\end{array}$

$\begin{array}{llllll}1 & 2 & 3 & 4 & 5 & 6\end{array}$

1

1

$\begin{array}{lllll}2 & 3 & 4 & 5 & 6\end{array}$

1

$2 \quad 3 \quad 4$

5

6

PART 5: This section contains questions about your intentions to use sport psychology services in the future.

3. How likely is it that you will use sport psychology services ...

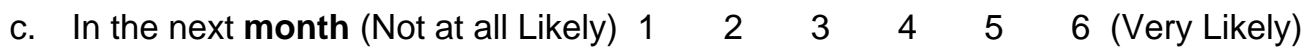

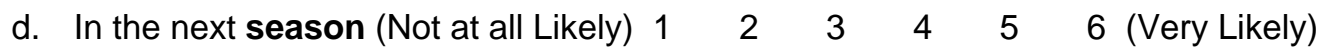

4. How likely is it that you would refer an athlete to a sport psychology consultant for ...

c. Personal concerns

or relationship problems (Not at all Likely) $\begin{array}{lllllll}1 & 2 & 3 & 4 & 5 & 6 & \text { (Very Likely) }\end{array}$

d. Performance problems (Not at all Likely) $\begin{array}{llllllll}1 & 2 & 3 & 4 & 5 & 6 & \text { (Very Likely) }\end{array}$

3. How likely is it that you will seek out more information about sport psychology in the next month?

(Not at all Likely) $1 \quad 2 \quad \begin{array}{lllll} & 2 & 4 & 5 & 6\end{array}$ (Very Likely)

4. What was the impact of the workshop on your impression of sport psychology services?

(Very negative impact) $1 \quad 2 \quad 3 \quad 4 \quad 5 \quad 6$ (Very positive impact)

THANK YOU FOR COMPLETING THIS QUESTIONNAIRE!

PLEASE RETURN THE SURVEY PACKET TO THE RESEARCHER 
Tailored Coach Intervention 79

\section{Appendix B}

Coaches Survey Packet Pre and Post-Workshop 


\section{COACHES PRE-WORKSHOP SURVEY}

PART 1: Please circle or fill in the most appropriate answers below. There are no right or wrong answers, and all information will be kept confidential. We value your honest responses.

1. Sport that you primarily coach (please list only one):

a. What gender do you coach in your primary sport? Male Female Both

2. Have you heard of AAASP certification for sport psychology? Yes No

3. Do you have access to sport psychology services? Yes No

4. Do you currently have a sport psychology consultant (SPC) working with your team?

Yes $\quad$ No (if no, skip to question 5)

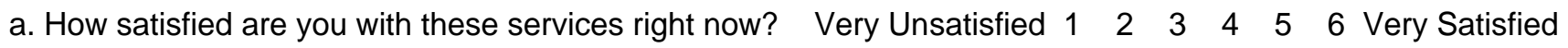

5. In the past, have you previously had a SPC work with your team? Yes No (if no, skip to Part 2)

a. Please estimate the total number of seasons that a SPC has worked with your team(s):

b. Based on this previous experience, would you consider using services in the future? Yes No

PART 2: Please indicate your level of agreement with each of the following statements by circling the response that corresponds to your feelings toward each statement. Please respond to each statement as truthfully as you can.

$\begin{array}{cccccc}\text { SD } & \text { MD } & \text { D } & \text { A } & \text { MA } & \text { SA } \\ 1 & 2 & 3 & 4 & 5 & 6 \\ \text { Strongly } & \text { Moderately } & \text { Slightly } & \text { Slightly } & \text { Moderately } & \text { Strongly } \\ \text { Disagree } & \text { Disagree } & \text { Disagree } & \text { Agree } & \text { Agree } & \text { Agree }\end{array}$

Question (SPC= Sport Psychology Consultant)

6. A sport psychology consultant (SPC) can help athletes improve their mental toughness.

7. I would not want a SPC working with my athletes because other coaches would think less of me.

8. I would like to have the assistance of a SPC to help me better understand my athletes.

9. I would feel uneasy having a SPC work with my athletes because some people would disapprove.

10. Having seen a SPC is bad for an athlete's reputation.

11. Athletes emotional difficulties tend to work themselves out in time.

12. I think a SPC would help my athletes perform better under pressure.

13. A SPC could help my athletes fine-tune their performance.
1

1

1

1

1

1

1

1
SD

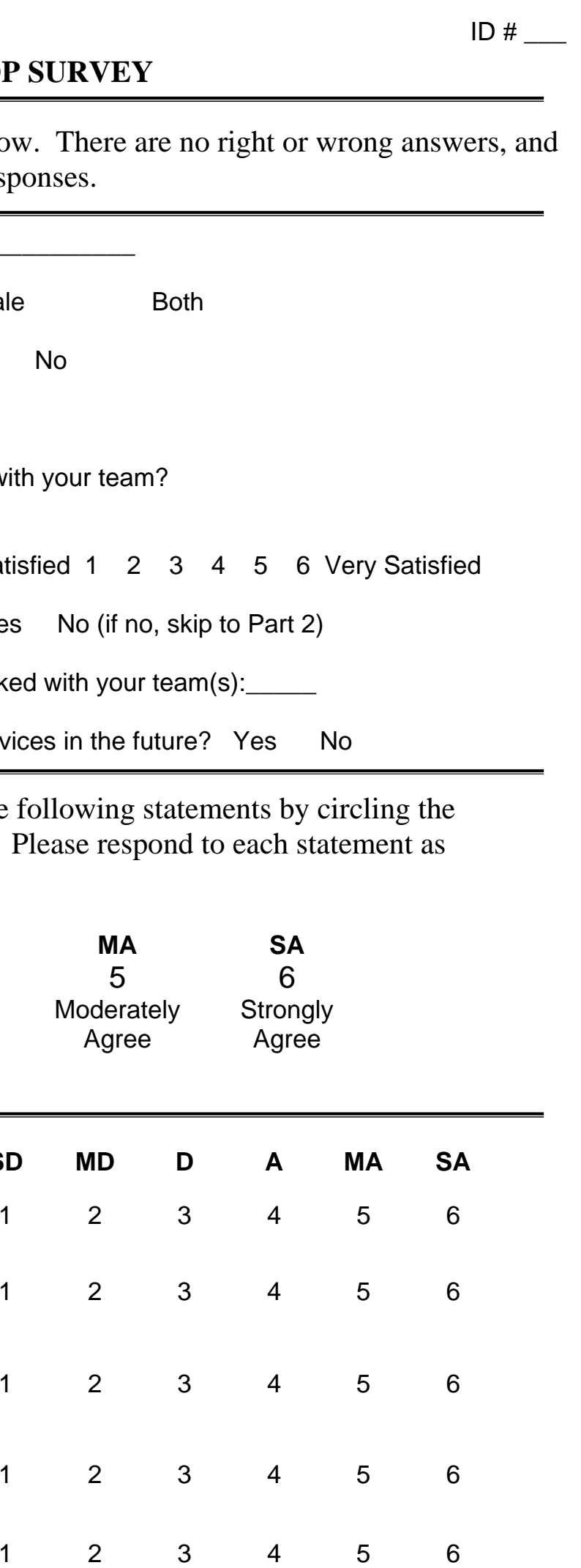

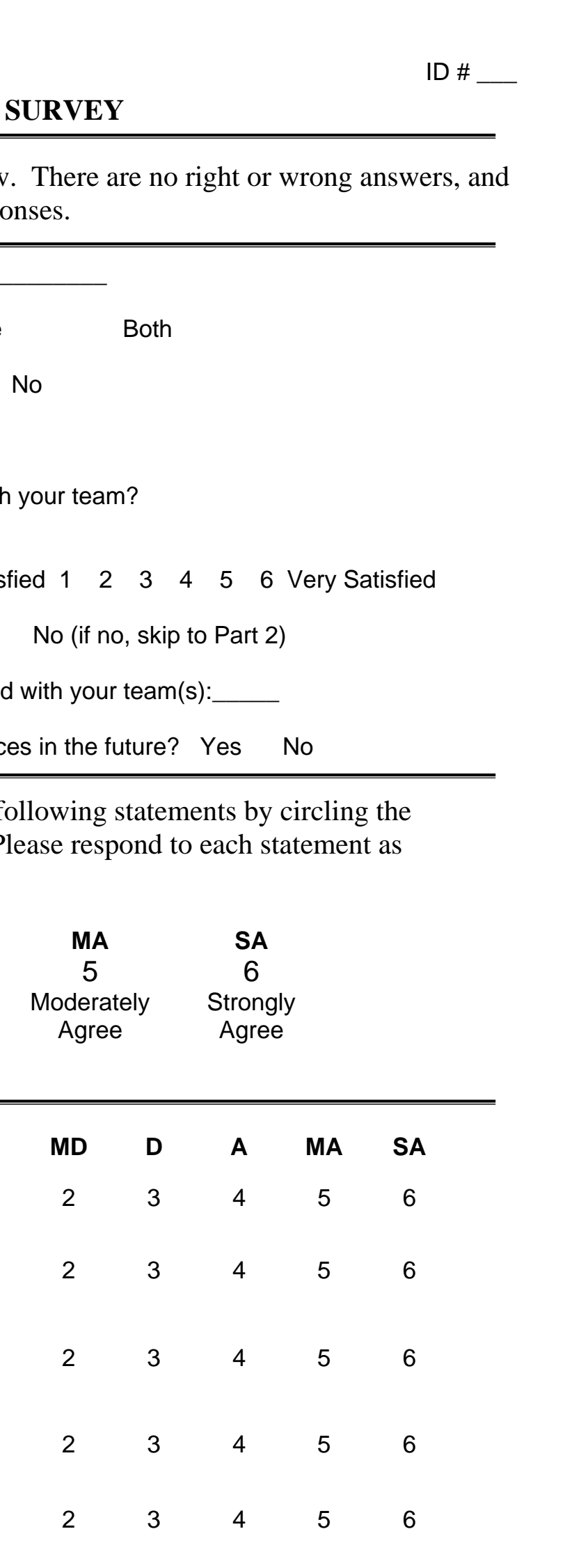

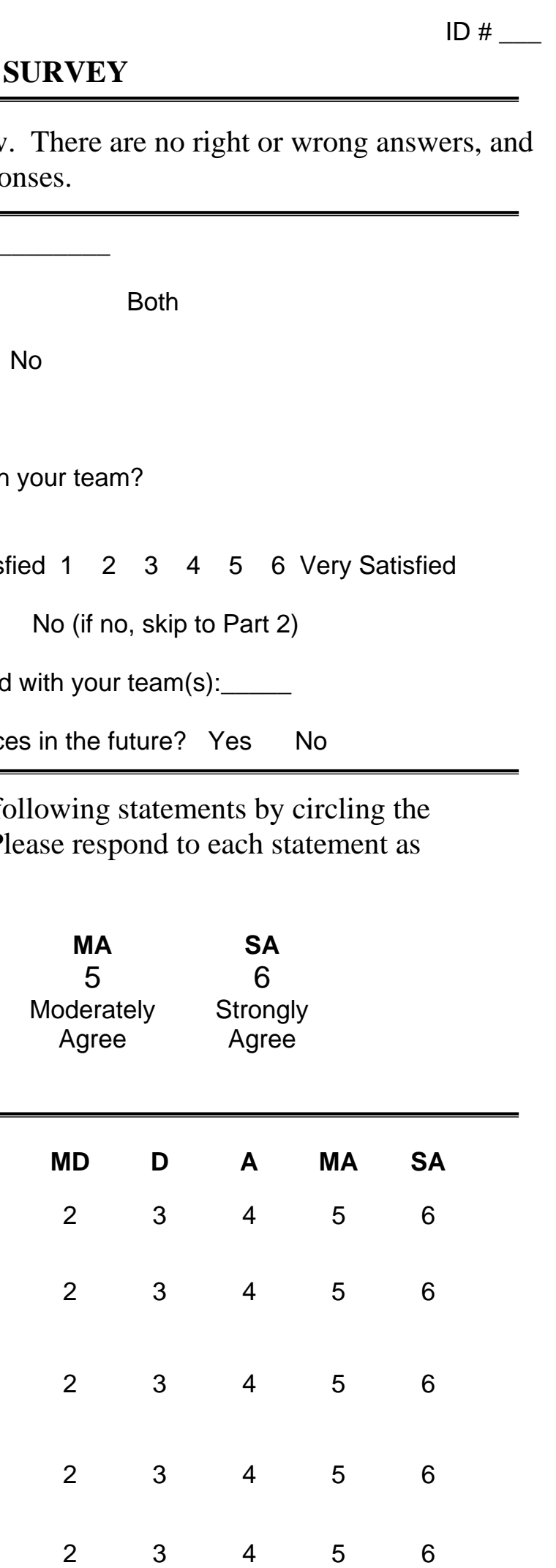

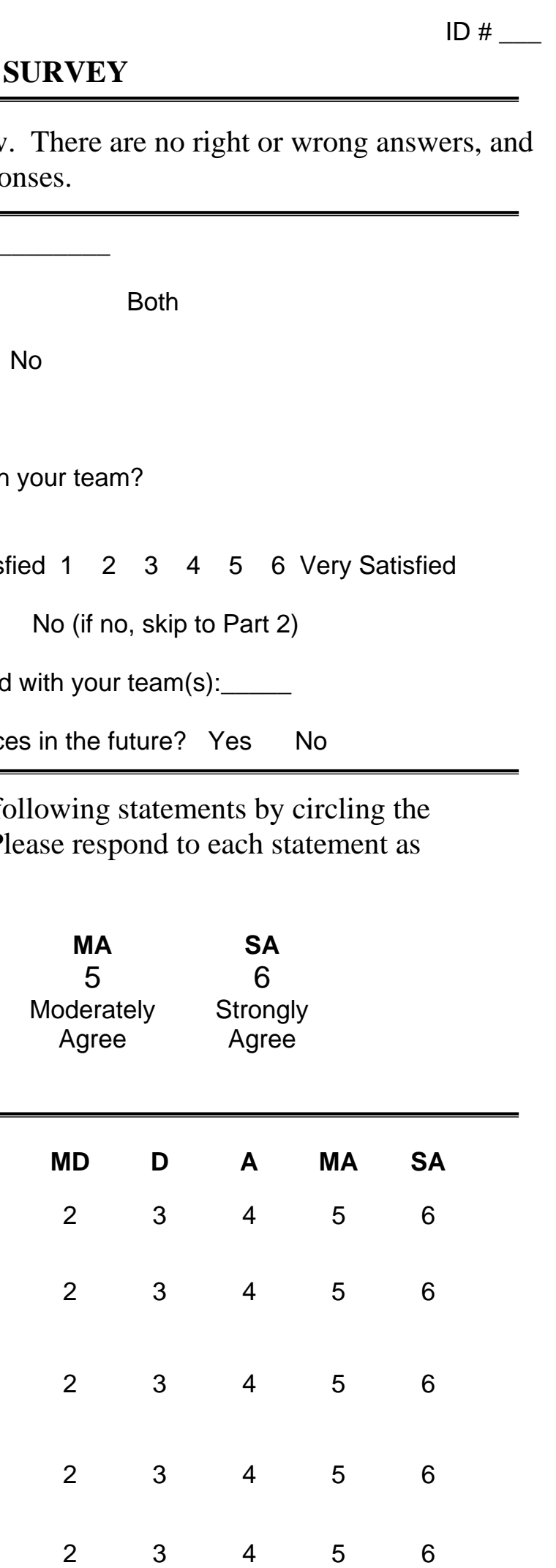

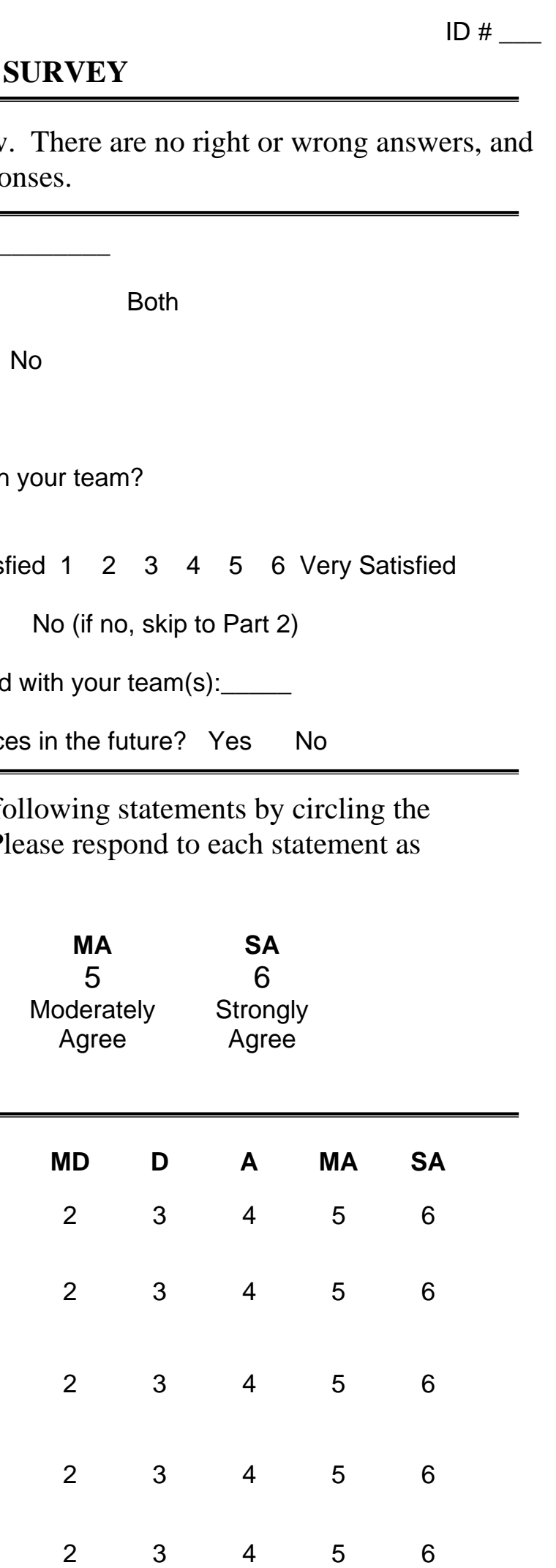

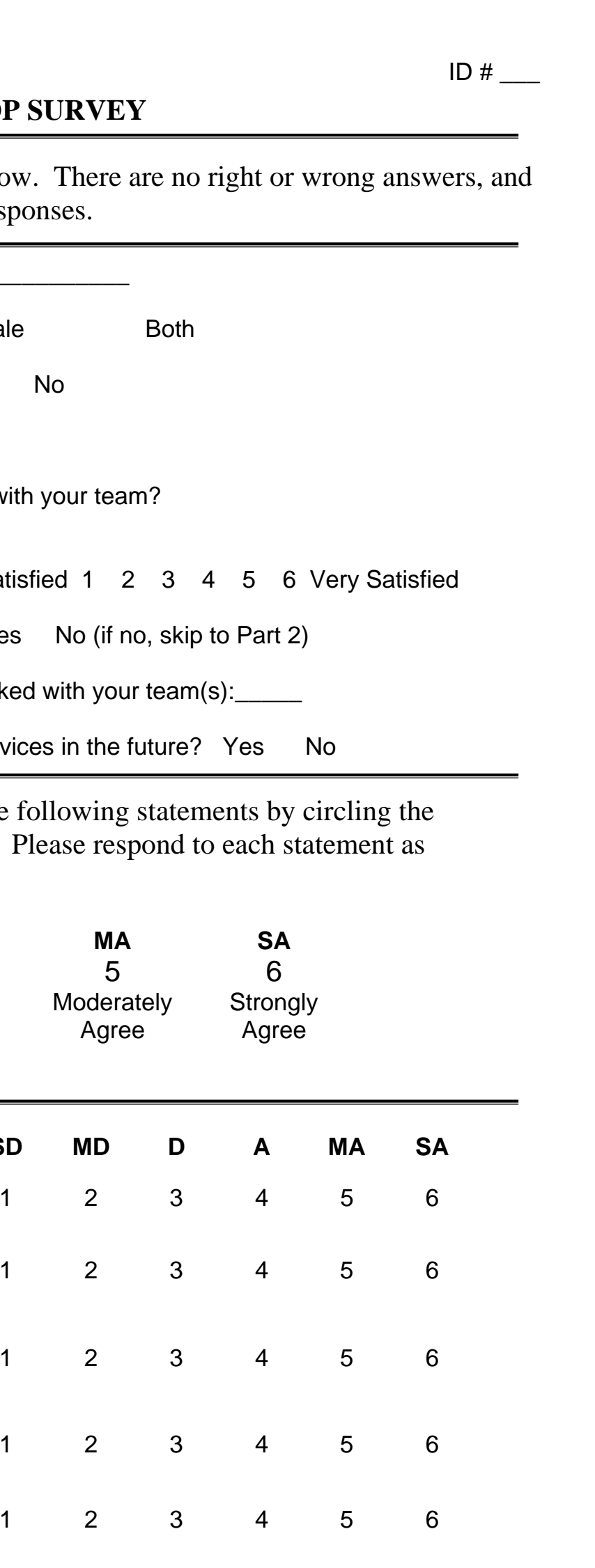

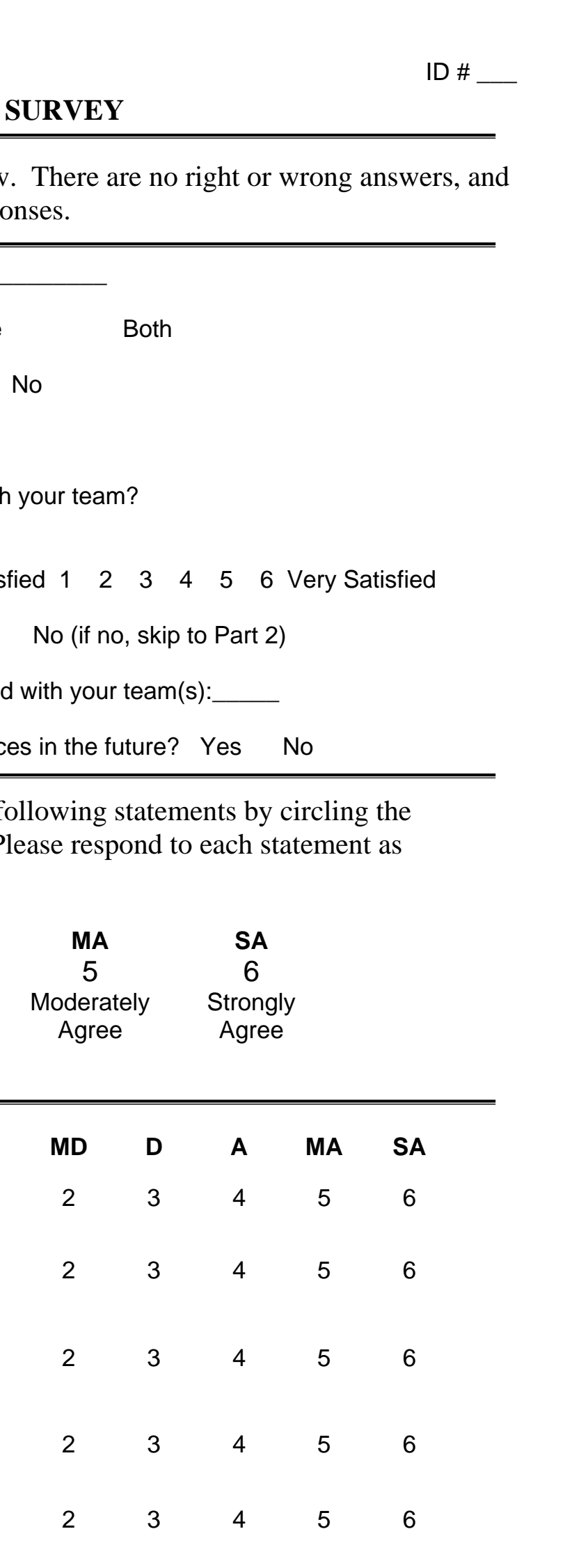

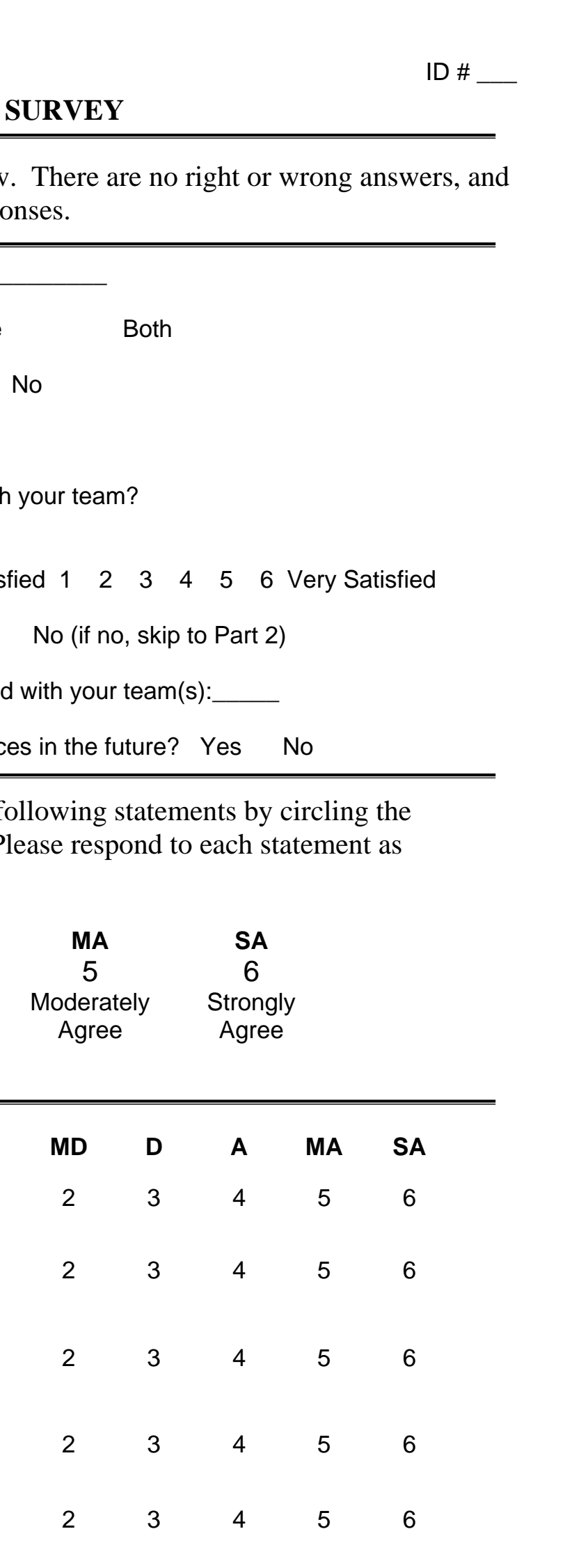

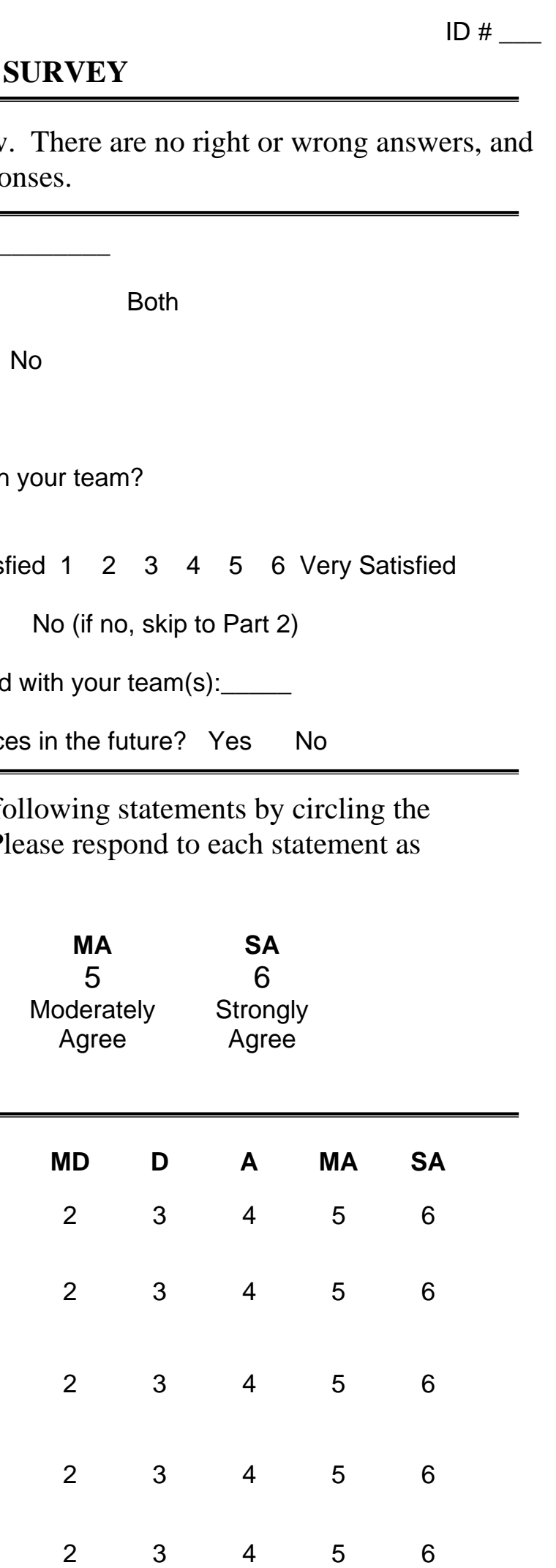

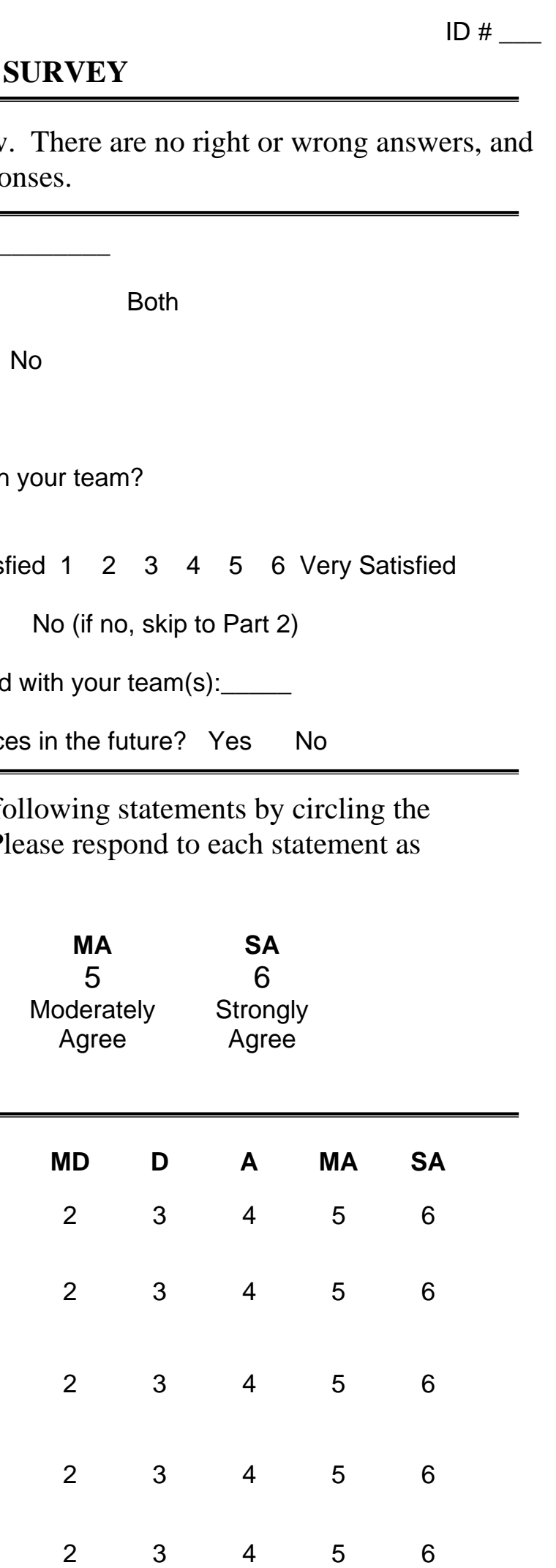

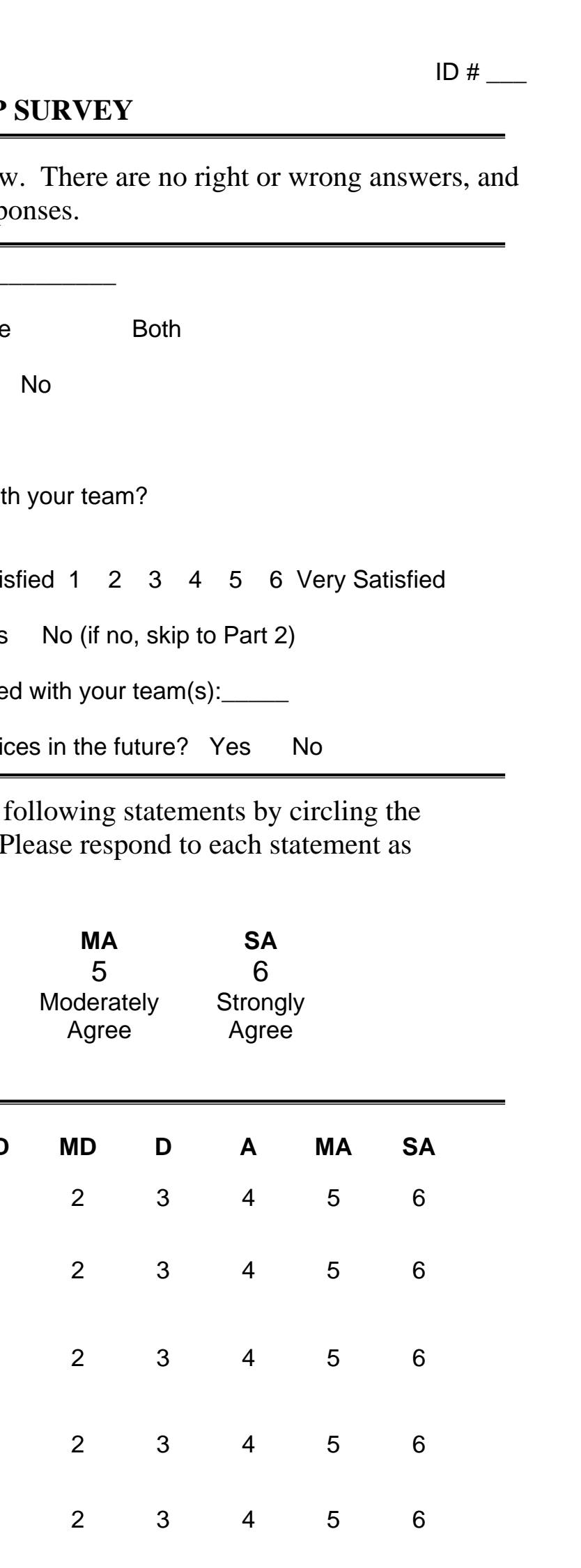

$\begin{array}{lllll}2 & 3 & 4 & 5 & 6\end{array}$

$\begin{array}{lllll}2 & 3 & 4 & 5 & 6\end{array}$

$\begin{array}{lllll}2 & 3 & 4 & 5 & 6\end{array}$


Tailored Coach Intervention 81

$\begin{array}{cccc}\text { SD } & \text { MD } & \text { D } & \text { A } \\ 1 & 2 & 3 & 4 \\ \text { Strongly } & \text { Moderately } & \text { Slightly } & \text { Slightly } \\ \text { Disagree } & \text { Disagree } & \text { Disagree } & \text { Agree }\end{array}$

Question (SPC= Sport Psychology Consultant)

14. If my athletes worked with a SPC, I would not want other coaches to know about it.

15. My athletes would be more comfortable with a SPC if he/she were of the same race or ethnicity as them.

16. I would think less of my athletes if they went to a SPC.

17. Athletes with a strong character can get over mental conflicts by themselves.

18. An athlete may relate best to a SPC if he/she were the same race or ethnicity.

19. Athletes should know how to handle problems without needing assistance from a SPC.

20. I would be more comfortable hiring a SPC if he/she were from the same cultural background as my athletes.

$\begin{array}{cccccc}\text { SD } & \text { MD } & \text { D } & \text { A } & \text { MA } & \text { SA } \\ 1 & 2 & 3 & 4 & 5 & 6 \\ 1 & 2 & 3 & 4 & 5 & 6 \\ 1 & 2 & 3 & 4 & 5 & 6 \\ 1 & 2 & 3 & 4 & 5 & 6 \\ 1 & 2 & 3 & 4 & 5 & 6 \\ 1 & 2 & 3 & 4 & 5 & 6 \\ 1 & 2 & 3 & 4 & 5 & 6\end{array}$

PART 3: Use of mental skills and sport psychology services

21. Please circle the letter that best describes your team's current use of sport psychology services. Sport psychology services include consulting with a sport psychology professional, having a sport psychology professional meet with your team/athletes, having a sport psychology professional meet with the coach or coaching staff, and referring athletes for performance enhancement or counseling.

**Using sport psychology services consistently each week or every two weeks is considered regular. **

We currently do not use and are not thinking of using sport psychology services as part of our athletes

A. overall training program.

B. We currently do not use sport psychology services as part of our athletes overall training program, but we are thinking about starting by the upcoming season.

C. We currently use sport psychology services as part of our athletes overall training program, but not regularly.

D. We regularly use sport psychology services as part of our athletes overall training program, but we have only begun doing so within the past season

E. We regularly use sport psychology services as part of our athletes overall training program and have done so for longer than one season

22. What are some of the reasons why you do or would use sport psychology services (please list 2-3)?

23. What are some reasons why you do not or would not use sport psychology services (please list 2-3)? 
PART 4: Please rate your level of agreement with the following statements.

\section{Question}

13. Other coaches on our staff would be supportive of using sport psychology services with our athletes.

14. Other coaches at my level are using sport psychology services with their athletes.

15. I feel pressure from people who are important to me to not access and use sport psychology services with our athletes.

16. The coaches whose opinions I respect use sport psychology services with their athletes.

17. If the coaching staff wanted to, we could easily access and use sport psychology services for the upcoming season.

18. I would not know how to access a sport psychology professional for the upcoming season.

\section{Strongly \\ Disagree}

\section{Strongly}

Agree

$\begin{array}{llllll}1 & 2 & 3 & 4 & 5 & 6 \\ 1 & 2 & 3 & 4 & 5 & 6 \\ 1 & 2 & 3 & 4 & 5 & 6 \\ 1 & 2 & 3 & 4 & 5 & 6 \\ 1 & 2 & 3 & 4 & 5 & 6 \\ 1 & 2 & 3 & 4 & 5 & 6\end{array}$

PART 5: Please rate your level of agreement with regards to expectations and barriers to using sport psychology services with your athletes right now.

\section{Question}

30. I would struggle with not knowing what would be said between the sport psychology consultant and our athlete(s).

31. Our team does not have enough time to use sport psychology services.

32. It would be difficult for me to trust a sport psychology consultant to work with our athletes.

33. Using sport psychology services might make our athletes' think too much during practice or competition.

34. We do not have the money in our budget to use sport psychology services.

35. I am not familiar with why I should use sport psychology services.

36. Using sport psychology services would be counterproductive; athletes either have mental skills or they don't.

37. I do not know enough about sport psychology to feel comfortable using sport psychology services with my athletes.

38. I am not familiar with the role of a sport psychology professional.

39. The benefits of sport psychology would be difficult to prove.

\section{Strongly \\ Disagree}

Strongly

Agree

$\begin{array}{llllll}1 & 2 & 3 & 4 & 5 & 6\end{array}$

1

2

3

4

5

6

1

2

3

4

5

6

1

2

3

4

5

6

1

2

3

$$
4
$$

5

6

1

1

1

1

1

2

\section{3}

4

5

3

4

5

6

2

3

4

5

6

2

3

4

5

6

1

2

3

4

5 
Tailored Coach Intervention 83

ID \#

PART 6: This section contains questions about your intentions to use sport psychology services in the future.

40. How likely is it that you will use sport psychology services ...

e. In the next month (Not at all Likely) $\begin{array}{lllllll}1 & 2 & 3 & 4 & 5 & 6 & \text { (Very Likely) }\end{array}$

f. In the next season (Not at all Likely) $\begin{array}{lllllll}1 & 2 & 3 & 4 & 5 & 6 & \text { (Very Likely) }\end{array}$

41. How likely is it that you would refer an athlete to a sport psychology consultant for ...

e. Personal concerns

$\begin{array}{llllllll}\text { or relationship problems (Not at all Likely) } & 1 & 2 & 3 & 4 & 5 & 6 & \text { (Very Likely) }\end{array}$

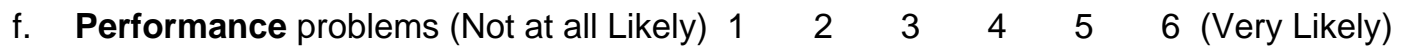

42. How likely is it that you will seek out more information about sport psychology in the next month?

$\begin{array}{lllllll}\text { (Not at all Likely) } & 1 & 2 & 3 & 4 & 5 & 6\end{array}$ (Very Likely)

PART 7: Please tell us a bit about who filled out this survey...

43. What is your Gender: Male Female

44. Age: 21-29years 30-39years 40-49years 50-59years 60+years

45. Ethnicity/Race: African-American Caucasian Hispanic American Indian

Asian or Pacific Islander Other (specify):

46. Highest Degree Completed: High School BA/BS MA/MS

EdD/PhD/PsyD Other Degree (specify):

47. Current Work Setting: Division I Division II Division III NAIA NJCAA NSCAA Junior College High School Other (specify):

48. Current Job Title in Primary Sport: Head Coach Assistant Coach Other (specify):

Number of years at current position:

Total number of years of work experience as a coach:

49. Are you currently in season? Yes No

50. Are you actively coaching a team or athlete at this point in the year? Yes No

51. What months are you most busy with coaching (please be specific)?

52. Do you coach a team, individual(s), or both (circle one)? Team Individual(s) Both Team \& Individual(s)

53. Please list any certifications you currently hold related to coaching: 
Your contact information will be kept confidential. It will ONLY be used for the purpose of providing you with information during the following month as well as to complete the one-month follow up survey. Neither your name or any information from which you might be identified will be published. Your contact information will be destroyed immediately upon completion of the study. Thank you for your time and help.

Initials (example: R.A.Z.):

Please provide information for contacting you via email:

E-mail Address (please print clearly):

If you do not have an e-mail address, please provide your mailing address:

Mailing Address (please print clearly):

THANK YOU FOR COMPLETING THIS QUESTIONNAIRE! 


\section{COACHES POST-WORKSHOP SURVEY}

PART 1: Please indicate your level of agreement with each of the following statements by circling the response that corresponds to your feelings toward each statement. Please respond to each statement as truthfully as you can.

$\begin{array}{cccccc}\text { SD } & \text { MD } & \text { D } & \text { A } & \text { MA } & \text { SA } \\ 1 & 2 & 3 & 4 & 5 & 6 \\ \text { Strongly } & \text { Moderately } & \text { Slightly } & \text { Slightly } & \text { Moderately } & \text { Strongly } \\ \text { Disagree } & \text { Disagree } & \text { Disagree } & \text { Agree } & \text { Agree } & \text { Agree }\end{array}$

\section{Question (SPC= Sport Psychology Consultant)}

1. A sport psychology consultant (SPC) can help athletes improve their mental toughness.

2. I would not want a SPC working with my athletes because other coaches would think less of me.

3. I would like to have the assistance of a SPC to help me better understand my athletes.

4. I would feel uneasy having a SPC work with my athletes because some people would disapprove.

5. Having seen a SPC is bad for an athlete's reputation.

6. Athletes emotional difficulties tend to work themselves out in time.

7. I think a SPC would help my athletes perform better under pressure.

8. A SPC could help my athletes fine-tune their performance.

9. If my athletes worked with a SPC, I would not want other coaches to know about it.

10. My athletes would be more comfortable with a SPC if he/she were of the same race or ethnicity as them.

11. I would think less of my athletes if they went to a SPC.

12. Athletes with a strong character can get over mental conflicts by themselves.

13. An athlete may relate best to a SPC if he/she were the same race or ethnicity.

14. Athletes should know how to handle problems without needing assistance from a SPC.

15. I would be more comfortable hiring a SPC if he/she were from the same cultural background as my athletes.

\begin{tabular}{|c|c|c|c|c|}
\hline SD & MD & D & $A$ & MA \\
\hline 1 & 2 & 3 & 4 & 5 \\
\hline 1 & 2 & 3 & 4 & 5 \\
\hline 1 & 2 & 3 & 4 & 5 \\
\hline 1 & 2 & 3 & 4 & 5 \\
\hline 1 & 2 & 3 & 4 & 5 \\
\hline 1 & 2 & 3 & 4 & 5 \\
\hline 1 & 2 & 3 & 4 & 5 \\
\hline 1 & 2 & 3 & 4 & 5 \\
\hline 1 & 2 & 3 & 4 & 5 \\
\hline 1 & 2 & 3 & 4 & 5 \\
\hline 1 & 2 & 3 & 4 & 5 \\
\hline 1 & 2 & 3 & 4 & 5 \\
\hline 1 & 2 & 3 & 4 & 5 \\
\hline 1 & 2 & 3 & 4 & 5 \\
\hline 1 & 2 & 3 & 4 & 5 \\
\hline
\end{tabular}


PART 2: Use of mental skills and sport psychology services

16. Please circle the letter that best describes your team's current use of sport psychology services. Sport psychology services include consulting with a sport psychology professional, having a sport psychology professional meet with your team/athletes, having a sport psychology professional meet with the coach or coaching staff, and referring athletes for performance enhancement or counseling.

**Using sport psychology services consistently each week or every two weeks is considered regular.**

We currently do not use and are not thinking of using sport psychology services as part of our athletes

A. overall training program.

B. We currently do not use sport psychology services as part of our athletes overall training program, but we are thinking about starting by the upcoming season.

C. We currently use sport psychology services as part of our athletes overall training program, but not regularly.

D. We regularly use sport psychology services as part of our athletes overall training program, but we have only begun doing so within the past season

E. We regularly use sport psychology services as part of our athletes overall training program and have done so for longer than one season

PART 3: Please rate your level of agreement with regards to expectations and barriers to using sport psychology services with your athletes right now.

\section{Question}

17. I would struggle with not knowing what would be said between the sport psychology consultant and our athlete(s).

18. Our team does not have enough time to use sport psychology services.

19. It would be difficult for me to trust a sport psychology consultant to work with our athletes.

20. Using sport psychology services might make our athletes' think too much during practice or competition.

21. We do not have the money in our budget to use sport psychology services.

22. I am not familiar with why I should use sport psychology services.

23. Using sport psychology services would be counterproductive; athletes either have mental skills or they don't.

24. I do not know enough about sport psychology to feel comfortable using sport psychology services with my athletes.

25. I am not familiar with the role of a sport psychology professional.

26. The benefits of sport psychology would be difficult to prove.

\section{Strongly \\ Disagree}

1

2

1

2

3

4

5

6

1

2

3

4

5

6

1

2

3

4

5

6

1

2

3

4

5

6

1

2

3

4

5

6

1

2

3

4

5

6

1

2

3

4

5

6

1

2

3

4

5

6

1

\begin{abstract}
2
\end{abstract}
3

4

5

6 
PART 4: Please rate your level of agreement with the following statements.

\section{Question}

27. Other coaches on our staff would be supportive of using sport psychology services with our athletes.

28. Other coaches at my level are using sport psychology services with their athletes.

29. I feel pressure from people who are important to me to not access and use sport psychology services with our athletes.

30. The coaches whose opinions I respect use sport psychology services with their athletes.

31. If the coaching staff wanted to, we could easily access and use sport psychology services for the upcoming season.

32. I would not know how to access a sport psychology professional for the upcoming season.

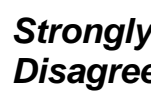

\section{Strongly}

Agree

$\begin{array}{llllll}1 & 2 & 3 & 4 & 5 & 6\end{array}$

1

2

3

4

5

6

1

2

1

2

3

4

5

6

1

2

1

2

3

4

5

6

PART 5: This section contains questions about your intentions to use sport psychology services in the future.

33. How likely is it that you will use sport psychology services ...

g. In the next month (Not at all Likely) $\begin{array}{llllllll}1 & 2 & 3 & 4 & 5 & 6\end{array}$ (Very Likely)

h. In the next season (Not at all Likely) $\begin{array}{lllllll}1 & 2 & 3 & 4 & 5 & 6 & \text { (Very Likely) }\end{array}$

34. How likely is it that you would refer an athlete to a sport psychology consultant for ...

g. Personal concerns

or relationship problems (Not at all Likely) $\begin{array}{lllllll}1 & 2 & 3 & 4 & 5 & 6 & \text { (Very Likely) }\end{array}$

h. Performance problems (Not at all Likely) $\begin{array}{lllllll}1 & 2 & 3 & 4 & 5 & 6 & \text { (Very Likely) }\end{array}$

35 How likely is it that you will seek out more information about sport psychology in the next month?

$\begin{array}{lllllll}\text { (Not at all Likely) } & 1 & 2 & 3 & 4 & 5 & 6\end{array}$ (Very Likely)

36. What was the impact of the workshop on your impression of sport psychology services?

(Very negative impact) $1 \quad 2 \quad 3 \quad 4 \quad 5 \quad 6$ (Very positive impact)

THANK YOU FOR COMPLETING THIS QUESTIONNAIRE!

PLEASE RETURN THE SURVEY PACKET TO THE RESEARCHER 
Tailored Coach Intervention 88

\section{Appendix C}

Coaches One-Month Follow-Up Survey Packet 
PART 1: Please circle or fill in the most appropriate answers below. There are no right or wrong answers, and all information will be kept confidential. We value your honest responses.

1. In the past month, have you accessed the website provided? Yes No

a. If yes, please estimate the \# of times in the past month you accessed the website provided?

b. If you did visit the website, how helpful was it? (Not at all) $1 \quad 2 \quad \begin{array}{llllll} & 2 & 4 & 5 & 6 & \text { (Very) }\end{array}$

2. In the past month, did you contact the researcher with questions or to inquire about sport psychology services? Yes No

a. If yes, please estimate the \# of times you contacted the researcher in the past month:

3. In the past month, did you seek out more information about sport psychology? Yes No

a. Please briefly describe below the type of information you sought out?

4. In the past month, did you contact a sport psychology consultant to inquire about services? Yes No

5. If you did contact a sport psychology consultant, are you planning on using services...

a. With your team/athletes for the upcoming season? Yes No

b. With your coaching staff for the upcoming season? Yes No

PART 2: Please indicate your level of agreement with each of the following statements by circling the response that corresponds to your feelings toward each statement. Please respond to each statement as truthfully as you can.

$\begin{array}{cccccc}\text { SD } & \text { MD } & \text { D } & \text { A } & \text { MA } & \text { SA } \\ 1 & 2 & 3 & 4 & 5 & 6 \\ \text { Strongly } & \text { Moderately } & \text { Slightly } & \text { Slightly } & \text { Moderately } & \text { Strongly } \\ \text { Disagree } & \text { Disagree } & \text { Disagree } & \text { Agree } & \text { Agree } & \text { Agree }\end{array}$

Question (SPC= Sport Psychology Consultant) their mental toughness.

7. I would not want a SPC working with my athletes because other coaches would think less of me.

8. I would like to have the assistance of a SPC to help me better understand my athletes.

9. I would feel uneasy having a SPC work with my athletes because some people would disapprove.

10. Having seen a SPC is bad for an athlete's reputation.

11. Athletes emotional difficulties tend to work themselves out in time.

12. I think a SPC would help my athletes perform better under pressure.
SD

1

SD MD D $\quad$ A $\quad$ MA SA

$\begin{array}{llllll}1 & 2 & 3 & 4 & 5 & 6\end{array}$

$\begin{array}{llllll}1 & 2 & 3 & 4 & 5 & 6\end{array}$

$\begin{array}{llllll}1 & 2 & 3 & 4 & 5 & 6\end{array}$

$\begin{array}{llllll}1 & 2 & 3 & 4 & 5 & 6\end{array}$

$\begin{array}{llllll}1 & 2 & 3 & 4 & 5 & 6\end{array}$

$\begin{array}{llllll}1 & 2 & 3 & 4 & 5 & 6\end{array}$


Tailored Coach Intervention 90

$\begin{array}{cccc}\text { SD } & \text { MD } & \text { D } & \text { A } \\ 1 & 2 & 3 & 4 \\ \text { Strongly } & \text { Moderately } & \text { Slightly } & \text { Slightly } \\ \text { Disagree } & \text { Disagree } & \text { Disagree } & \text { Agree }\end{array}$

\section{Question (SPC= Sport Psychology Consultant)}

13. A SPC could help my athletes fine-tune their performance.

14. If my athletes worked with a SPC, I would not want other coaches to know about it.

15. My athletes would be more comfortable with a SPC if he/she were of the same race or ethnicity as them.

16. I would think less of my athletes if they went to a SPC.

17. Athletes with a strong character can get over mental conflicts by themselves.

18. An athlete may relate best to a SPC if he/she were the same race or ethnicity.

19. Athletes should know how to handle problems without needing assistance from a SPC.

20. I would be more comfortable hiring a SPC if he/she were from the same cultural background as my athletes.

\section{SD}

MA
5
Moderately
Agree
SA
6
Strongly
Agree

ID\#

\section{A MA SA}

$\begin{array}{llllll}1 & 2 & 3 & 4 & 5 & 6\end{array}$

$\begin{array}{llllll}1 & 2 & 3 & 4 & 5 & 6\end{array}$

$\begin{array}{llllll}1 & 2 & 3 & 4 & 5 & 6\end{array}$

$\begin{array}{llllll}1 & 2 & 3 & 4 & 5 & 6\end{array}$

$\begin{array}{llllll}1 & 2 & 3 & 4 & 5 & 6\end{array}$

$\begin{array}{llllll}1 & 2 & 3 & 4 & 5 & 6\end{array}$

$\begin{array}{llllll}1 & 2 & 3 & 4 & 5 & 6\end{array}$

PART 3: Use of mental skills and sport psychology services

21. Please circle the letter that best describes your team's current use of sport psychology services. Sport psychology services include consulting with a sport psychology professional, having a sport psychology professional meet with your team/athletes, having a sport psychology professional meet with the coach or coaching staff, and referring athletes for performance enhancement or counseling.

**Using sport psychology services consistently each week or every two weeks is considered regular.**

We currently do not use and are not thinking of using sport psychology services as part of the overall

A. training program.

B. We currently do not use sport psychology services as part the overall training program, but we are thinking about starting by the upcoming season (within 6 months).

C. We currently use sport psychology services as part the overall training program, but not regularly.

We regularly use sport psychology services as part of the overall training program, but we have only begun doing so within the past season (past 6 months).

E. We regularly use sport psychology services as part of the overall training program and have done so for E. longer than one season (longer than 6 months).

22. What would be/are some of the benefits for using sport psychology services right now?

23. What are the main barriers, if any, that are preventing you from using sport psychology services right now? 
PART 4: Please rate your level of agreement with the following statements.

\section{Question}

19. Other coaches on our staff would be supportive of using sport psychology services with our athletes.

20. Other coaches at my level are using sport psychology services with their athletes.

21. I feel pressure from people who are important to me to not access and use sport psychology services with our athletes.

22. The coaches whose opinions I respect use sport psychology services with their athletes.

23. If the coaching staff wanted to, we could easily access and use sport psychology services for the upcoming season.

24. I would not know how to access a sport psychology professional for the upcoming season.

\section{Strongly \\ Disagree}

\section{Strongly}

Agree

$\begin{array}{llllll}1 & 2 & 3 & 4 & 5 & 6 \\ 1 & 2 & 3 & 4 & 5 & 6 \\ 1 & 2 & 3 & 4 & 5 & 6 \\ 1 & 2 & 3 & 4 & 5 & 6 \\ 1 & 2 & 3 & 4 & 5 & 6 \\ 1 & 2 & 3 & 4 & 5 & 6\end{array}$

PART 5: Please rate your level of agreement with regards to expectations and barriers to using sport psychology services with your athletes right now.

\section{Question}

30. I would struggle with not knowing what would be said between the sport psychology consultant and our athlete(s).

31. Our team does not have enough time to use sport psychology services.

32. It would be difficult for me to trust a sport psychology consultant to work with our athletes.

33. Using sport psychology services might make our athletes' think too much during practice or competition.

34. We do not have the money in our budget to use sport psychology services.

35. I am not familiar with why I should use sport psychology services.

36. Using sport psychology services would be counterproductive; athletes either have mental skills or they don't.

37. I do not know enough about sport psychology to feel comfortable using sport psychology services with my athletes.

38. I am not familiar with the role of a sport psychology professional.

39. The benefits of sport psychology would be difficult to prove.

\section{Strongly \\ Disagree}

Strongly

Agree

$\begin{array}{llllll}1 & 2 & 3 & 4 & 5 & 6\end{array}$

1

2

3

4

5

6

1

2

3

4

5

6

1

2

3

4

5

6

1

2

3

$$
4
$$

5

6

1

1

1

12

2

3

4

5

3

4

5

6

12

3

4

5

6

3

4

5

6

1

2

3

4

5 
PART 6: This section contains questions about your intentions to use sport psychology services in the future.

40. How likely is it that you will use sport psychology services ...

i. In the next month (Not at all Likely) $1 \quad \begin{array}{lllllll}2 & 2 & 3 & 4 & 5 & 6 & \text { (Very Likely) }\end{array}$

j. In the next season (Not at all Likely) $\begin{array}{lllllll}1 & 2 & 3 & 4 & 5 & 6 & \text { (Very Likely) }\end{array}$

41. How likely is it that you would refer an athlete to a sport psychology consultant for ...

i. Personal concerns

$\begin{array}{llllllll}\text { or relationship problems (Not at all Likely) } & 1 & 2 & 3 & 4 & 5 & 6 & \text { (Very Likely) }\end{array}$

j. Performance problems (Not at all Likely) $\begin{array}{lllllll}1 & 2 & 3 & 4 & 5 & 6 & \text { (Very Likely) }\end{array}$

42. Did you refer an athlete to a sport psychology consultant in the past month? Yes No

a. If yes, did you refer for personal concerns or performance? Personal Both

b. Please estimate the \# of athletes you referred to a sport psychology professional?

43. I would prefer a sport psychology consultant (please circle one):
a. To work with the coach/coaching staff.
b. To work with the athlete(s) directly.
c. To work with both the coach/coaching staff and the athlete(s)

45. Did you receive an attachment (manual) through email one week following the workshop? Yes No

a. If you received an attachment did you read the information (manual) sent to you? Yes No

b. If you read the material e-mailed to you, how helpful was it?

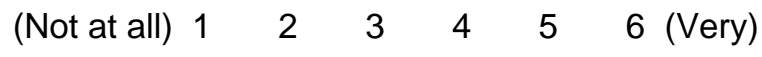

c. What was the most useful information you read from the manual e-mailed to you?

THANK YOU FOR COMPLETING THIS QUESTIONNAIRE!!

YOUR TIME IS APPRECIATED!! 
Tailored Coach Intervention 93

Appendix D

Coach Workshop Outline 


\section{Coaches Workshop Outline}

\section{Introduction}

A. Overview of my background and experience

B. Purpose, Process, Payoff

- WHAT, WHY, WHEN, HOW of using SP services.

Ask: How important is being mentally tough (mental skills) in your sport? On a scale from 1-10?

ASK: why do some coaches use SP services and some coaches do not?

\section{Teasing out the Myths and Misperceptions of SP services}

A. I'm the Sport Psychologist:

B. It's too touchy feely:

C. It will take away from practice time (No Time):

D. Athletes either have mental skills or they don't:

E. SP services are for problem athletes only:

F. We don't need a "shrink":

G. I don't know enough about SP:

H. SP is for elite athletes only OR Elite Coaches only Use:

I. SP doesn't work (where is the proof?):

ASK: What would make coaches most confident in the use of SP services?

o How do you know it worked?; Time efficient ; Qualifications of SP

J. It's not in the budget: (What are your options?)

K. Don't have Access: (Research- more colleges hiring full/part time consultant)

L. No Need

M. SP is a quick fix: SP- takes regular practice just like physical skills. ASK: When would you use SP services?

N. Athlete would Rely too much on SPC or would make athlete think too much: (goal= self regulation)

From research with coaches: $43 \%$ of coaches had access, $22 \%$ had a SPC working with their team. Most coaches who have used SP services in the past continue to.

\section{SPC: WORKING WITH YOU not AGAINST YOU}

ASK: What coaches use SP services? (may tie into SP is for elite only)

III. Be a good consumer: The HOW of SP services (could go with Access)

A. Getting in touch with a SPC: Be Pro-Active \& Committed (AASP handout)

- Who do you talk to? How do you know they are qualified? What questions do you ask?

- What is their role/Your Role? What about Confidentiality? (Myths section?)

IV. Review: Purpose, Process, Payoff: summary 
Tailored Coach Intervention 95

Appendix E

Website Sample 


\section{Sport Psychology: Coaching Tools}

Welcome!! This website is designed to be a quick and convenient way for coaches to gather information about sport psychology services. Feel free to browse around. New resources and links will be added regularly to provide you with the most up to date information.

${ }^{* *}$ Contact and ask Rebecca a specific question about your team or athlete: $\underline{\text { coachingtool@gmail.com. }} .{ }^{* *}$

\section{Sport Psychology In the Media}

Kulbacki fueled by mental power

- Read about James Madison's outfielder

Kellen Kulbacki and how working with a performance enhancement consultant helped his game.

Motivating Mind and Body

Mental toughness consultant helps athletes with performance anxieties.

Stressed, Stretched and Skating on Thin Ice

Sport psychology and youth sports.

\section{Testimonials: Making a Difference!!}

Optimal Performance Consulting:

Read about what coaches had to say...

Australian Psychological Society:

YES- Sport Psychology Consultants are being utilized all around the world...

\section{Competitive Advantage:}

What parents, coaches, and athletes had to say about one-on-one consulting services...

\section{Tapping Into Your Resources!!}

The following are worth checking out...

\section{Coaching for the Inner Edge}

Author: Robin S. Vealey

Available from: Fitness Information Technology

\section{Developing Mentally Tough Swimmers}

Author: Alan Goldberg

Available from: Competitive Advantage

\section{The Swim to Win Playbook}

Author: Keith Bell

Available from: Keel Publications

\section{Relaxation Training (Cassette/CD)}

Author: Keith Bell

Available from: Keel Publications
Here are some online coaching tools...

Sport-Psychology.Com

Information about what sport psych is, links to other sites, and free answers to sport psychology questions.

Center For Sport Psychology and Performance Excellence at UNT

Useful information for coaches/athletes. Free services to community/university. Free access to newsletters/weekly mailings for practical tips (e.g. suggestions for dealing with athletes emotions).

- Check out their free newsletter about Gaining a Mental Edge in High School Athletics

- Check out their Performance Excellence Weekly Mailing 


\section{Sport Psychology: Coaching Tools}

Welcome!! This website is designed to be a quick and convenient way for coaches to gather information about sport psychology services. Feel free to browse around. New resources and links will be added regularly to provide you with the most up to date information.

${ }^{* *}$ Contact and ask Rebecca a specific question about your team or athlete: coachingtool@gmail.com. ${ }^{* *}$

\section{Sport Psychology In the Media}

Tewksbury Gets in Their Heads

Read about a sport psychology coach hired for minor league baseball.

The Power of Pre-Event Thought

Mind training tips for swimmers.

Anorexia in Athletes- Starving for Speed

Discussion about eating disorders and athletes.

\section{Testimonials: Making a Difference!!}

Peak Performance Sports:

Read about what athletes have said about a mental coaching program and resources.

\section{Ohio Center for Sport Psychology:}

- Read about the usefulness of one-on-one sessions, seminars, and workshops in sport psychology. This organization works with several sports and all competitive levels.

Mental Training, Inc:

Click on several links to read about what others had to say about consulting services.

\section{Tapping Into Your Resources!!}

The following are worth checking out...

- Coaching Mental Excellence

Author: Ralph Vernacchia, Rick McGuire, and David Cook

Available from: Warde Publishers

\section{The Sport Psych Handbook}

Author: Shane Murphy

Available from: Human Kinetics Publishers

\section{Successful Coaching- $3^{\text {rd }}$ Edition}

Author: Rainer Martens

Available from: $\underline{\text { Human Kinetics Publishers }}$

Coaching for the Inner Edge

Author: Robin S. Vealey

Available from: Fitness Information Technology
Here are some online coaching tools...

Mind Training for Swimmers

Gather practical tips for swimmers.

Center for Sport Psychology

A Coach's Guide to Developing a Positive Youth Sport Program.

\section{Optimal Performance Consulting}

Provide a free initial phone/email consultation and have access to free Optimal Performance Newsletters.

- Check out their newsletter about Goal Setting 
Tailored Coach Intervention 98

Appendix F

Stage-Matched Manuals 


\section{"Why Mental Skills Training?"}

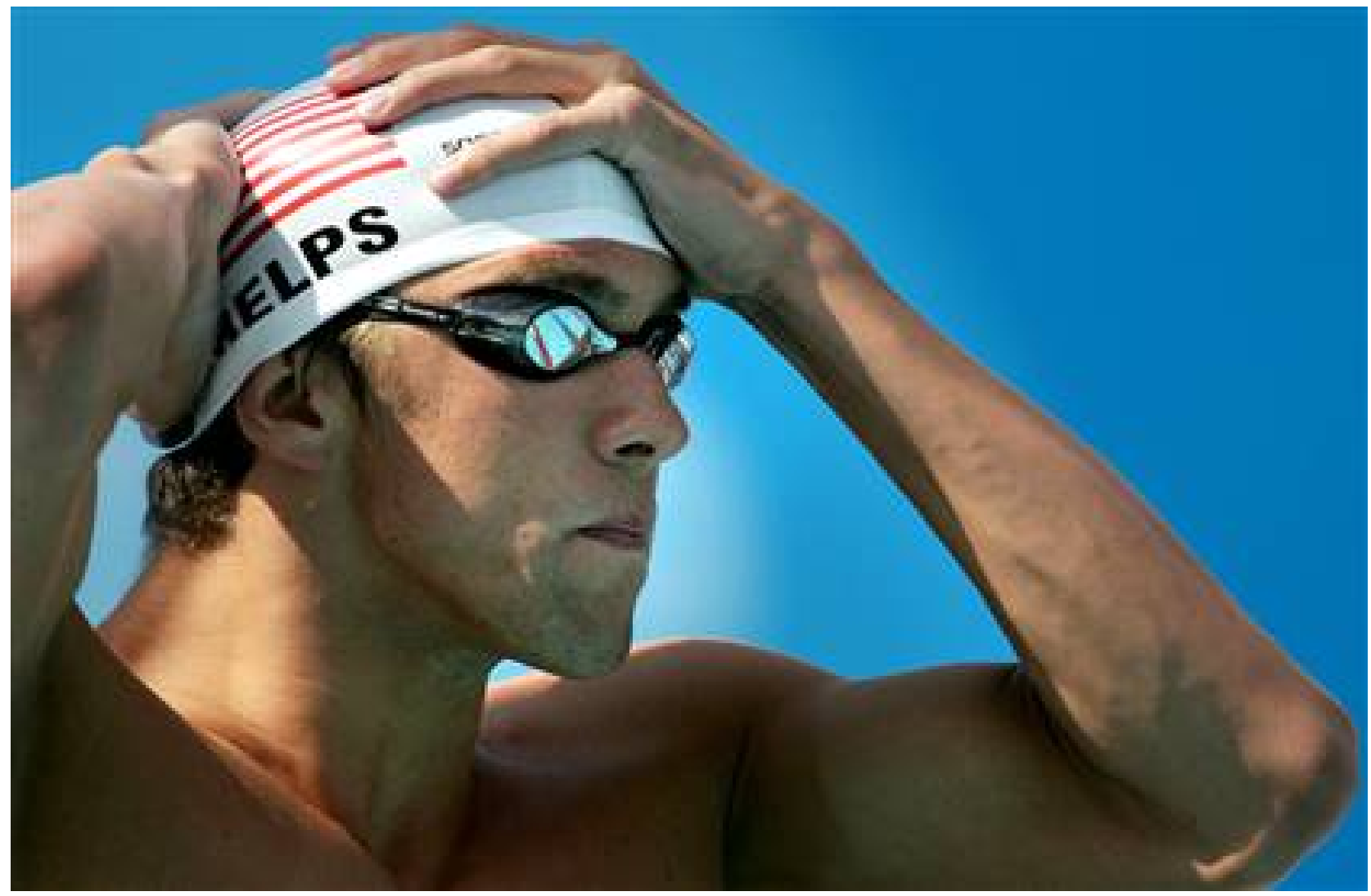

"... at the highest levels of sport the difference between the performance of individual athletes is measurable only in tenths or hundredths of a second. Any technique that will tighten those fractions has to be used."

-Sally Gunnell

Olympic Gold Medalist and World Champion Hurdler 
Tailored Coach Intervention 100

Read through the following sentences and place a $\sqrt{ }$ next to any you can relate to or have experienced with your athlete(s).

_ _ Have you ever had an athlete whose anxiety interfered with their performances?

Have you ever wished an athlete had a more positive attitude?

Have you ever had any athletes train faster than they race?

_ Have you ever wished an athlete had more confidence during competition?

Have you ever wondered what makes some athletes respond well under pressure and other don't?

Have you ever wondered why an injured athlete can sometimes heal physically more quickly then they can heal mentally and successfully rejoin the team?

Think about how many of the above scenarios you have encountered.

What other competitive obstacles do your athletes experience?

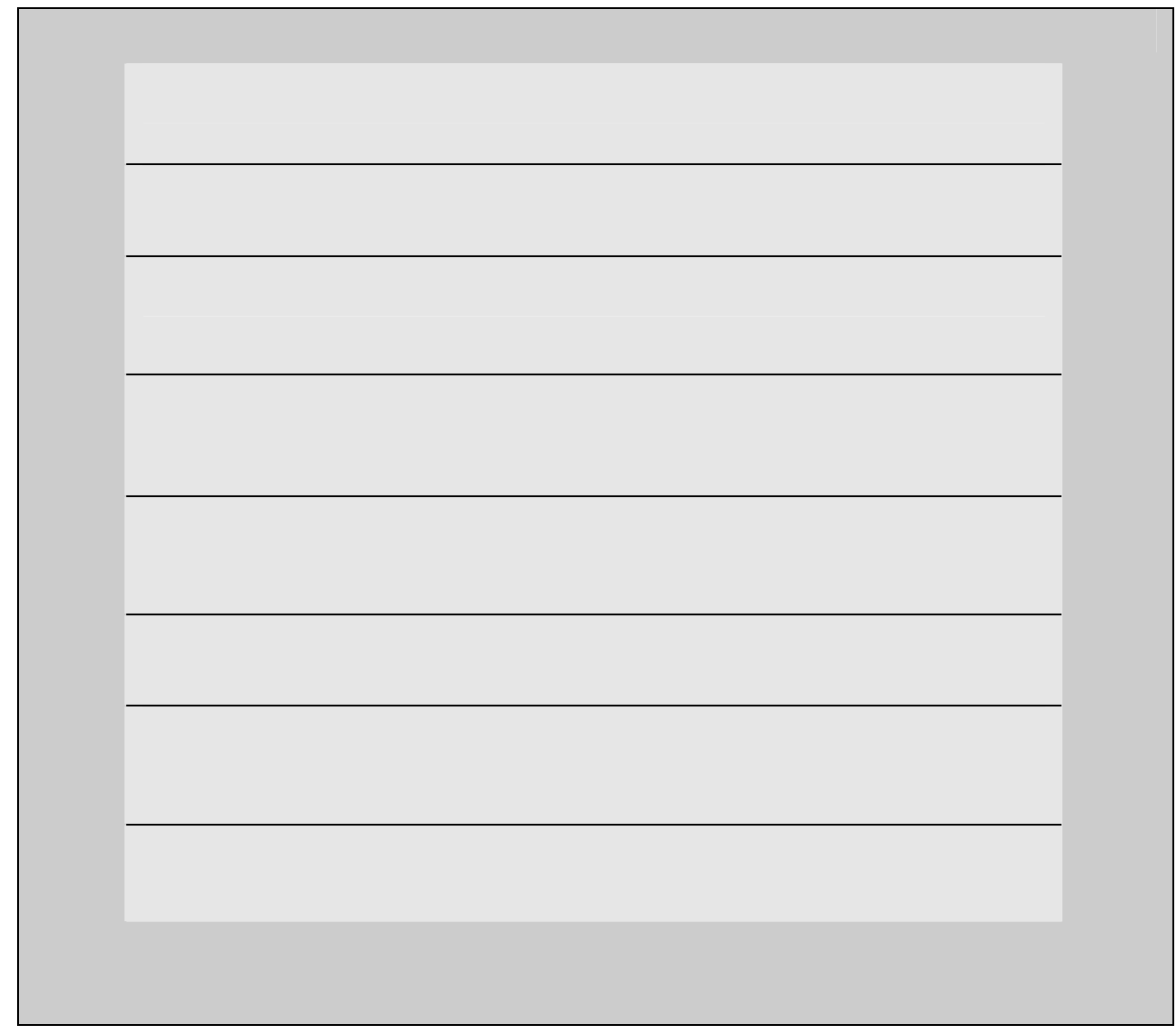


Now...Think about the following sentences \& guesstimate a percentage...

How many other teams do you think put in the "pool time" each week?

How many other teams do you think weight train?

How many other teams have at least one coach?

How many other teams train hard?

How many other teams have specific skills, talents, and abilities?

Take a look at your percentages. In the sport world, we know how important it is to train the physical, tactical, and technical. And...You are most likely comfortable training the physical, tactical, and technical.

"In training everyone focuses on 90\% physical and 10\% mental, but in the races its $90 \%$ mental because there's very little that separates us physically at the elite level".

-Elka Graham

\section{How Important Are Mental Skills In Your Sport?}

From 1 (not at all important) to 10 (very important): How important is having strong mental skills in your sport?

So...what do you do to address and train the mental?

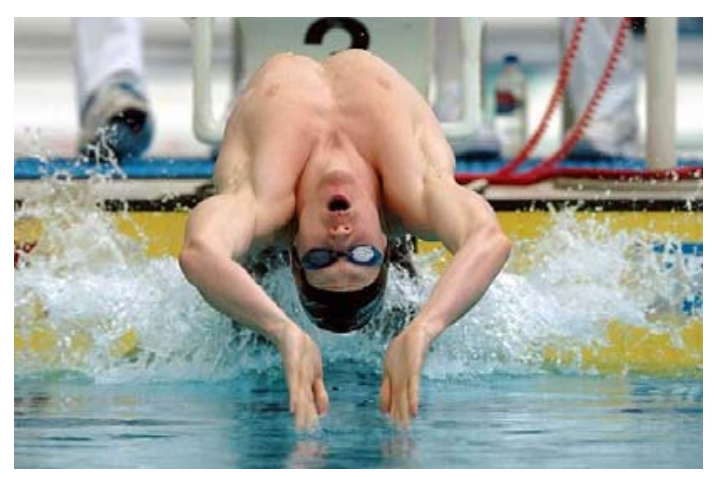




\section{Sport Psychology Consultation: \\ What it Is \& What it is Not}

It is typical for others to view sport psychology consultants as working with "head cases" or "problem" athletes. Oftentimes, athletes, coaches, and others may think that a sport psychology consultant is going to sit them on a couch so they can talk about their deep rooted problems. The "shrink" connotations associated with sport psychology can result in individuals being hesitant toward seeking the assistance of a sport psychology consultant.

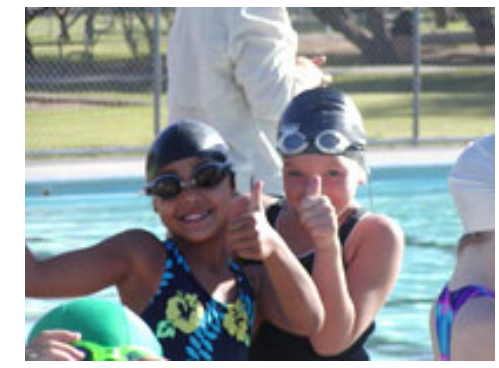

In reality, sport psychology consultants share the same goals as coaches, teammates, and athletes: to increase performance and help athletes reach their potential!! Sport psychology consultants work with athletes to facilitate and increase their consistency in performance. Consultations often involve chatting between the athlete and sport psychology consultant so the professional can provide the athlete with some tools to respond more effectively to various situations.

\section{Sport Psychology Services...}

Help athletes do for themselves (SelfRegulate).

Help athletes learn to be in control and perform more consistently.

Are pro-active.

Are useful for all ages and skill level athletes.

- Empower coaches by being involved.

\section{Sport Psychology Services Are Not...}

Something done to athletes.

A quick fix solution.

Used to undermine coaches.

A weakness.

A replacement for physical and technical training.

Only applicable to elite level athletes. 


\section{Mental Skills Can Be Trained!!}

Mental skills training is built on the foundation that mental skills are like physical skills, they can be taught, trained, and developed. Many coaches recognize the importance of mental skills; however, there is the common perception that athletes develop these skills on their own through experience.

Athletes can and do develop mental skills through experience. However, this is trial and error learning where athletes often make mistakes first before they learn and improve their mental skills. Many athletes have expressed that if they had been taught mental skills they could have been performing at a higher level earlier in their careers.

Trial and error is less efficient and usually takes longer for athletes to develop their mental skills. As a coach, you know that time is precious!! Mental skills training ENHANCES the rate of PROGRESS by sidestepping the trial and error process. Athletes accumulate several "tools" they can use at appropriate times during practice and competition.

\section{**Mental Skills Training is Designed to STRETCH the Potential of all Athletes ${ }^{* *}$}

The sooner these skills are taught and learned, the sooner athletes can tackle various performance obstacles. All athletes experience anxiety and distractions when it comes to the pressure of competition. The key difference is that athletes who have developed their mental skills respond more effectively to this pressure. 


\section{Mental Skills Training Makes A Difference!!}

Clear evidence continues to support mental training as an effective performance enhancement technique:

Research has found:

Mental training interventions (e.g. goal setting, positive thoughts, concentration, arousal regulation, imagery) Enhance Performance!

- Improves self-reported anxiety, confidence, performance AND individual performance statistics.

- Can help athletes respond to pressure more effectively \& perform better.

Successful athletes engage in mental preparation more regularly than less successful athletes!

- Olympic athletes used imagery, thinking techniques, emotional control skills, and mental preparation routines.

- More successful athletes coped better with distractions and stuck more closely to their pre-competition routines.

- Mental skills and coping strategies were practiced and internalized more with medalists compared to non-medalists.

Successful athletes have more developed mental skills than less successful athletes!

- Higher confidence, greater self regulation \& anxiety management, better concentration and focus, higher motivation to perform, and in control but not forcing it attitude, positive thoughts and imagery.

- More determined and committed.

Successful athletes achieved peak performance by using mental skills of...

- Goal setting, imagery, arousal control \& management, thought control, competitive plans, coping strategies, and mental preparation routines.

- Olympians identified mental skills, preparation, attitude, support, and coaching as factors that positively influenced the results at the Nagano and Atlanta games. 


\section{Personal testimonials: The Value of Mental Training}

"Before the (Olympic) trials I was doing a lot of relaxing exercises and visualization. And I think that that helped me to get a feel of what it was gonna be like when I got there. I knew that I had done everything that I could to get ready for that meet, both physically and mentally". -Michael Phelps

"I just refused to give up, to give up the dream. I was in excruciating pain, my arm was numb and they said it would be six months, if ever, for me to be back in the water. I thought my career was over, I was shattered but I never lost hope. I've always believed if you want to do something badly enough you will do it. Some told me that if you visualized healing an injury it would heal faster and that's what I did" -2004 Australian Olympic diving team qualifier Lynda Dackiw, 4 months before the Athens Olympics

"I know I've made huge gains in my confidence, and knowing more about my racing and myself as a person. That has made me a better athlete". -Libby Lenton

"at the collegiate level [the mental component] is extremely important because the athletes have usually developed their physical skills to a high degree...Failure to execute [the physical skills] may be the result of various psychological factors." -As one of the first coaches of a women's team to utilize sport psychology services, Pat Summit discussed the importance of mental skills and how she sought out the expertise of a sport psychology consultant to help mentally prepare her athletes before big games (Wrisberg, 1990).

**Highly skilled athletes who are known to continually integrate mental skills training into physical practice ${ }^{* *}$

Tiger Woods

Jackie Joyner-Kersee

Curt Schilling

Greg Louganis
**Highly successful coaches who integrate mental skills training into physical practice**

Patt Summit

John Wooden

Doc Councilman

Pia Nilsson 
The Media:

More attention has been devoted in the media on sport psychology and more athletes and coaches are speaking out about the usefulness of sport psychology services.

In a recent ESPN article, James Madison outfielder Kellen Kulbacki, spoke about the value of working with a sport psychology consultant:

"It was a way for me to clear the things that were bothering me from my head and get onto the field, where I could put it behind me and not worry about it," he says.

"Hearing from athletes in the pros, I know A-Rod has one, it was an opportunity that I needed to check out to see if it helped my game at all," he says.

"I figured if I give [sports psychology] a shot and pick up a few pointers, I can have that mental edge as an athlete throughout the season."

"I don't really think there is any real reason why I should hide," he says. "It is definitely beneficial for me to want to have a mental advantage over other people. I have played a hundred games after going through [sports psychology]. I have seen a huge difference in the way I approach the game. I think it has had a huge effect on me having a successful year. I don't have a problem being open about it because it works for me."

\section{Athletes who have practiced their mental skills are better able to:}

- perform more consistently across competitions

- recover their composure more quickly after a mistake or distraction

- perform at their best when the pressure is on 


\section{How Can Sport Psychology Services Benefit YOU?}

What are some potential benefits for you that could come from using sport psychology services and integrating mental skills training?

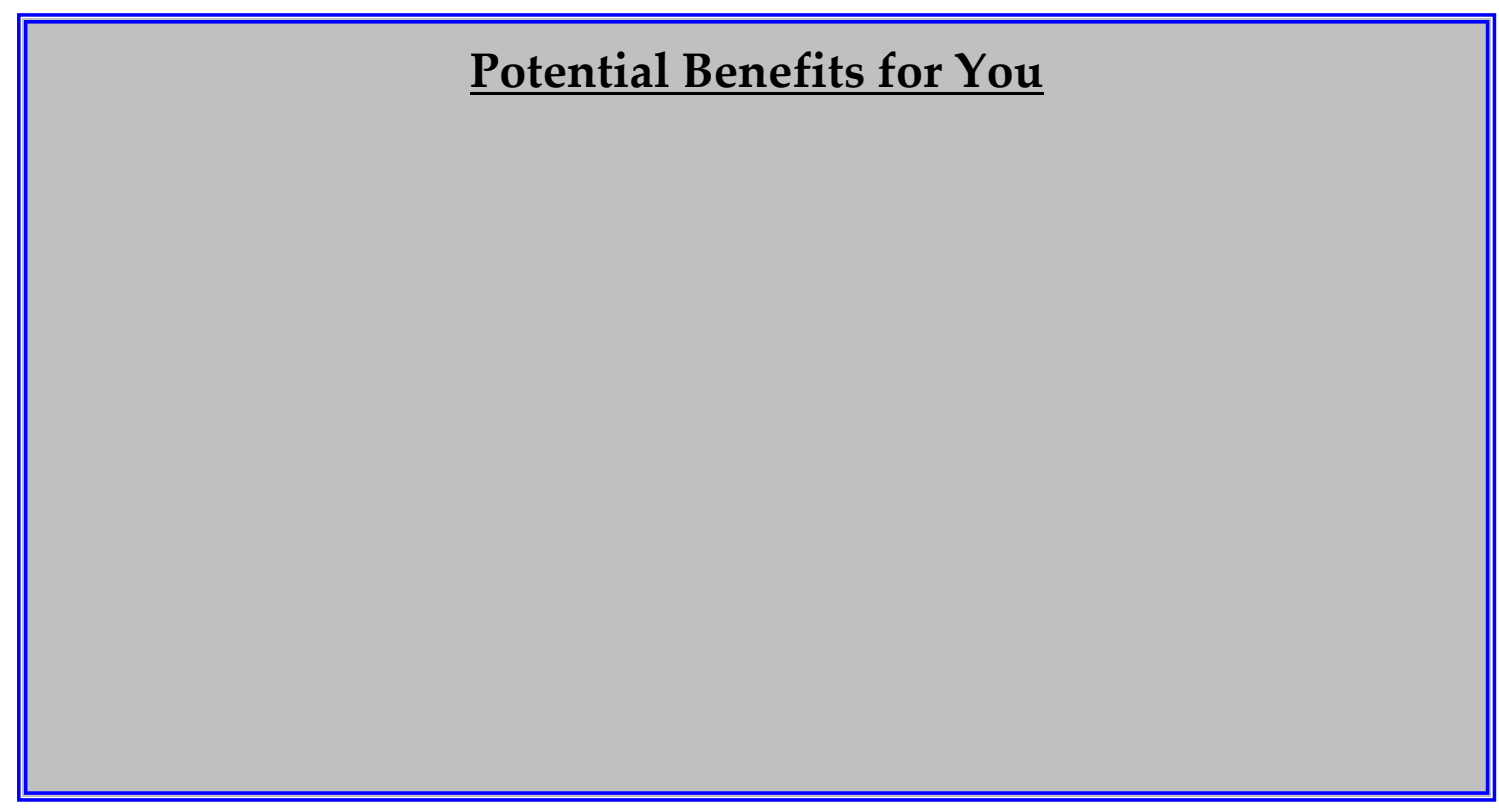

What are some potential benefits for your athletes if you used sport psychology services and integrated a mental skills training program?

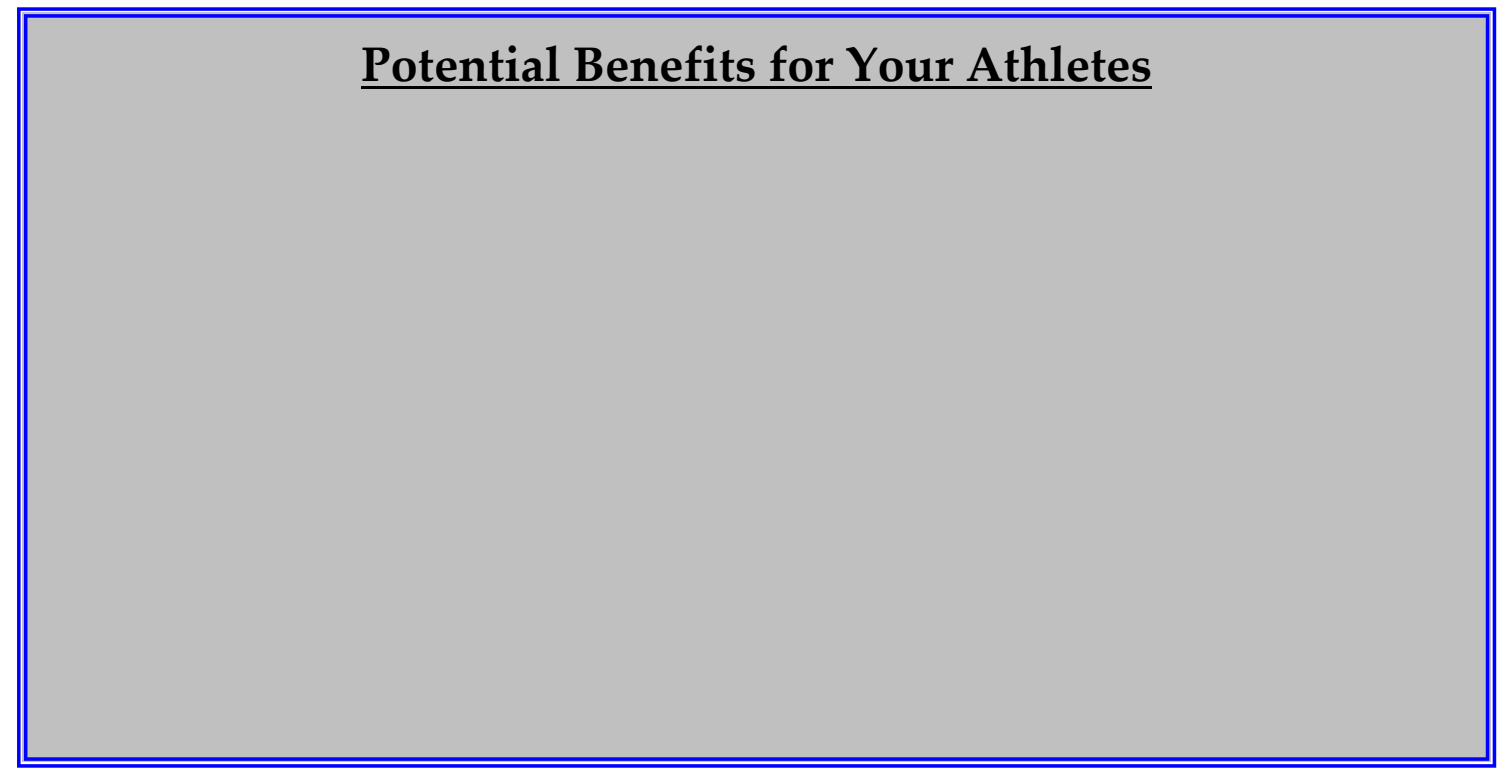


Here are some more suggested benefits for you...

A consultant is a resource that is trained in sport
psychology.
Can devote more attention and effort to overall coaching
program.
Can learn how to integrate mental skills training with
your athletes in a more efficient manner.
Have a "total package" program: Physical, Tactical,
Technical, Mental, \& Well-being.

Here are some suggested benefits for your athletes (which are also benefits for you)...

\begin{tabular}{|c|}
\hline $\begin{array}{l}\text { Reduced nervousness before races } \\
\text { Less pain and fatigue during swimming races } \\
\text { Sharpening concentration/ Letting go of distractions } \\
\text { (e.g. not concerned about swim competitors) } \\
\text { Improving swimming technique and overcoming stroke } \\
\text { problems } \\
\text { A calm, clear mind } \\
\text { Increasing confidence on the block } \\
\text { A belief in self and swimming abilities } \\
\text { - Greater inner strength / physical energy } \\
\text { - Gecoming and more consistent performances in swim meets } \\
\text { - Controlling thoughts and using positive self statements } \\
\text { Increasing motivation in practice and competition / } \\
\text { Preventing burnout }\end{array}$ \\
\hline
\end{tabular}


"In most sports they have a physical effect on your performance, in swimming only psychological. If you worry about what your rival is doing, you take your mind off what you are doing and so fail to concentrate on your performance."

-Bachrach, great Chicago coach of the 20's

Sport psychology has demonstrated that mental training programs make a difference!!

A "total package" mental skills training program is individualized, systematic, and uses a variety of psychological techniques. 


\section{“Give It A Try!"}

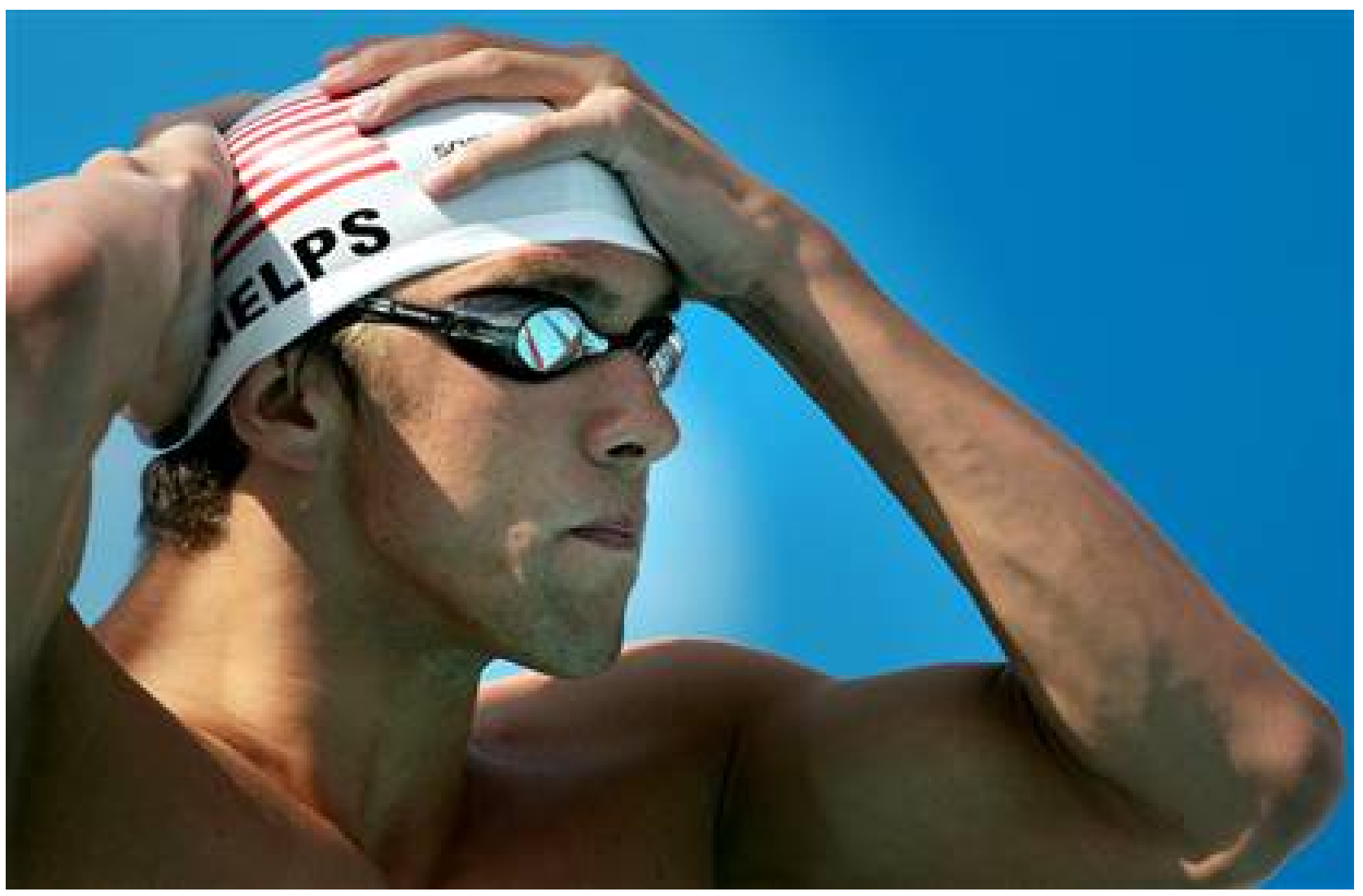

"... at the highest levels of sport the difference between the performance of individual athletes is measurable only in tenths or hundredths of a second. Any technique that will tighten those fractions has to be used."

-Sally Gunnell

Olympic Gold Medalist and World Champion Hurdler 


\section{How Can Sport Psychology Services Benefit YOU?}

What are some potential benefits for you that could come from using sport psychology services and integrating mental skills training?

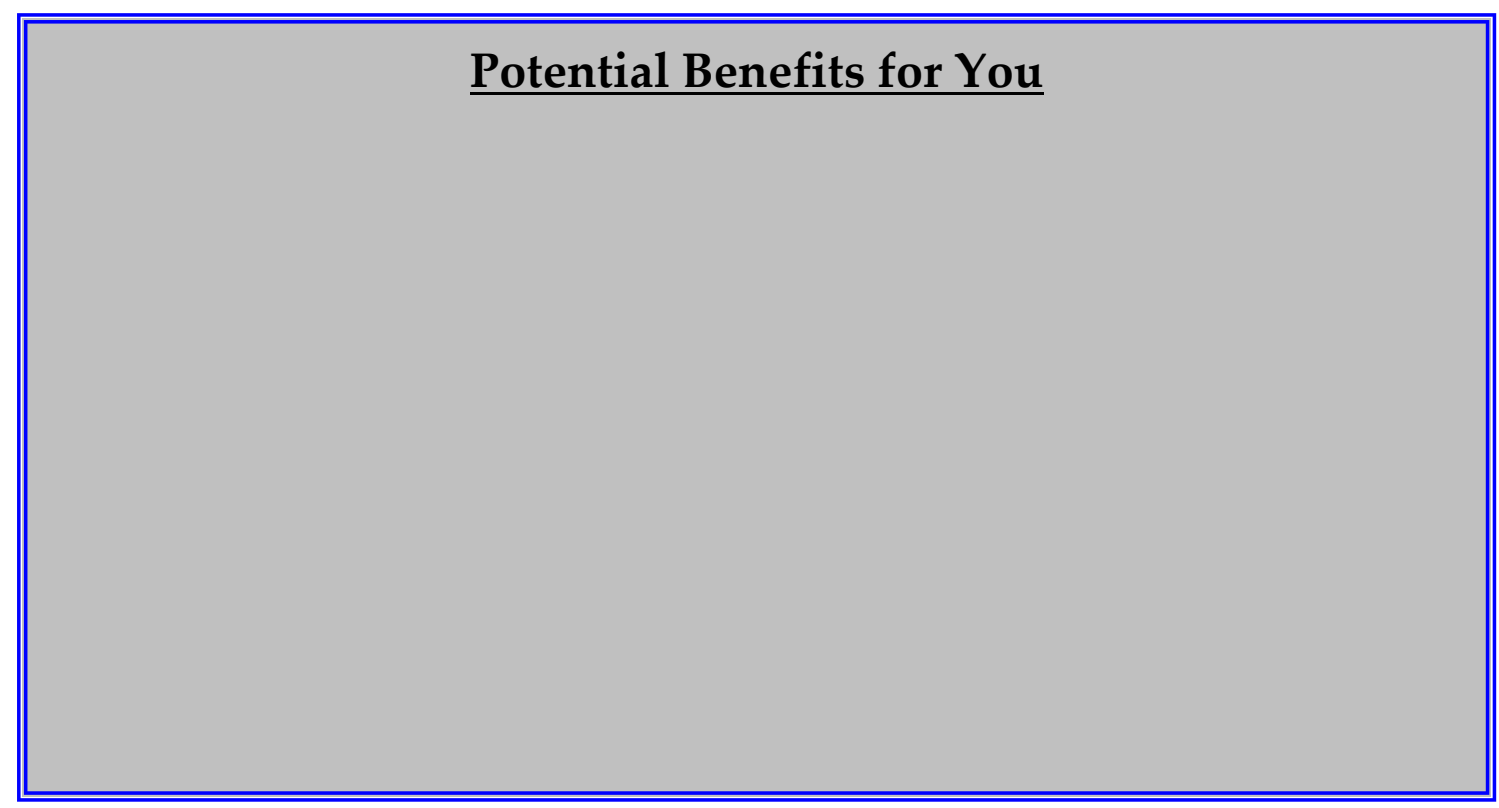

What are some potential benefits for your athletes if you used sport psychology services and integrated a mental skills training program?

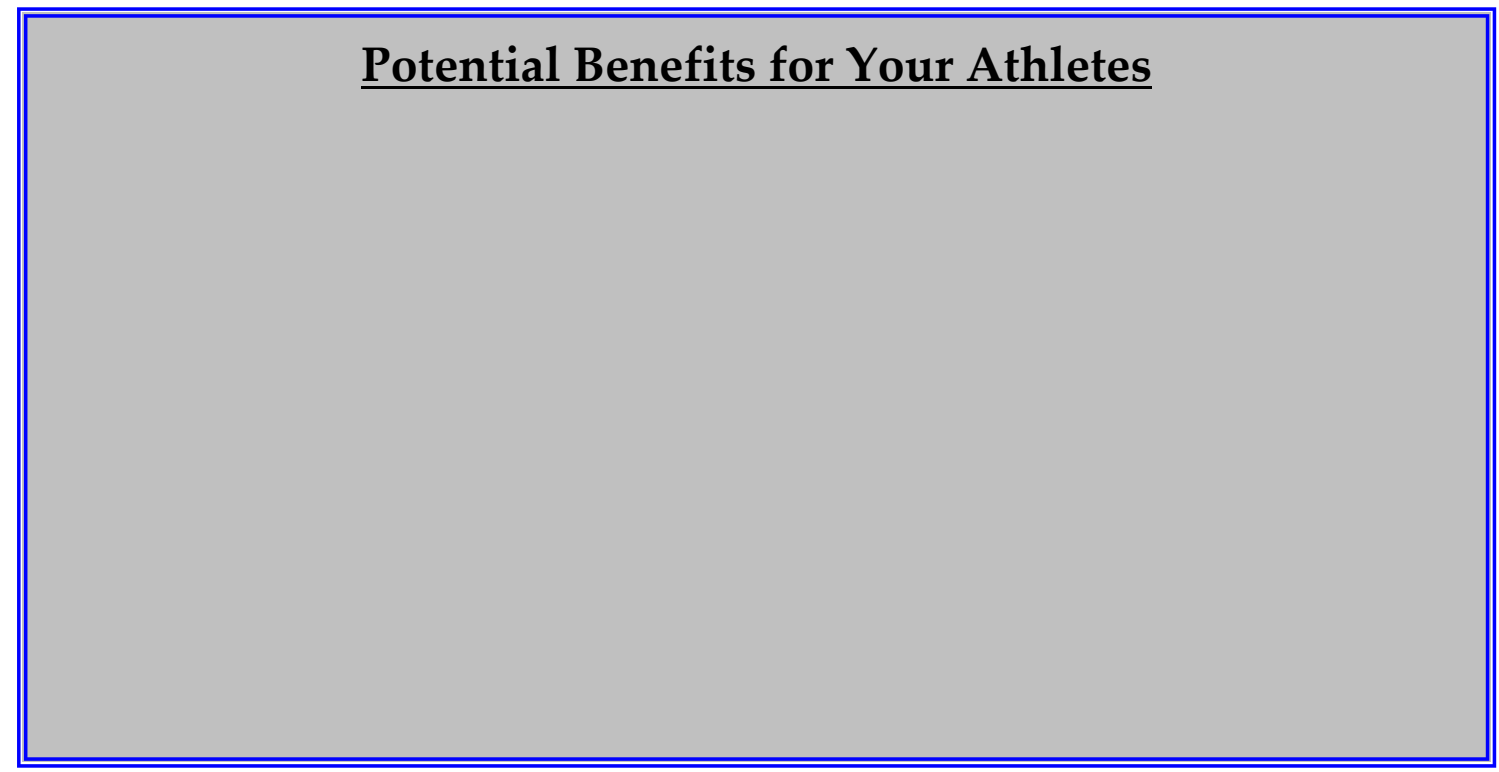


Here are some more suggested benefits for you...

A consultant is a resource that is trained in sport
psychology.
Can devote more attention and effort to overall coaching
program.
Can learn how to integrate mental skills training with
your athletes in a more efficient manner.
Have a "total package" program: Physical, Tactical,
Technical, Mental, \& Well-being.

Here are some suggested benefits for your athletes (which are also benefits for you)...

\begin{tabular}{|c|}
\hline $\begin{array}{l}\text { Reduced nervousness before races } \\
\text { Less pain and fatigue during swimming races } \\
\text { Sharpening concentration/ Letting go of distractions } \\
\text { (e.g. not concerned about swim competitors) } \\
\text { Improving swimming technique and overcoming stroke } \\
\text { problems } \\
\text { A calm, clear mind } \\
\text { Increasing confidence on the block } \\
\text { A belief in self and swimming abilities } \\
\text { - Greater inner strength / physical energy } \\
\text { - Gecoming and more consistent performances in swim meets } \\
\text { - Controlling thoughts and using positive self statements } \\
\text { Increasing motivation in practice and competition / } \\
\text { Preventing burnout }\end{array}$ \\
\hline
\end{tabular}




\section{What's Stopping You?}

What do you believe you would have to give up in order to work with a sport psychology consultant and integrate mental skills training into your program?

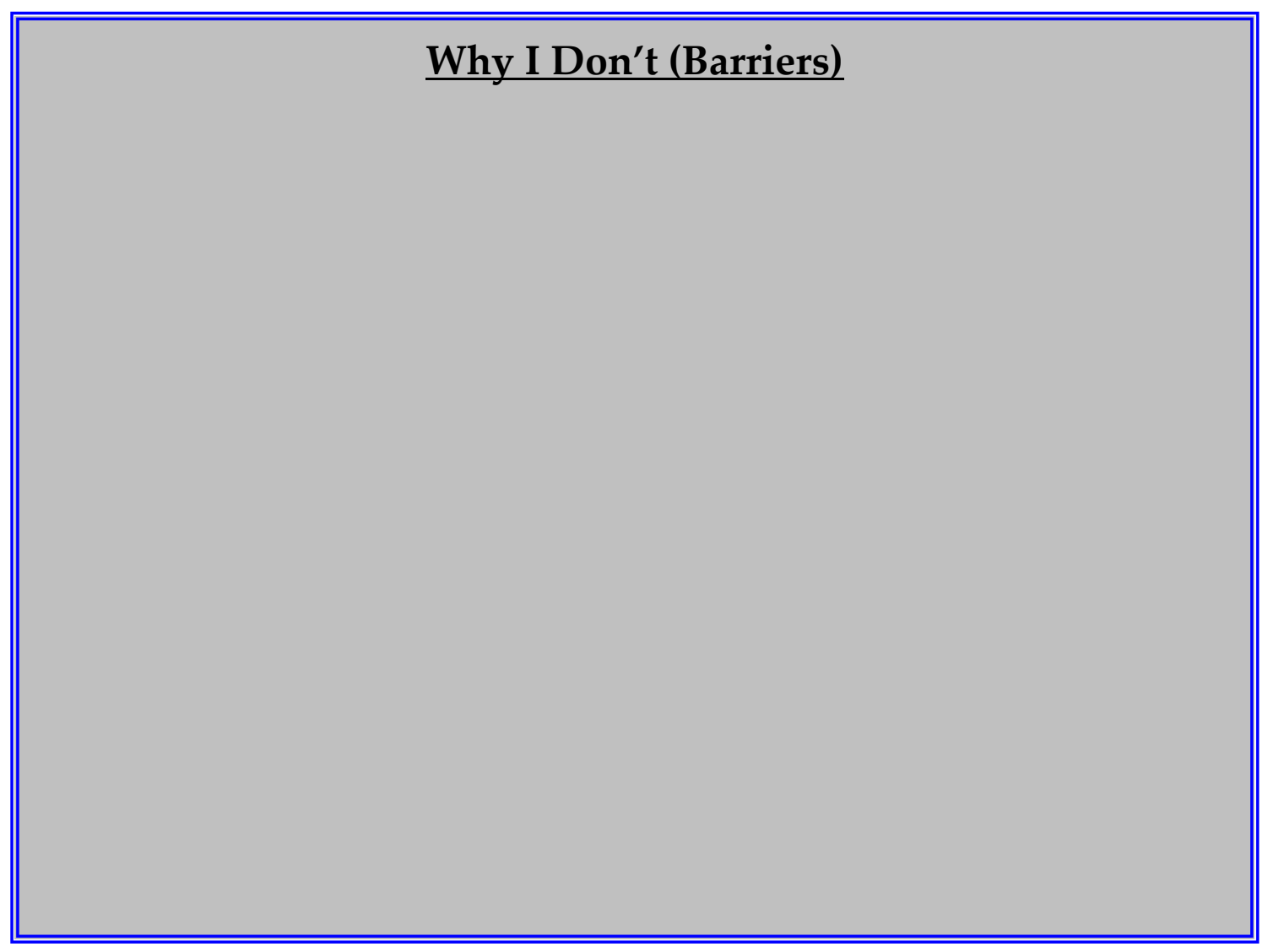

Take a look at your list of why you don't use a performance enhancement consultant and implement mental skills training into your program.

Rate how important each barrier is in preventing you from integrating a mental skills program: on a scale from 1 (not important) to 10 (very important)

From 1 (not at all important) to 10 (very important): How important is having strong mental skills in your sport?

So, what can you do to overcome the obstacles mentioned above? 


\section{GAIN CONTROL!!}

Some of the most common reasons why coaches do not use sport psychology services are TIME, ACCESS, and MONEY.

Time: TIME IS PRECIOUS. Sport psychology services, if used appropriately, should not significantly add to the already demanding schedule. A small amount of time on mental skills training can have an impact on performance and not take away from technical training which is typically more time intensive.

By using sport psychology services, YOU are taking a pro-active step toward enhancing your athletes. SOLUTION: make it a routine (e.g. part of their warm up, stretching exercise at the end of practice, or during drills). Learning how to regulate and control one's thoughts, feelings, and behavior needs to occur IN their sport environment and DURING practice. I have known several coaches who integrate mental training when practicing sport skills (e.g. during a drill).

\section{When integrating mental and physical practice, there should be a performance-specific focus.}

After learning how to recognize harmful tension and relaxation techniques athletes should be instructed to scan for harmful tension and practice appropriate relaxation techniques while performing. A good way to integrate mental and physical practice may be to scan and relax before serving a tennis ball, pitching, shooting a free throw, or stepping on the block. 
Tailored Coach Intervention 115

Access: Several coaches have said... "Even if we wanted to we just don't have the access to sport psychology" OR "I would not know how to go about gaining access to services." As coaches, you have several options for gaining access to sport psychology.

\section{Where to Look?}

Contact a college or university nearby

- Sport psychology professionals or doctorate students may be willing to travel to provide consultations. Personally, I've traveled between 2 to 4 hours to have the opportunity to work with a team.

- More Universities are hiring a sport psychology consultant within their athletic departments.

- Talk with someone in counseling services.

- AASP Sport Psychology Consultant Finder

- http://www.aaasponline.org/cc/ccfinder.php

- Check out some consultant websites

- Go to: http://www.aaasponline.org/cc/index.php and click on "Links to Certified Consultant Websites".

The United States Olympic Committee (USOC)

- You can contact their administration to ask about sport psychology services and mental training (719.866.4517).

- Check out their webpage regarding sport psychology. http://www.usoc.org/teamusanet/TeamUSAnet 46377.cfm

- Use the INTERNET

- Type "sport psychology services" into a search engine (google).

- You can also look within a state (sport psychology services and Ohio).

- Talk to other coaches or athletes.

- Someone you know may have worked with a sport psychology consultant.

- Contact a sport organization/ association.

- If you belong to an association, it may be worthwhile to contact someone in office (president/ executive director/ coaching education coordinator). They may have some people in mind that can help.

Make Use of the Resources

- There are excellent mental training books, manuals, and videos for coaches.

Workshops

- Look for mental skills training workshops nearby or during a coaching convention. 


\section{** More sport psychology professionals are being utilized by coaches and athletes of all competitive levels (age group, club, high school, college, elite, etc.) ${ }^{* *}$}

Money: When it comes to paying for services, coaches have several options. If you are interested in hiring a sport psychology professional make sure you contact him/her and ask about services and rates.

A Tight Budget? Here Are Some Options:

- If you are at a college or university, the service may be provided for free.

- A doctoral student who is being supervised may provide the service for free or lesser charge. I've known several doctoral students to provide services to a variety of ages and competitive levels (e.g. age group, club, high school, elite, etc.).

- Check out sport psychology resources (books, videos, manuals). You can find some great tips to help you learn more about mental skills training techniques.

- Have a consultant do some workshops with the coaching staff. This may be cheaper than hiring a consultant for the season.

- Hire a consultant to come work with the coaching staff/athletes for a set number of sessions (depending on your budget). During this time, the consultant can teach the coaching staff how to integrate the skills into practice.

- Some consultants provide individual consultations over the phone. This may be something to check into.

- Attend workshops. Look for a mental skills training workshop in your local area or during a coaching convention. There may be workshops given on specific skills and techniques (e.g. goal setting, confidence, concentration, etc.).

- Request a mental skills training workshop. Your athletic department, school, or sport organization (during a convention) may respond positively to brining in a consultant to provide a mental skills training workshop to the coaches. 
How much services cost may also depend on what you want. Take a look at the box below...

\section{Sport Psychology Services Often Available}

Mental Skills Training: Teaching mental skills such as goal setting, relaxation, imagery, self-talk, concentration, energy management, motivation, coping with pressure, confronting fear, breaking out of a slump, pre-performance routines, team cohesion, etc. Training can either be in a team or individual setting.

Personal Counseling: Individual counseling to address issues related to relationships, anxiety, depression, injury rehabilitation, stress management, grief/loss, identity, homesickness, and substance abuse.

Consultation: Consultations with coaches, trainers, and others regarding performance and personal issues (e.g., coaches might call to ask about a team-building exercise, to refer a depressed athlete, or to ask for ways to approach an athlete about an eating disorder).

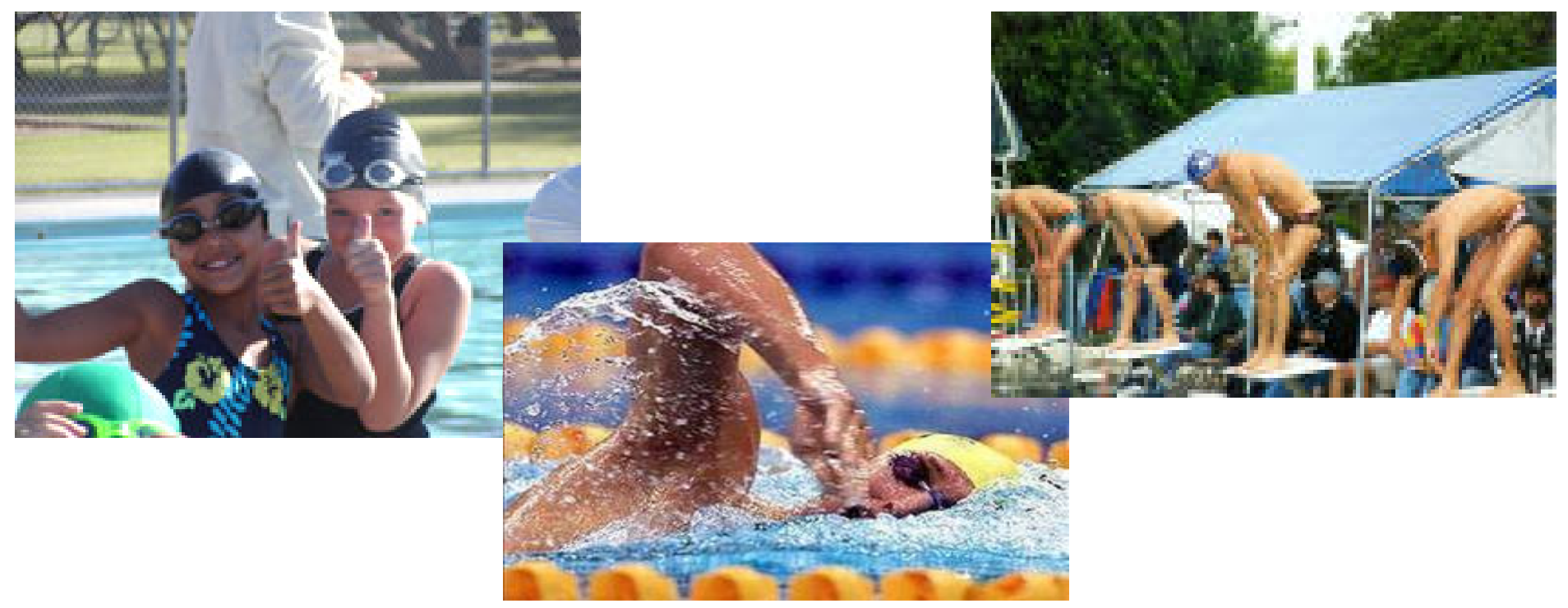




\title{
Performance Success!!
}

Within sport, performance success depends on developing four areas...

\author{
Physical \\ Tactical \\ Technical \\ Mental
}

How do you address all of the above areas with your athletes?

\section{Go Ahead...Give it a Try!!}

One of the most important steps to successfully using sport psychology services and integrating mental skills into training is making the commitment. As the coach, this is YOUR program. You are involved in every aspect of your athletes training. Using a sport psychology consultant is no exception. BE INVOLVED!!

Your athletes' commitment to your program starts when you are committed. You are a central figure within the athletic environment and your attitudes and values filter down and influence your athletes' attitudes and values. Using a sport psychology consultant is a PROACTIVE step designed to "stretch" not "shrink" the potential of athletes.

Remember, performance success involves developing the physical, tactical, technical, and mental aspect of sport. Therefore, mental skills training is a part of sport and your program.

How do you want to be involved in the mental skills training program?

Sport psychology has demonstrated that mental training programs make a difference!!

A "total package" mental skills training program is individualized, systematic, and uses a variety of psychological techniques. 


\section{"Getting Started!"}

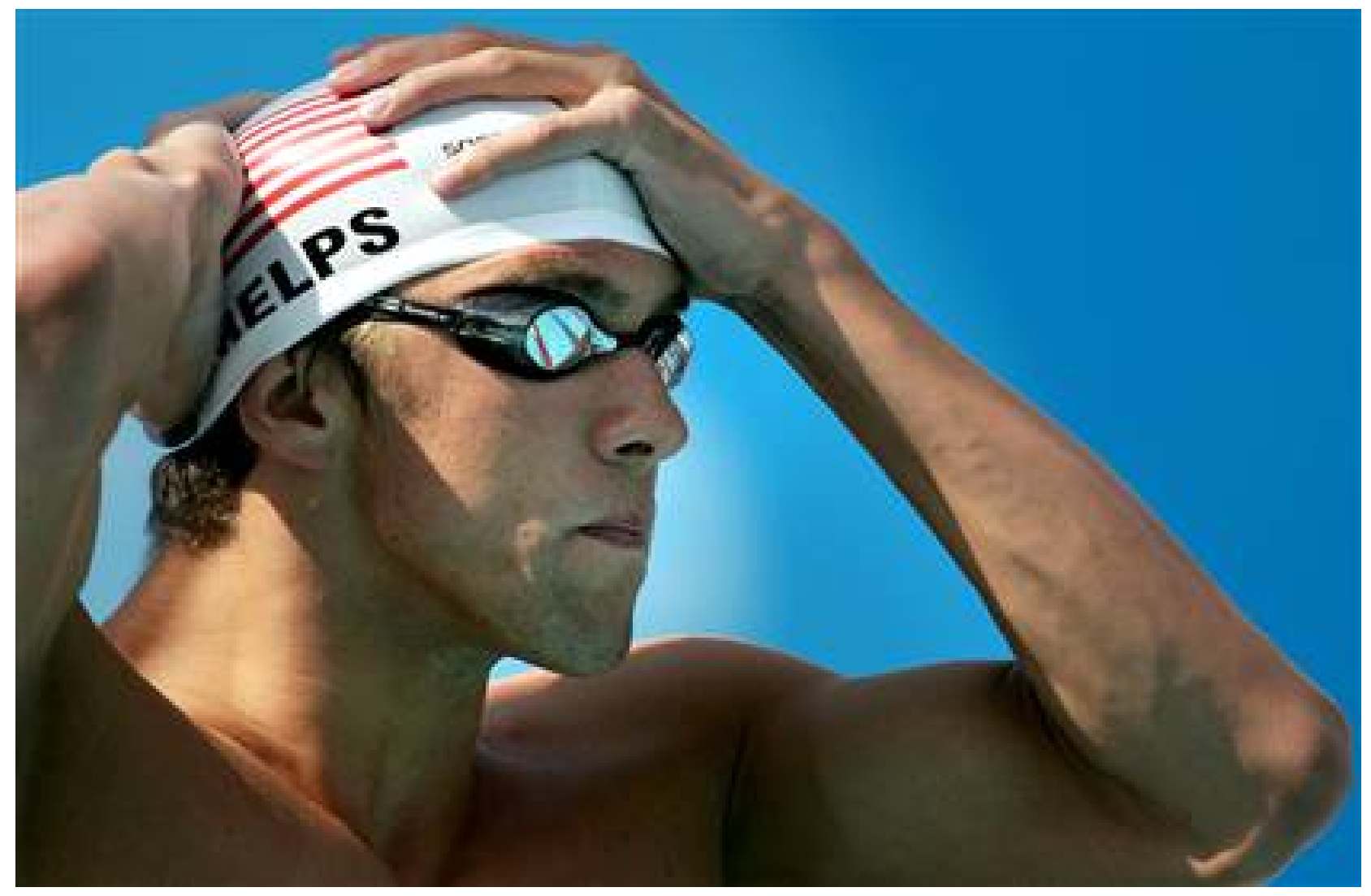

"... at the highest levels of sport the difference between the performance of individual athletes is measurable only in tenths or hundredths of a second. Any technique that will tighten those fractions has to be used."

-Sally Gunnell

Olympic Gold Medalist and World Champion Hurdler 


\section{Go Ahead....Make the Commitment!!}

One of the most important steps to successfully using sport psychology services and integrating mental skills into training is making the commitment. As the coach, this is YOUR program. You are involved in every aspect of your athletes training. Using a sport psychology consultant is no exception. BE INVOLVED!! Mental training must involve the coach in order to be successfully integrated into your program.

Your athletes' commitment to your program starts when you are committed. You are a central figure within the athletic environment and your attitudes and values filter down and influence your athletes' attitudes and values.

Regularly using sport psychology services will create an environment that mental skills training is a part of sport and your program. If you view mental skills training as something "extra" than your athletes will also view it as something "extra."

How do you want to be involved in the mental skills training program?

Do you remember a time when it was the coaches' job to be the "trainer" or "strength coach?" Many coaches have said that they already fill the role of the sport psychologist. For coaches with training in sport psychology, it would make sense for coaches to implement some interventions (e.g. educational) but not others (e.g. psychotherapy).

Having a sport psychology consultant work with your team can allow you to devote more attention and effort toward your overall coaching program. 


\section{Let's Take A Look at WHY Mental Skills Training?}

There are several benefits to using sport psychology services and integrating mental skills training into your program.

\section{How Can It Benefit Your Team?}

- Reduced nervousness before races

- Less pain and fatigue during swimming races

- Sharpening concentration/ Letting go of distractions (e.g. not concerned about swim competitors)

- Improving swimming technique and overcoming stroke problems

- A calm, clear mind

- Increasing confidence on the block

- A belief in self and swimming abilities

- Greater inner strength / physical energy

- Strong and more consistent performances in swim meets

- Becoming mentally tough

- Setting useful goals

- Get more out of practice

- Controlling thoughts and using positive self statements

- Increasing motivation in practice and competition / Preventing burnout

- Enhance injury rehabilitation

- Facilitate reaching potential and achieving goals

- Puts athletes in the "position to win"

**Sport psychology services work WITHIN your program** 


\section{Overcoming Obstacles}

Coaches often report access, time, and money as common obstacles that may get in the way of successfully using sport psychology services.

Time: TIME IS PRECIOUS. Sport psychology services, when used appropriate, should not significantly add on to the already demanding schedule. By using sport psychology services, YOU are taking a pro-active step toward enhancing your athletes. Learning how to regulate and control one's thoughts, feelings, and behavior needs to occur IN their sport environment and DURING practice. I have known several coaches who integrate mental training when practicing sport skills (e.g. during a drill).

\section{When integrating mental and physical practice, there should be a performance-specific focus.}

After learning how to recognize harmful tension and relaxation techniques athletes should be instructed to scan for harmful tension and practice appropriate relaxation techniques while performing. A good way to integrate mental and physical practice may be to scan and relax before serving a tennis ball, pitching, shooting a free throw, or stepping on the block.

\section{**In what specific ways can you use mental skills in conjunction with physical training?**}


Tailored Coach Intervention 123

Access: Several coaches have said... "Even if we wanted to we just don't have the access to sport psychology" OR "I would not know how to go about gaining access to services." As coaches, you have several options for gaining access to sport psychology.

Under "How to Get Started" you will find a bullet that provides information on where to look for sport psychology services.

** More sport psychology professionals are being utilized by coaches and athletes of all competitive levels (age group, club, high school, college, elite, etc.) ${ }^{* *}$

Money: When it comes to paying for services, coaches have several options. If you are interested in hiring a sport psychology professional make sure you contact him/her and ask about services and rates.

\section{A Tight Budget? Here Are Some Options:}

- If you are at a college or university, the service may be provided for free.

- A doctoral student who is being supervised may provide the service for free or lesser charge. I've known several doctoral students to provide services to a variety of ages and competitive levels (e.g. age group, club, high school, elite, etc.).

- Check out sport psychology resources (books, videos, manuals). You can find some great tips to help you learn more about mental skills training techniques.

- Have a consultant do some workshops with the coaching staff. This may be cheaper than hiring a consultant for the season.

- Some consultants provide individual consultations over the phone. This may be something to check into.

- Attend workshops. Look for a mental skills training workshop in your local area or during a coaching convention. There may be workshops given on specific skills and techniques (e.g. goal setting, confidence, concentration, etc.). 
Tailored Coach Intervention 124

- Request a mental skills training workshop. Your athletic department, school, or sport organization (during a convention) may respond positively to brining in a consultant to provide a mental skills training workshop to the coaches.

How much services cost may also depend on what you want. Take a look at the box below...

\section{Sport Psychology Services Often Available}

Mental Skills Training: Teaching mental skills such as goal setting, relaxation, imagery, self-talk, concentration, energy management, motivation, coping with pressure, confronting fear, breaking out of a slump, pre-performance routines, team cohesion, etc. Training can either be in a team or individual setting.

Personal Counseling: Individual counseling to address issues related to relationships, anxiety, depression, injury rehabilitation, stress management, grief/loss, identity, homesickness, and substance abuse.

Consultation: Consultations with coaches, trainers, and others regarding performance and personal issues (e.g., coaches might call to ask about a team-building exercise, to refer a depressed athlete, or to ask for ways to approach an athlete about an eating disorder). 


\section{What To Expect: The Process}

\section{When?}

It is not uncommon for coaches or athletes to want to start a mental skills training program in the middle of the season. This is because of some situation that arises: such as a slump in performance. For best results, the time to initiate a program is in the preseason or off season. This allows you and your athletes to introduce a mental skills training component without the pressure of winning. It also allows you to learn how you can best integrate the mental component into your physical training.
A tennis player would not change his/her grip on the racket right before a tournament without using the new grip in practice for several weeks. What would happen if he/she did change the grip right before a tournament? Performance would probably be worse, not better. This is similar to introducing a new mental skill. Mental skills need to be practiced systematically and integrated with physical practice in order to expect lasting optimal results.

\section{How often?}

If a new skill is being learned, it is typical for the consultant to work with the athletes for 10-15 minutes about 3 times a week. This can be done at the beginning or end of practice. Another approach is to hold fewer (e.g. once a week to a few times a month) but longer sessions for mental training. This approach may work better if hiring a sport psychology consultant on a part time basis (typically not present every day).

Some weeks, no mental skills "sessions" will be needed because mental practice can occur with physical workouts. In addition fewer sessions are needed as athletes develop their mental skills.

\section{Up Front}

At the start of a mental skills training program, the consultant usually explains his/her role, philosophy, and what sport psychology really is. It will be good for you to be there during this meeting with the athletes. You can be there to reinforce what you have planned for your program and the value of mental skills training. This is also a good time to enforce the idea that using a sport psychology consultant does not mean 
there is something "wrong" with them. This is another TOOL to their training that helps to put them in the position to succeed.

\section{Education, Acquisition, Practice}

Generally, mental skills training programs follow three phases: education, acquisition, and practice. Take a look at the main objectives of each stage:

\begin{tabular}{|c|c|c|}
\hline $\begin{array}{l}\text { Education } \\
\text { - Recognize importance of } \\
\text { developing mental skills } \\
\text { training. } \\
\text { - Awareness of how mental } \\
\text { skills affect performance. }\end{array}$ & \begin{tabular}{l}
\multicolumn{1}{c}{ Acquisition } \\
- Strategies and techniques \\
for learning mental skills. \\
- Tailoring strategies for \\
athlete's individual needs.
\end{tabular} & $\begin{array}{l}\quad \text { Practice } \\
\text { - Automate mental skills. } \\
\text { - Integrate mental skills into } \\
\text { performance situations. } \\
\text { - Apply to competition. }\end{array}$ \\
\hline
\end{tabular}

\section{Group Meetings}

Oftentimes the sport psychology consultant will start with group sessions and then move toward working with athletes individually. Group sessions are often used to explain general sport psychology concepts and help create awareness of the role of mental skills in the athletes own performance. If consultants are hired to work with an individual athlete, this process would move directly to individual work.

Several coaches that I have encountered prefer starting with group sessions during the preseason. This allows the athletes to form a relationship with the consultant and create an environment that the consultant is there to "stretch" their potential. After seeing the consultant as a normal aspect of their sport environment, athletes are often more comfortable meeting individually.

\section{Individual Meetings}

Individual sessions are usually used as a follow up to group sessions (unless you hire a consultant to work directly with an individual athlete up front).

\section{Integration into Practice}

As soon as possible you want to integrate mental skills practice with physical skills practice. The ultimate goal is for mental skills to be seen as an integral part of physical practice. Consistently practicing mental skills will achieve lasting results compared to short-term effects. 
**You and the sport psychology consultant can work together to think of practical ways on how to integrate mental skills into training AND how to reinforce the mental skills being developed during practice. ${ }^{* *}$

\section{Coach-Consultant Meetings}

Ideally, you will want to set up meetings with the consultant to discuss ways that you can apply and reinforce what is emphasized during the mental training sessions. Additionally, you can know exactly what is happening and can provide feedback on what needs to be done. Knowing what's going on will also limit any misunderstandings regarding what the sport psychology consultant is doing.

These meetings can be formal (e.g. office) or informal (e.g. locker room, hotel lobbies, at or after meals)

\section{Being Around}

It is beneficial for the consultant to "be around" during practice and competition. The consultant may not be able to be with the athletes on a day to day basis. However, it is important for the consultant to be at some practices and competition on a regular basis (e.g. weekly). Again, this creates a climate that sport psychology is a natural part of the environment. It also helps to build a relationship between the consultant and athletes. The consultant will also want to observe, first hand, how athletes train and respond to different situations. 


\section{What Is Your Role?}

\section{An Enforcer}

As a coach you exert a strong influence over the behavior of athletes. In fact, what you say and do probably has the most influence and impact with athletes than anyone else. You have the power to influence athletes' behavior and attitude by your behavior and attitude.

It can be argued that an athletes' commitment to sport is the most important factor influencing their performance. This is also true for their physical and mental trainingthe athletes' commitment to the program is a key factor influencing the effectiveness of the process. The main idea is for you to be an enforcer of the mental training process by helping to increase an athletes' commitment to the program.

Since you are in contact with your athletes on a daily basis, you are in a prime position to enforce and reinforce mental skills training during practice.

What does it mean to be an Enforcer?

- Know about the mental skills training program.

- Be involved-it is recommended that you attend some of the group meetings.

- Reinforce the importance of the mental skills training.

- Ensure the effectiveness of mental skills training (e.g. seeing appropriate application during practice).

- Verbal reminders and reinforcement for integrating mental practice with physical practice.

- Provide Support.

- Ensure compliance

- Listen to and challenge athletes' self-talk.

- Make a referral when appropriate.

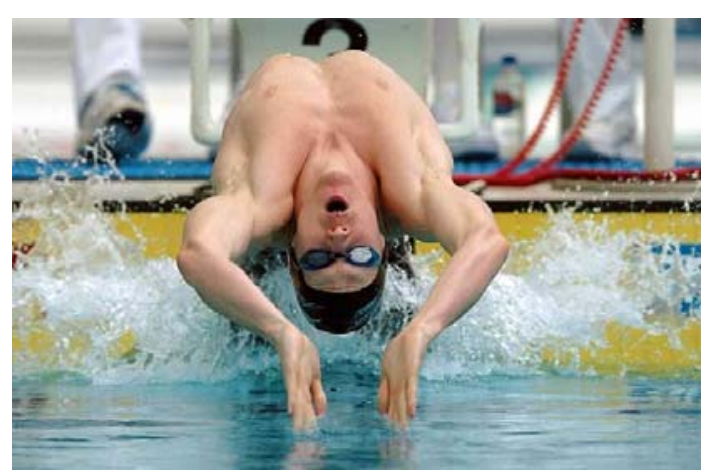




\section{Shopping for a Sport Psychology Consultant Who is Qualified?}

If you were to hire an assistant coach, what steps would you take? It would be important to know their background, credentials, and how well you think they would fit into your program. Looking for a sport psychology consultant is often similar to searching for an assistant coach.

This section provides some quick and easy tips for finding the right, and qualified, person for you.

\section{Background and Training}

Are you looking for an educational consultant to teach athlete mental skills, someone to provide counseling services, or both? The background and training that you want your consultant to have will depend on what type of service you are looking for.

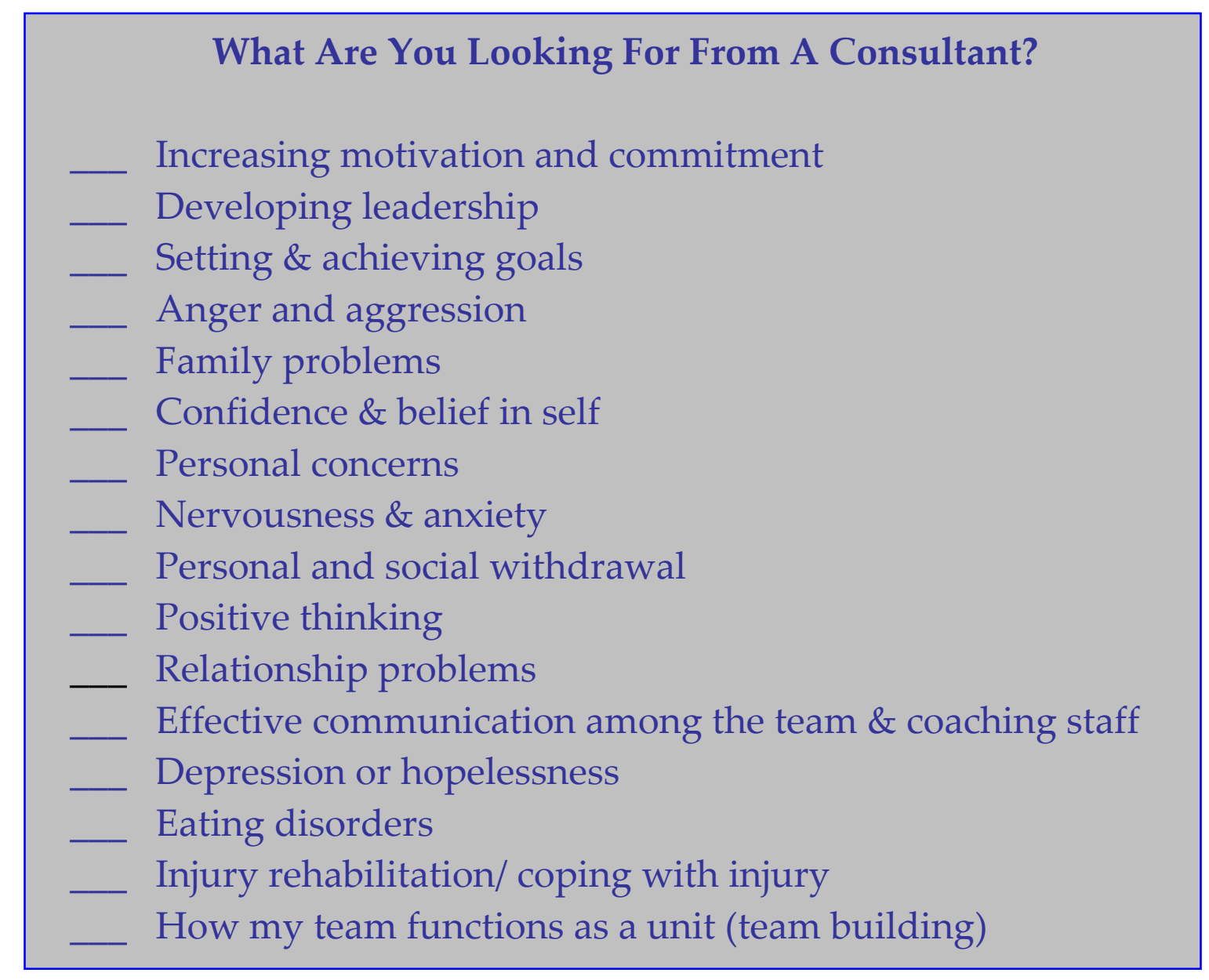


Take a look at your list. The background and training you are looking for will depend on what group(s) your needs fall under.

\begin{tabular}{|l|l|}
\hline \multicolumn{1}{|c|}{ Educational } & \multicolumn{1}{|c|}{ Counseling/Clinical } \\
\hline - Motivation \& commitment & • Personal concerns \\
- How team functions as a unit (team & • Family problems \\
building) & • Relationship problems \\
- Developing leadership & - Anger \& aggression \\
- Setting \& achieving goals & - Personal \& social withdrawal \\
- Confidence/ belief in self & - Depression \& hopelessness \\
- Nervousness/ anxiety & - Eating disorders \\
- Positive thinking & \\
- Communication & \\
\hline
\end{tabular}

\section{Educational}

There are many consultants/practitioners that are not licensed psychologists. These professionals take an educational approach to their interventions and emphasize teaching athletes' skills to handle the pressures of competition. Oftentimes they may be referred to as a "mental coach" because they teach athletes mental skills much like coaches teach physical skills. Most likely this person will have their Master's or Doctorate in Sport \& Exercise Psychology. Ideally, this person will also have certification (see Certification).

\section{- Clinical/Counseling}

Some consultants/practitioners have been trained in clinical or counseling psychology and are licensed to provide counseling services. These professionals consult with athletes regarding issues such as depression, relationships, drug and alcohol rehabilitation, anger, and eating disorders. Most likely this person will have their Doctorate in Clinical or Counseling Psychology. It is ideal for this individual to be trained in sport \& exercise psychology and have experience working with athletes.

Licensed psychologists who are also trained in sport psychology may also be able to offer you the educational services mentioned above. 
Recognizing When An Athlete Requires

Clinical/Counseling Services

Problem exists over a long period of time

- Problem interferes with daily life \& normal functioning

Problem threatens core identity and sense of self (e.g. sense of self threatened by possibility of losing)

Eating disorders (related to identity and self esteem)

Out of the ordinary emotional reactions (e.g. depression, personal \& social withdrawal, anger \& aggression, hopelessness)

\section{Certification:}

Is the consultant certified? The Association for Applied Sport Psychology (AASP) has developed certification in sport \& exercise psychology. Those who are an AASP Certified Consultant have met professional criteria and have undergone a review of their credentials, coursework, and consulting experience.

AASP has a Certified Consultant finder to assist coaches in locating a qualified consultant. Go to www.aasponline.org for more information or call 608.443.2475.

\section{Professional OR Student:}

- If the consultant you are hiring is a professional than follow the background and training guidelines above. Preferably this person will also be AASP certified.

- You also may have the opportunity to work with a graduate student. Find out what degree this student is working toward and make sure it is one listed above. Many teams have worked with graduate students. Oftentimes, students may provide their service for free. If you decide you are interested in working with a student, make sure he/she is getting supervised by an AASP Certified Consultant.

\section{References:}

Ask for and check their references!! 
Sport Experience:

- Has this person worked with athletes and teams before?

- What sports has this person worked with in the past?

- Was the consultant an athlete at one time? This is not a necessary component to be a qualified consultant. Some coaches prefer an athletic background and some do not. None-the-less it is good to ask about the individual's experience within the athletic environment.

How long have they been working within the athletic environment?

\section{Talk to Other Coaches or Athletes}

Speak to other coaches/athletes who have worked with the consultant.

Speak to other coaches who have worked with a sport psychology consultant to gather their experiences.

\section{Quick Tips: Finding a Sport Psychology Consultant For You}

Will he/she be focusing on teaching mental skills for enhancing performance (e.g. educational approach)?

Will he/she be focusing on personal and emotional issues (e.g. clinical approach)?

- Does the person have experience with the age group your athletes are in?

- Does the person have experience with the competitive level of your athletes?

- Does he/she have sufficient knowledge about your sport?

- How much time does the person have to spend with your team?

- Does he/she have references from teams or individuals that he/she worked with?

Is he/she an AASP, Certified Consultant?

- If he/she is a student: what program are they in and are they supervised by an AASP , Certified Consultant? 


\section{How to Get Started!!}

Now that you know what you are looking for, how do you get started?

\section{Where to Begin}

Do you already have someone in mind? If so, contact that person directly by phone or e-mail (see Initiating Contact on the next page).

- Full or part time? The following are all questions to ask yourself when considering the use of either a full or part time consultant. If you are considering using a student- this individual will most likely be on a part time basis.

- How often do you want the consultant working with your team? For example, will it be each week, every two weeks, etc?

- How often do you want the consultant to attend practice (days per week/month) and competition (home/away)?

- How much money are you able to pay for a sport psychology consultant to work with your team?

Who is the consultant working with?

- Some teams hire a consultant to work directly with the coaching staff to teach them how to teach mental skills to athletes and integrate it into practice. Some teams hire a consultant to work directly with the athletes only. And lastly, some teams hire consultants to work with the athletes as well as provide feedback to the coaching staff on how to implement mental skill into practice.

- If the consultant is working with your athletes: do you want team sessions only, individual sessions only, or both?

Where to look?

- Contact a college or university nearby?

- Sport psychology professionals or doctorate students may be willing to travel to provide consultations. Personally, I've traveled between 2 to 4 hours to have the opportunity to work with a team.

- Look to see if there is a sport psychology program. Sometimes sport psychology professionals can be found within coaching education programs...so look there too!! 
- Contact and talk with someone in the athletic department. More universities and colleges are hiring a full or part time sport psychology consultant within the athletic department.

- Contact and talk with someone in the counseling services.

* Go to aasponline.org and use the AASP Certified Consultant Registry.

- Under "certified consultants" at the top of the webpage, click on "find a certified consultant". You can search by country or by state.

- Check out some consultant websites.

- Go to: http://www.aaasponline.org/cc/index.php and you will find a link entitled "Links to Certified Consultant Websites".

- The United States Olympic Committee (USOC).

- You can contact their administration to ask about sport psychology services and mental training (719.866.4517).

- Check out their webpage regarding sport psychology http://www.usoc.org/teamusanet/TeamUSAnet 46377.cfm

- Talk to other coaches or athletes. Someone you know may have worked with a sport psychology consultant.

- Contact a sport organization/ association.

- If you belong to an association, it may be worthwhile to contact someone in office (president/ executive director/ coaching education coordinator). They may be have some people in mind that can help.

* Use the INTERNET

- Type "sport psychology services" into a search engine (google).

- You can also look within a state (sport psychology services and Ohio).

\section{Initiating contact}

- What is your preference: phone or email? This is a good place to start when inquiring about the services that a sport psychology consultant provides and availability.

- Ask about the services they provide, availability, and price.

- You will want to set up a meeting. Face to face is best. The second option would be by phone. But, before you "officially" hire someone you will want to meet with him/her face to face.

- SET UP THE MEETING: expect to schedule between 30 to 60 minutes. It may be a good idea to ask the consultant how much time to allot for the initial meeting. 


\section{What to Talk About}

- Have the consultant communicate his/her philosophy. It will be good for you to also communicate your philosophy.

- Talk about the nature of the team and individual athletes he/she will be working with. It will be important for the consultant to integrate it with his/her background, training, and orientation.

- Talk about availability. How many weeks of practice or preseason are available? How much practice time will be devoted to mental skills training (team sessions)? Will this continue after the competitive season begins?

Will the consultant be doing individual meetings? If so, where will this take place? What times are available?

- Confidentiality. This is a good area to talk about up front with the consultant regarding both team and individual sessions.

- Clarify expectations up front. For example, what are your expectations from the consultant (e.g. attending practice, competition, providing team sessions, individual sessions, teaching coaches how to integrate mental skills into practice, etc.). Make sure you also clarify the consultant's expectations up front.

\section{Is it a Match?}

Lastly, is the consultant a good fit for your program?

Sport psychology has demonstrated that mental training programs make a difference!!

A "total package" mental skills training program is individualized, systematic, and uses a variety of psychological techniques. 
Tailored Coach Intervention 136

Appendix G

Review of Literature 
Applied sport psychology and psychological skills training has received more attention, interest, and acceptance within the athletic environment over the past decade. Not only has the effectiveness of psychological skills training been well documented within the literature, some athletes and coaches are publicly recognizing the usefulness of mental skills training to sport performance. In addition, sport psychology organizations [i.e. Advancement of Applied Sport Psychology (AASP), American Psychological Association (APA) Division 47], the establishment of AASP certification and the United States Olympic Committee (USOC) sport psychology registries, and educational programs have all worked together to increase the visibility and accessibility of sport psychology services to athletes and coaches. Despite the efforts to increase accessibility, some athletes and coaches continue to be hesitant in using sport psychology services. This chapter is a review of literature pertaining to: (1) research on coaches' use of sport psychology services; (2) the transtheoretical model of behavior change (TTM) and its application to SP service use; (3) attitudes toward and intentions to use sport psychology services; (4) an overview of coach education; (5) how the TTM can be used as a framework for tailoring coach education programs; and (6) will conclude with an integrative summary and future directions section.

\section{Coaches’ Interest and Use of Sport Psychology}

Literature consistently reports that the vast majority of coaches surveyed have an interest and willingness to use sport psychology (SP) services and agree that psychological skills are important to training and athletic success (Kimiecik \& Gould, 1987; Partington \& Orlick, 1987; Rice, 1996; Scully \& Hume, 1995; Sullivan \& Hodge 1991; Wrisberg, 1990; Zakrajsek \& Zizzi, 2007). Pat Summit, a head coach for a 
women's collegiate basketball team, stated that "at the collegiate level [the mental component] is extremely important because the athletes have usually developed their physical skills to a high degree...Failure to execute [the physical skills] may be the result of various psychological factors” (Wrisberg, 1990, p. 181). A head swimming coach at the national level, James "Doc" Counsilman stated that "the swimmer who has it together mentally in the big meets is going to outperform the other competitors” (Kimiecik \& Gould, 1987, p. 351). When it comes to the importance of mental skills, most coaches consider sport to be 50\% mental and some sports (e.g. golf, tennis, figure skating) are considered by coaches to be $80 \%$ to $90 \%$ mental (Weinberg \& Gould, 1999).

A national survey of 236 high school and collegiate coaches revealed that $68.2 \%$ of coaches surveyed indicated a desire for a SP consultant to work with their team (Silva, 1984). Sullivan and Hodge (1991) reported that out of 46 national coaches, 97.6\% indicated an interest in working with a SP consultant. Although coaches place high importance on psychological skills and report an interest in using SP services, literature consistently reports that only about $21-22 \%$ of coaches' sampled use some form of SP services (Rice, 1996; Zakrajsek \& Zizzi, 2007). This is similar to findings outside the U.S. in which a study with 47 elite level coaches in Ireland found that $80 \%$ reported an interest in working with a SP consultant and 70\% felt their athletes would perform better if they were working with a SP consultant, yet only $12 \%$ of coaches used SP services (Scully \& Hume, 1995). From these findings, it is clear that a discrepancy exists between interest and importance placed on mental skills training and coaches actual implementation and use of SP services into practice. Because the coach is often the one who employs a SP consultant and decides if work is continued or terminated with a team 
or athlete (Partington \& Orlick, 1987; Voight \& Callaghan, 2001), gaining acceptance and trust from the coach first is highly important toward gaining entry with athletes and working within applied SP. Understanding coaches as consumers and the factors that continue to inhibit SP service use is essential toward understanding the possible factors that that may shift coaches from willingness and interest to actual implementation and use of SP services.

There are several possible reasons as to why some coaches do not utilize SP services. Researchers and applied practitioners have suggested that the use of SP services is influenced by athletes and coaches’ perceptions and attitudes toward SP consultation (Leffingwell, Rider, \& Williams, 2001; Linder, Pillow, \& Reno, 1989; Ravizza, 1989; Zakrajsek \& Zizzi, 2007). Despite the importance placed on mental skills, negative connotations associated with the discipline of SP continue to be reported by coaches and identified as a barrier to SP service use (Kremer \& Merchant, 2002; Pain \& Harwood, 2004). Some coaches still hold the misconception that SP is for problem athletes only and are aware that athletes could be ridiculed for seeing a SP consultant due to the term “psychology” within the title. This perception has been a common theme within the literature, in which undergraduate students, athletes, professionals, and male sport fans perceived SP to be more closely associated with mental-health professions compared to all other sport-oriented professions (e.g. coaching; Linder, Brewer, Van Raalte, \& Delange, 1991; Van Raalte, Brewer, Linder \& DeLange, 1990; Van Raalte, Brewer, Brewer \& Linder, 1992; Van Raalte, Brewer, Brewer \& Linder, 1993; Van Raalte, Brewer, Matheson \& Brewer, 1996). This suggests that others’ perceptions of SP may be based on the term "psychology”, which is perceived to work with deeper, more abnormal 
problems (Murstein \& Fontain, 1993), as well as examine vulnerabilities and weaknesses (Ravizza, 1989).

However, research has also shown that sport psychologists have been viewed as having more sport expertise than all other non-coaching professionals (Maniar, Curry, Sommers-Flanagan, \& Walsh, 2001; Zizzi, Blom, Watson, Downy, \& Geer, 2005) and not all stigmatize a SP consultant as a head "shrink” (Maniar et al.; Van Raalte, Brewer, Brewer, \& Linder, 1992). Despite these findings, research continues to report that student-athletes prefer to consult with professionals that do not have any reference to psychology or counseling (i.e. performance enhancement specialist) for optimal performance interventions (Maniar et al.). In addition, some coaches have said that SP should be re-labeled as “mental skills,” “performance enhancement,” or "mental toughness” (Pain \& Harwood, 2004) and that employing a sport psychologist and selling SP to players would be easier under a different name. It is apparent that there is still the awareness of the stigma that others may associate with the field as well as how working with a SP consultant could be viewed with suspicion.

Lack of funding and time constraints have also been consistently reported in the literature as some of most common reasons why coaches and universities do not utilize mental skills training or SP services (Anshel, 1989; Gould, Medberry, Damarjian, \& Lauer, 1999; Gould, Tammen, Murphy, \& May, 1989; Haslam, 2004; Kremer \& Marchant, 2001; Pain \& Harwood, 2004; Voight \& Callaghan, 2001). Sport psychology and mental skills training are not a traditional aspect of coaching and may further inhibit coaches from going outside of their comfort zone and implement SP into practice (Anshel, 1989; Gould et al, 1999; Haslam, 2004). Because SP is often not viewed as a 
traditional aspect of sport training and the benefits of SP in terms of actual performance may be difficult to prove (Gould et al., 1999; Pain \& Harwood, 2004), some coaches and universities may not consider SP essential, beneficial, or a top priority (Voight \& Callaghan, 2001, Haslam, 2004).

It appears that coaches consider several factors (e.g. perceived gains, losses, and barriers) when weighing the decision to use SP services. Some coaches may be aware of the benefits of using SP services but the perceived barriers (e.g. access, time, money) continue to inhibit motivational readiness to integrate SP into training. In order to increase the use of SP services, professionals should seek to understand and address coaches' attitudes, beliefs, and motivational readiness to use SP services within a theoretical framework.

\section{Transtheoretical Model of Behavior Change}

The transtheoretical model (TTM) of behavior change was originally developed to understand change in addictive behaviors (Prochaska \& DiClemente, 1983), but has since been applied successfully to a variety of problem and healthy behaviors, including the adoption of mental skills training with athletes (Grove, Norton, VanRaalte, \& Brewer, 1999; Leffingwell, Rider, \& Williams, 2001; Zizzi \& Perna, 2003). TTM of behavior change is a process that involves progressing through five predictable stages: precontemplation; contemplation; preparation; action; and maintenance (Prochaska \& DiClemente, 1983).

The TTM incorporates 10 strategies employed to initiate or modify change in behavior, cognition, or affect that are used within the five stages of change. Grouped into experiential (cognitive and affective activity) and behavioral factors, the processes of 
change include consciousness raising, self-liberation, social liberation, self-reevaluation, counterconditioning, stimulus control, reinforcement management, dramatic relief, and helping relationships (Prochaska \& DiClemente, 1983; Prochaska, Velicer, DiClemente, \& Fava, 1988). Different processes of change have been found to be more useful during certain stages of behavior change compared to others (Perz, DiClemente, \& Carbonari, 1996; Prochaska \& DiClemente). Individuals in precontemplation were found to be the least likely to use the processes of change (Prochaska \& DiClement), suggesting that they spend less time reevaluating themselves, experience fewer emotional reactions, and do little to turn their attention and environment toward change. Individuals are more likely to be more open and respond to feedback and education once in the contemplation stage in which cognitive and affective reevaluation processes are found to carry over to action. Once in action, individuals have been found to engage in counterconditioning and stimulus control, report more self and social reinforcement, and rely more on helping relationships for support. Those in maintenance have been found to continue the use of counterconditioning and stimulus control (Prochaska \& DiClemente).

Engaging in cognitive and emotional activities early on is designed to lead to attitudinal changes that lay the groundwork for future success in the action stage. Once action has begun, a reduction in cognitive and attitudinal change should occur and an increase in behavioral activities should begin. This is important from an application standpoint, in which practitioners should incorporate stage appropriate tasks when working with behavior change rather than treating everyone as if they are in the action stage. Interventions that are targeted toward a specific stage of change can help speed up an individual's progress toward action and maintenance. During the contemplation and 
preparation stages, interventions toward successful behavior change should focus on tasks centered around experiential processes (consciousness raising and cognitive/affective reevaluation). As individuals move into action, a shift in focus occurs toward behavioral activities (counterconditioning, stimulus control, helping relationships; Perz et al., 1996; Prochaska \& DiClemente, 1983).

Velicer, DiClemente, Prochaska, and Brandenburg (1985) integrated core constructs of a decisional making model to the TTM. Janis and Mann (1977) conceptualized sound decision making as a process of considering all the potential gains (pros) and anticipated losses (cons) of changing behavior. When applying the decisional making model to the TTM, Velicer and colleagues found that the balance of the pros and cons of making a decision vary depending on an individual's stage of change. For those in the precontemplation stage, the cons of changing the behavior outweighed the pros. The opposite was found with those in the action stage, in which the pros of changing behavior outweighed the cons. This predictable pattern has continued to emerge when examining the relationship between the pros and cons and stage of change with both the cessation of negative behaviors (e.g. smoking) and acquisition of positive behaviors (e.g. exercise adoption; Prochaska et al., 1994). Therefore, before people take action, a crossover effect occurs in which people will make the decision that the pros of changing the behavior outweigh the cons. When examining the results further, the pros for changing behavior were higher for those in the contemplation stage compared to those in the precontemplation stage, and the cons for changing were lower in the action stage compared to the contemplation stage. 
Studying the cognitive and motivational shifts across the stages and being able to predict the crossover in decisional balance provides useful information toward developing interventions to facilitate change from precontemplation to action. Prochaska and colleagues (1994) suggested that increasing the pros of changing the behavior should be emphasized first in order to progress from precontemplation to contemplation. Decreasing the specific barriers of changing and making plans to change should then be targeted to facilitate the progression from contemplation to action.

\section{TTM Applied to Other Behaviors}

Understanding interventions that use the TTM as a framework for the adoption of other positive behaviors is beneficial toward the application of the TTM to the adoption of SP services. Marcus, Banspach, Lefebvre, Rossi, Carleton, and Abrams (1992) applied the stage of change model to a community intervention designed to increase adoption of physical activity. The stages of contemplation, preparation, and action were targeted since the purpose of the study was aimed at the non-exercisers or occasional exercisers. Of the 610 community participants, 39\% were in the contemplation stage, 37\% were in the preparation stage, and 24\% were in action. Participants engaged in a six-week intervention program that included written materials tailored toward specific stages to encourage participants to initiate or increase physical activity. Material tailored toward those in the contemplation stage focused on increasing lifestyle activity, the costs and benefits of increasing physical activity, the social benefits of activity, and rewarding yourself for increasing activity. Those in the preparation stage received information focused on the costs and benefits of activity, setting short and long term goals, rewards for activity, time management, and material on developing a walking program. Material 
for those in the action stage focused on goal setting, troubleshooting situations that may lead to relapse, cross training, rewards, avoiding injury, and exercise partners. Results of the stage specific intervention showed that most participants increased their stage of exercise adoption, in which $30 \%$ of those in the contemplation stage and $61 \%$ of those in the preparation stage moved to action. Additionally, 31\% of those in contemplation advanced to the preparation stage. Although a control group was not included in this study, the results show promise toward the effectiveness of stage-appropriate interventions with the adoption of positive behaviors.

Cardinal and Sachs (1995) also applied the stage of change literature to exercise. A total of 81 women participated in the study and were randomly assigned to one of three conditions that received mail-delivered, self-instructional exercise packets. Stage of change was measured through a single five-item ordered-categorical scale. The lifestyle exercise packet (LEP) encouraged women participants to integrate physical activity in their daily life (e.g. take the stairs instead of the elevator), and included information on health status, predicted body fat percentage, predicted $\mathrm{VO}_{2 \text { peak }}$, and stage of change for exercise. In addition, the packet included feedback with cognitive and behavioral activities tailored toward the participant's stage. For instance, packets for those in precontemplation included a decision balance activity, packets for contemplation included a behavioral assessment activity, packets in preparation included a goal-setting activity, and packets for action and maintenance included relapse prevention activities. The second group received the structured exercise packet (SEP) that included all information from the LEP (e.g. cognitive and behavioral stage specific activities) plus a standard exercise prescription that encouraged participants to follow recommendations 
for frequency, intensity, and duration of exercise. The third group (control group) received a fitness feedback packet (FFP) that only included information on their health status, predicted body fat percentage, and predicted $\mathrm{VO}_{2 \text { peak. }}$ After baseline, participants' stage of change was assessed at one month and seven months. At baseline, $24.7 \%$ of participants were in precontemplation and contemplation (inactive), 35.8\% were in preparation (some activity), and 39.5\% were in action or maintenance (regular activity). At seven months, 9.9\% were in precontemplation and contemplation, $40.7 \%$ in preparation, and $49.4 \%$ were in action or maintenance.

Overall, stage of change for exercise improvements were seen across the two time periods. Participants' improvement rate from baseline to one-month was 39.3\%, in which improvement was seen with $100 \%$ of those in precontemplation, $55.6 \%$ of those in contemplation, $24.1 \%$ of those in preparation, and $41.7 \%$ of those in action. Those in maintenance were not included since they were viewed as not able to improve in stage assignment. The improvement rate at seven months was $57.4 \%$, with $100 \%$ of those on precontemplation, $88.9 \%$ of those in contemplation, $41.4 \%$ of those in preparation, and 41.7\% of those in action showed improvement. Again, excluding those in maintenance, it was found that $57.4 \%$ of participants improved their stage of change profile, $29.5 \%$ maintained, and $13.1 \%$ regressed.

No significant differences within groups and stage assignment were found; however, patterns generally favored the LEP group over both the SEP and FFP groups. A total of $45.8 \%$ of those in the LEP group improved their stage of change assignment from baseline to one month compared to $42.1 \%$ and $27.8 \%$ of those in the FFP and SEP groups. From baseline to seven months, 58.3\% of those in LEP group improved their 
stage of change profile, whereas 57.9\% and 55.5\% improved in the FFP and SEP groups. Participants from the LEP group also had greater adherence, which may indicate that they were more satisfied with the intervention or the intervention "fit” better. These results may not be very strong but they do provide some preliminary support toward the use of tailored, mail-delivered programs to help motivate, encourage, and support individuals through stages of change for exercise behavior. Although not significant, differences in percentages between the LEP and SEP groups provide some evidence toward promoting physical activity compare to promoting vigorous physical activity. And lastly, maildelivered interventions may be a relatively effective and inexpensive means of reaching a number of individuals who are not yet ready to take action.

Marcus et al. (1998) conducted a work-place based study investigating the usefulness of a stage appropriate physical activity program for healthy sedentary employees. Participants were randomly assigned to one of two self-help physical activity interventions: (1) stage-matched and (2) not stage-matched. Participants' stage of change profile was assessed at the beginning of the study and three months later. Those assigned to the stage-matched program received a tailored manual based on their assigned stage of change at the beginning of the study. One month later, individuals in the stage-match program received a tailored manual that matched their current stage in addition to a manual designed for the next stage. A manual entitled “Do I Need This?” was tailored toward the precontemplation stage and contained information focused on increasing awareness of the benefits of being active as well as the barriers that prevented them from being active. Those in the contemplation stage received manuals entitled “Try it, You'll Like it” and focused on decision making (e.g. reasons to stay inactive versus reasons to 
become active), rewarding oneself, social support, and setting realistic goals. Those in the preparation stage received manuals entitled "I’m on My Way" that included information reviewing the benefits of activity, goal setting, possible obstacles to regular activity, and suggestions regarding safe and enjoyable activities. Participants in action received manuals entitled "Keep it Going” that reviewed the benefits of regular activity, staying motivated, rewarding oneself, overcoming obstacles, and increasing confidence in being active. Lastly, those in maintenance received “I won’t Stop Now” focusing on the benefits of regular activity, injury prevention, goal setting, rewarding oneself, varying activities, and planning ahead.

Participants in the non stage-matched program received one of five manuals from the American Heart Association designed to represent the standard "action-oriented” type of self-help material: "Walking for a Healthy Heart," “Swimming for a Healthy Heart,” “Cycling for a Healthy Heart,” "Dancing for a Healthy Heart,” and “Running for a Healthy Heart.” Participants received the first manual (randomly selected) at the beginning of the study and one month later received the second manual (randomly selected) as well as another copy of the first manual.

Results revealed that $37 \%$ of participants in the stage-matched group became more active at the three month follow-up compared to $27 \%$ in the non stage-matched group. Additionally, the researchers found that the stage-matched intervention was particularly useful for individuals in precontemplation, contemplation, or preparation at the beginning of the study. This is useful from an applied standpoint because most of the population is in either precontemplation or contemplation with regards to physical activity (Marcus and Forsyth, 2003); however, traditional intervention programs are 
designed for exercisers in preparation and action. This study provides further evidence toward stage-based interventions and are particularly useful toward improving readiness to start exercising with those in precontmeplation and contemplation compared to maintaining. This study also adds to previous literature and offers further evidence toward the impact of using written self-help material for providing cost-effective stagematched interventions.

In sum, applying the stage of change approach has facilitated forward movement in stage profiles for physical activity behaviors. Compared to interventions that are not stage-matched, stage-appropriate interventions are more effective and successful toward helping individuals progress through the stages of change. Furthermore, cost-effective intervention strategies that focus on tailored self-help material may facilitate forward movement in an individual's readiness to change.

The TTM in Sport Psychology with Athletes

The TTM has more recently been applied to the adoption of mental skills training with athletes. Grove, Norton, Van Raalte, and Brewer (1999) evaluated the effectiveness of a mental skills training program by using stage of change as an outcome measure with 37 male youth baseball players. Stage of change was measured with a single item descriptor of each stage. A total of 20 baseball players received a six-week mental skills training program (treatment) while 17 served as the control group and participated in a six-week strength training program. Stage of change was assessed prior to the six-week program, immediately following the program, and three months later. No significant difference was found in stage classification between treatment and control groups on the pretest. Significant differences in stage classification were found immediately following 
the six-week program and were maintained three months later. Prior to the intervention, $40 \%$ of the athletes in the treatment group identified being in the action or maintenance stage. Immediately following the program, athletes in the maintenance stage increased to 90\% and dropped slightly to $75 \%$ three months later.

Results suggest that athletes exposed to the mental skills training program showed movement toward regular implementation of mental skills training into practice. Though to a lesser degree, the intervention showed continued impact in which the movement was retained three months later. This movement was not evident in the control group. Athletes in the treatment group were required to attend the six-week training program, which may explain the increase immediately post-test. However, the authors suggest that the three month follow-up provided evidence that the behaviors were internalized and had continued impact. Because the mental skills training program was mandatory and reinforced by the coaches, athletes may have viewed it as an important and integral part of training. The SP consultant attended all training sessions and intrasquad games, assigned homework, conducted weekly meetings during regularly scheduled training times, assisted coaches in learning how to implement mental skills during training drills, and provided on-field guidance to athletes for using specific strategies. With the involvement of the coach, athletes may have viewed the mental skills program as a part of training, rather than a separate piece, which may further explain the continued impact. Although stage of change can be a useful evaluative measure, the researchers also suggest that stage of change allows practitioners to distinguish between athletes who are not thinking about using mental skills, are intending to use mental skills in the near future, have made some attempts at using mental skills, and have actively integrated 
mental skills into training. Distinguishing between different stages of readiness would allow SP consultants to use their efforts more effectively by providing stage-matched interventions.

Leffingwell, Rider, and Williams (2001) used the TTM as a framework for addressing collegiate athletes' attitudes and behaviors with regards to SP consultation. The researchers focused on the stages of precontemplation, contemplation, action, and maintenance and measured stage of change with a 32 item questionnaire (8 items measuring each stage). In addition to stage of change, athletes’ decisional balance was measured with a 30 item questionnaire assessing their pros (17 items) and cons (13 items) of participating in mental skills training programs. Lastly, a five item measure was used to assess athletes' confidence to improve mental skills in the presence of various factors (e.g. time, costs, benefits, approval or disapproval by important others).

Results with 308 NCAA Division I athletes revealed stage of change to be related to subsequent participation in psychological skills training. Athletes in the contemplation stage of change were more than twice as likely than those in precontemplation to initiate individual consultation. Athletes in action were three times as likely compared to athletes in precontemplation to initiate individual consultation. With regards to decisional balance, athletes in the precontemplation stage reported higher scores on the cons and lower scores on the pros, while those in the contemplation stage reported significantly higher scores on the pros than all other stages. In addition, a large decrease in cons for engaging in mental skills training occurred from precontemplation to contemplation and remained low through action and maintenance. This continues to support that before action is taken, a crossover in decisional balance occurs in which the pros of making a 
decision outweigh the cons. Furthermore, three of the nine decisional balance items addressed athletes concerns of being stigmatized in which those in the precontemplation stage reported more detrimental consequences for engaging in a mental skills training program. The stigma associated with SP seems to be an important factor for those in the precontemplation stage, which suggest stigma as an area to address in the early stages of change regarding the use of SP services.

Zizzi and Perna (2003) examined the initial impact of a 45-minute workshop with 220 college and high school athletes (7 women’s teams and 7 men’s teams) on stage of change scores. The researchers focused on the precontemplation, contemplation, and action stages of the TTM as well as decisional balance scores. Stage of change was measured with a 12-item Stages of Change for Mental Training questionnaire and decisional balance was measured with a 10-item Decisional Balance for Mental Training questionnaire. The workshop included an overview of several mental skills (e.g. relaxation, imagery, concentration, confidence, and goal setting) and addressed the athletes’ perceptions and stigma associated with SP.

Results revealed a significant impact in stage of change profiles immediately following a workshop. From pre-post workshop, contemplation and pros scores increased, precontemplation and con scores decreased, and no change was observed in action scores. With regards to stage assignments pre to post workshop, 71 athletes (32\%) were found to shift between stages. Twenty-four athletes moved from precontemplation to contemplation, 11 moved from contemplation to action, and 36 moved from action or contemplation to a lower stage. With regards to the negative shift in stage of change assignment, 21 of the 36 athletes originally identified themselves in the action stage prior 
to the workshop. When assessing the pros and cons, an increase in pros (approximately $3 / 4$ standard deviation) and decrease in cons (approximately $1 / 2$ standard deviation) occurred from pre to post workshop. And lastly, athletes' did report that the workshop had a positive impact on their perception and understanding of SP services.

Zizzi and Perna (2003) explained the unexpected negative cognitive shift by suggesting that athletes may have developed a more accurate view of what stage they were actually in. The researchers also suggest that the broad workshop may not have met the specific needs of some of the athletes. However, since athletes reported gaining a better understanding of SP services following the workshop, it is probable that athletes did develop a more accurate view of themselves. Furthermore, the change observed in pros and cons is encouraging. Leffingwell et al. (2001) suggested that addressing stigma may be important in the early stages of change. Thirty five athletes had a positive shift from a lower stage assignment (precontmeplation, contemplation) to a higher stage assignment. This may have been partly due to addressing the stigma associated with SP services. Zizzi and Perna provide some support that addressing the stigma associated with SP can have an impact on athletes’ pros and cons and attitudes toward SP services.

During a one-month follow-up to the workshop, Zizzi and Perna (2002) measured the frequency and type of contacts made by athletes. Teams were randomly assigned to either a "traditional” contact (i.e. phone and in person) or "electronic" contact (i.e. email and web) group. Athletes had access to a free mental skills assessment and additional SP handouts either by setting up a meeting in person ("traditional” contact group) or completing the assessment on the web and getting feedback through email ("electronic" contact group). Results found that $16 \%$ of athletes in the "electronic" group attempted to 
contact a consultant as compared to $6 \%$ of athletes in the "traditional" group.

Additionally, $10 \%$ of athletes in the "electronic" group completed the mental skills assessment as compared to $3.6 \%$ of athletes in the "traditional" group. Overall, the sample preferred using electronic means (e.g. web and email) for contacting a SP consultant as compared to more traditional methods (e.g. phone). This suggests that follow-up interventions may be useful and can be done through a more cost effective approach, such as through email and web pages. Although researchers assessed stage of change profile immediately following the workshop, the researchers did not directly compare SP usage patters across the stages of change at the one-month follow-up. In addition, the $16 \%$ increase in contacting SP services through electronic means is encouraging given that the follow-up intervention was not stage-matched. Using electronic methods (e.g. web and email), it would be useful for future research to assess the impact of stage-matched follow-up interventions on coaches' SP usage patterns (e.g. web visits, email contacts, and phone calls).

In summary, Leffingwell et al. (2001) linked an individual's stage to actual behaviors in SP which provides important evidence for practitioners wishing to increase SP service use and develop interventions with athletes. Zizzi and Perna (2003) provided some evidence toward the ability of a SP workshop to stimulate positive cognitive shifts (e.g. moving forward within the stages of change) as well as changes in pros and cons. In addition to providing support for the effectiveness of a brief workshop, a one-month follow-up intervention found a $16 \%$ increase in contact rate for athletes using electronic methods. Other research has indicated that a mental skills training intervention can have impact over a 3 month period (Grove et al., 1999); however, future researchers should 
continue to investigate if stage of change profiles and pros and cons can be sustained over time. Future researchers should also assess the impact of using electronic methods for providing coach interventions.

The TTM with Coaches and Sport Psychology

Based on previous research with athletes, this model shows promise in providing a theoretical framework for addressing coaches’ attitudes and behaviors toward SP service use. Zakrajsek and Zizzi (2005) examined a subset of track and swimming coaches' stage of change in relation to intentions to use services. Out of the 374 coaches that participated in the study, 161 (43\%) coaches reported access to SP services and 82 of the coaches with access currently had a SP consultant working with their team. Stage of change was measured by using a single-item ladder, as suggested in previous literature with athletes (Grove et al., 1999). Of the 161 coaches who reported access to SP services, $17.8 \%$ were in precontemplation, $22.4 \%$ were in contemplation, $11.2 \%$ were in preparation, $9.2 \%$ were in action, and 39.5\% were in maintenance. Coaches' intentions to contact a SP consultant were found to increase as they progressed through the stages of change (precontemplation, contemplation, preparation, action, and maintenance).

What is interesting is that coaches' intentions to refer athletes for personal or performance related problems did not increase as they progressed through the stages of readiness. Coaches in precontemplation and contemplation did not have intentions to regularly use SP services in the near future; however, they still reported intentions to refer athletes for personal problems. What this suggests is that coaches may still refer an athlete to a SP consultant if they felt they "needed it.” Perhaps spending some time on 
referring athletes could be beneficial during educational programs with coaches, particularly for those in the early stages of readiness.

Application of the TTM concepts with coaches. From previous literature, there are several implications toward the use of the TTM with coaches. First, with regards to measuring stage of change, researchers have expressed different preferences for establishing stage assignments. For instance, Leffingwell and colleagues (2001) prefer using several items for each stage, arguing that it leads to a more accurate assessment of assigning a stage. Several researchers have preferred a simplified approach of using a single item for each stage, in which some argue may add clarity to stage assignments (Cardinal, 1997; Keeler, 2006; Marcus \& Forsyth, 2003; Grove et al., 1999; Zizzi \& Perna, 2003). Marcus, Selby, Niaura, and Rossi (1992) compared using a single item four-stage measure to a single item five-stage measure. The four-stage measure assigned participants to precontemplation, contemplation, action, or maintenance whereas the fivestage measure included preparation. Marcus and colleagues suggest using the five-stage measure because it distinguished between those in preparation and action; therefore providing a more accurate description of the sample. Leffingwell and colleagues (2001) did not include items specific to the preparation stage in their measure; however, that does not mean that individuals in preparation were not present. Because those in preparation are thought to be distinctly different from those in action, it would be worthwhile to be able to assign individuals to the preparation stage in future research. Furthermore, Keeler (2006) questioned whether Leffingwell et al.’s measurement accurately assessed stage of change, in which some maintenance items seemed to actually 
measure relapse. It appears that there is a general consensus toward the accuracy and clarity of using a single item, that includes preparation, for assigning stage of change.

As further evidence toward the validity of stage of change assignments, Zakrajsek and Zizzi (2005) found that 78 coaches were in action and maintenance, which closely resembled the number of coaches who reported currently working with a SP consultant ( $n$ = 82). Using a single item can provide practitioners with a quick and practical assessment of gauging coaches’ readiness to use SP services. Furthermore, it appears that coaches’ readiness to use services may be closely related to current SP service use. Consistent with research with athletes, future researchers wishing to examine coaches’ readiness of SP service use should consider using a single item measure of stage of change that includes the preparation stage. In addition, Zizzi and Perna (2003) suggest that correctly assigning stages may be most accurate when using a combination of decisional balance scores and the single item stage of change.

Second, as coaches’ progress through the stages of change, their intentions to contact a SP consultant increased. Although Zakrajsek and Zizzi (2005) did not measure coaches' use of SP services across the stages of change, literature with athletes found that those in the advanced stages were more likely to initiate individual consultation (Leffingwell et al., 2001). It would be useful for future researchers to assess actual coach behavior (e.g. contacting a SP consultant, initiating SP consultation, referring athletes to a SP consultant) across the stages of change. Based on previous literature, it would make sense that coaches in the advanced stages of change would be more likely to initiate SP service use. 
Third, a shift in pros and cons between precontemplation and contemplation has also been found in previous literature with athletes (Leffingwell et al., 2001). Although not previously assessed, coaches’ perceived gains and losses for using SP services may shift between precontemplation to contemplation or vary over time. Future researchers should explore the potential pros and cons that coaches may consider when deciding to use SP services and how they change through intervention. Although a decisional balance measure has not been developed with coaches, researchers may consider including open ended questions inquiring about reasons why coaches use, or do not use, SP services. Furthermore, researchers could include questions referring to barriers that have been identified by coaches in previous research, such as time, money, access, and knowledge. Identifying pros and cons for using SP services would allow practitioners to tailor information towards the needs of coaches and possibly assist in forward movement along the stages of change.

Fourth, mental skills training workshops have been found to impact athletes' stage of change profiles both immediately and up to three months after the workshop. An increase in pros and a decrease in cons have also been observed following a mental skills training workshop with athletes. Furthermore, a 16\% increase in contact rate was found one month following a SP workshop when athletes were provided with electronic contact information and services. This implies that if a workshop can impact stage of change and pros and cons (e.g. by addressing benefits of SP and stigma associated with SP) then it may also impact subsequent use of SP consultation.

Fifth, researchers have suggested that assessing stage of change can be useful as a form of intake and evaluation of program effectiveness. Using stage of change as a form 
of intake would allow practitioners to create stage-matched interventions. Additionally, assessing a coach's shift in readiness may be a more useful outcome measure of the effectiveness of an educational workshop tailored toward impacting coaches' attitudes and expectations. Traditionally, mental skills training programs have been assessed in a dichotomous manner, which assumes that changes related to the program will be dramatic, obvious, or immediate (Grove et al., 1999). With this in mind, workshops providing "action oriented" information about SP skills (e.g. goal setting, leadership, confidence) to coaches also may assume that coaches' implementation of such skills will occur immediately following the program. However, stage of change assumes that more subtle changes (e.g. changes in attitudes and pros and cons) will precede more obvious ones (e.g. regular use of SP services) in which measuring stage of change and changes in attitudes may prove to be a better indicator of the impact of a workshop.

\section{Attitudes Toward Sport Psychology Consultation}

According to the TTM, attitudinal change is expected to occur before coaches decide to integrate SP into training on a regular basis. In addition, the TTM suggests that educating coaches on the benefits of SP and addressing the barriers to service use would be beneficial in moving coaches toward regular integration of mental skills training into their program. Therefore, in order to apply the TTM to SP service use we must explore current perception and attitude research. Using the TTM as a framework for addressing current perception and attitude research can help practitioners gain further insight into tailoring interventions toward impacting motivational readiness. Athletes’ Attitude and Intentions to Use Sport Psychology 
Measuring attitude. Previous literature has primarily relied on qualitative means toward understanding attitudes and the possible relationship between perceptions and help-seeking behavior. By looking into counseling psychology literature and perception research in sport, efforts have recently been extended toward developing a theoretically driven and valid assessment of athletes' attitudes toward SP consultation (Martin, Kellman, Lavallee, \& Page, 2002; Martin, Wrisberg, Beitel, \& Loundsbury,1997). Through the use of exploratory and confirmatory factor analysis with 1500 athletes from the United States, United Kingdom, and Germany, Martin and colleagues (2002) developed the Sport Psychology Attitudes- Revised (SPA-R) questionnaire. The SPA-R is a 25-item questionnaire that encompasses four-factors associated with athletes' attitudes toward SP: stigma tolerance (expected negative consequences of seeking SP consultation), confidence in SP consultation (belief that SP consultation and mental training are useful), personal openness (willingness of respondent to seek help and discuss concerns with others), and cultural preference (individual's identity to his/her own nationality, ethnicity, culture, or race). Internal consistency (Chronbach alpha) and test-retest reliability estimates were found to be adequate to good and the SPA-R has been found to be a robust and stable measure across groups and countries of athletes' attitudes toward seeking SP consultation. Although the SPA-R was not directly linked with use of SP services, Martin and colleagues (2002) suggested the instrument could assist consultants in measuring and understanding athletes' interest, receptiveness, and confidence in using SP services as well as athletes' tolerance of a SP consultant's personal characteristics. 
Understanding attitudes. Researchers have since used the SPA-R to further understand athletes’ attitudes as well as how several characteristics (e.g. gender, age, previous experience, cultural identity, and sport type) influence attitudes and possible SP service use. Martin, Lavallee, Kellmann, and Page (2004) surveyed 811 male and female adult athletes (ages 18-27) to understand attitudes toward SP consulting. A total of 404 athletes were from the United States, 147 athletes were from the United Kingdom, and 260 athletes were from Germany. Although the effects were small $\left(\eta^{2}=.04\right)$, results revealed significant differences with regards to nationality and attitude toward SP consulting. Athletes from the United States were more likely to associate a stigma with seeking SP consulting compared to athletes from the United Kingdom and Germany. Athletes from the United Kingdom also reported being more confident in SP consulting and were less likely to identify with their own nationality, ethnicity, or race compared to athletes from the United States and Germany.

Several other personal characteristics (e.g. previous experience, gender, and sport type) were found to have an impact on athletes' attitudes toward SP consulting. Out of the 811 athletes, 128 (16\%) had seen a SP consultant at least once. Compared to athletes with SP consulting experience, athletes who had no previous experience were less confident about SP consulting and associated a greater stigma toward seeking SP consultation. Differences in attitude were also found between gender and stigma, personal openness, and cultural preference. Male athletes were more likely to stigmatize SP consulting and were less willing to seek assistance (personal openness) compared to female athletes. Male athletes also identified more with their own culture, ethnicity, or 
race compared to female athletes, which may suggest that males are less accepting of others compared to females.

Of the sample, 360 athletes participated in physical contact sports (e.g., American football, baseball, basketball, boxing, net ball, rugby, soccer, softball, and wrestling) and 451 athletes participated in physical non-contact sports (e.g., golf, gymnastics, rowing, swimming, tennis, track and field/cross country, and volleyball). Although the magnitude was low, Martin et al. (2004) found that athletes' attitudes from the United States may be influenced by type of sport (e.g. physical contact vs. physical non-contact). With regards to athletes from the United States, those that competed in physical contact sports were more likely to associate a stigma with seeking SP consulting compared to physical noncontact sports. Interestingly, athletes from the United States in physical contact sports may also hold a more negative view of SP consulting compared to athletes in physical contact sports from the Untied Kingdom and Germany.

Using the SPA-R, Anderson, Hodge, Lavallee, and Martin (2004) sampled 112 elite athletes from New Zealand and found that overall, athletes’ attitudes were generally positive toward SP. On a Likert-type scale ranging from 1 (strongly disagree) to 7 (strongly agree), athletes’ stigma tolerance score was low $(M=2.00, S D=.08)$ which suggests that a negative stigma was not associated with working with a SP consultant. Confidence $(M=5.2, S D=0.9)$ and personal openness $(M=3.7, S D=1.1)$ scores revealed that athletes were confident in SP consultation and generally open to using SP services. Cultural preference $(M=3.9, S D=1.5)$ scores revealed that athletes identified with their culture and expressed some preference toward working with a SP consultant from the same cultural background. Anderson and colleagues also looked into the impact 
of several characteristics (e.g. gender, previous experience, competition level, and age) on New Zealand athletes' attitudes. Results with gender revealed that female athletes had a more favorable attitude toward SP. Specifically, female athletes were more open to SP and more confident in the usefulness of SP consultation compared to male athletes. Compared to those who had no previous experience with SP consulting, athletes who had worked with a SP consultant revealed higher confidence in SP consulting and a lower stigma toward SP. Age and competitive level were both found not to influence athletes’ attitudes toward SP consulting.

Anderson and colleagues (2002) compared their results with data collected by Martin et al. (2004) with athletes from the United States, United Kingdom, and Germany. Athletes from both studies were of the same competitive level. Results from the comparison revealed that New Zealand athletes had an overall more positive attitude toward SP. Athletes from New Zealand were found to have a lower stigma associated with SP, were more open to SP services, more confident in SP consulting, and more strongly identified with their culture compared to athletes from the United States, United Kingdom, and Germany.

Using the SPA-R, Martin (2005) surveyed 793 high school and collegiate athletes’ to further understand attitudes toward SP consulting. Results revealed significant differences in the following athlete characteristics and attitudes toward SP consulting: previous experience, gender, age, and type of sport. With regards to previous experience, athletes who had previously worked with a SP consultant were more likely to be confident in SP consulting and associated a lower stigma toward working with SP services. When examining differences in gender, male high school and collegiate athletes 
were more likely to stigmatize SP consulting and identified more with their own culture, ethnicity, or race compared to female high school and collegiate athletes. This suggests that female athletes may be more accepting of cultural backgrounds other than their own. When comparing high school and collegiate athletes, results revealed that high school athletes were more likely to associate a stigma toward SP consulting compared to college athletes. Although the magnitude of the effect was low $\left(\eta^{2}=.02\right)$, differences were found between physical contact and physical non-contact sports. Those in physical contact sports, especially wrestling and football, were more likely to associate a stigma to SP consulting compared to physical non-contact sports.

Summary and characteristics that impact attitudes. As suggested by Martin et al. (2002), it is clear that the SPA-R has the potential to assist practitioners in understanding if athletes are interested in mental skills, open to SP, confident in the abilities of the SP consultant, and tolerant of personal characteristics. Additionally, the SPA-R has been useful in understanding cross cultural and gender differences in attitude as well as differences in sport type, age, and those with and without SP experience. Some general patterns from the literature have emerged that would be important to highlight. For instance, athletes who had previously worked with a SP consultant at least once consistently report being more confident in SP consulting and associating a lower stigma with working with a SP consultant (Anderson et al., 2004; Martin et al., 2004; Martin, 2005). It appears that previous exposure to SP is more likely lead to a more positive attitude and less concern about seeking help from SP services (Martin et al., 2004). This supports previous literature in which elite athletes that had worked with a SP consultant were found to rate the consultant favorably and the majority of athletes were interested in 
retaining the SP consultant’s services (Gould, Murphy, Tammen, \& May, 1991).

Furthermore, Keeler (2006) found that $56 \%$ of athletes who contacted a mental skills trainer had previous experience with SP services. It appears that previous experience, especially a positive one, is related to a more positive attitude as well as future work with a SP consultant.

When it comes to previous experience, access may be a large contributing factor to services use. Anderson et al. (2004) found that the majority (65\%) of elite New Zealand athletes had used SP services at least once, whereas Martin (2005) and Martin et al. (2004) reported only 15 and 16 percent. New Zealand athletes may be different then athletes from the United States, United Kingdom, and Germany. However, Anderson and colleagues' sample of athletes were from the New Zealand Academy of Sport, in which the authors stated that sport academies typically include sport science within their services. Therefore, SP consultants may have been more easily accessible and viewed as part of the sport environment to Anderson and colleagues sample compared to others. Using the TTM as a framework, it appears that it may be useful for programs to educate athletes and coaches without experience, or in the early stages of readiness, with regards to gaining access to SP services. In addition, it may prove useful to promote gaining access without athletes and coaches putting in a large amount of “extra” effort to do so. And lastly, it may be helpful to promote SP as services that are an integral part of the sport environment instead of something “extra” or “outside.”

With regards to gender and attitude, female athletes have been consistently found to have a more favorable attitude toward SP compared to male athletes. Research reports that male athletes are more likely to stigmatize SP consulting, are more likely to attempt 
to work things out on their own before seeking assistance (personal openness), and are less confident in the usefulness of SP consultation compared to female athletes. Additionally, male athletes were found to identify more with their own culture, ethnicity, or race, suggesting that female athletes may be more accepting and tolerant of ethnic or cultural backgrounds different then their own. These findings are consistent with previous literature suggesting that male athletes may be less open and more apprehensive to seek SP consultation (Yambor \& Connelly, 1991). Differences between males and females attitude toward SP consultation have been explained through gender role socialization in sport (Curry \& Strauss, 1994; Good \& Wood, 1995; Messner, 1992; Nixon, 1996; Yambor \& Connelly; 1991). Negative perceptions of SP consultants may form due to the "macho" dimension of sport participation, in which male athletes may view selfdisclosure as a sign of weakness and vulnerability; therefore, their masculine image may be viewed as being jeopardized (Good \& Wood, 1995; Seller, 1993; as cited in Martin et al., 1997; Yambor \& Connelly, 1991).

The type of sport athletes are socialized in may also be a contributing factor in attitudes toward SP consulting. Martin (2005) found that athletes participating in physical contact sports, especially football and wrestling, were more likely to stigmatize SP consulting compared to those in physical non-contact sports. However, given the small effect size $\left(\eta^{2}=.02\right)$, caution must be noted with regards to the meaning of this impact on SP service use. Furthermore, Martin et al. (2004) did not find a significant difference between physical contact and non-contact sports with athletes from the United States, United Kingdom, and Germany. It is interesting to note that when comparing the descriptive statistics, athletes in the sports of football and wrestling showed the greatest 
stigma toward SP consulting. When separating athletes' attitudes and type of sport by country, athletes from the United States that competed in physical contact sports were found to be significantly more likely to stigmatize SP consulting compared to all other groups. But again, the low effect size $\left(\eta^{2}=.01\right)$ makes it difficult to conclude a meaningful impact on SP service use. Although small effects were found, future researchers should still consider the possible link between type of sport and attitudes toward SP consulting. Like gender, it can be argued that type of sport may also be related to socialization in sport. Physical contact sports, especially American football, may display more of the masculine ideals. If that is the case, it would make sense that athletes participating in contact sports, especially the sports of football and wrestling, would be more likely to stigmatize SP services compared to physical non-contact sports.

Results with age have been mixed. Martin (2005) found that high school athletes were more likely to associate a stigma toward SP consulting compared to collegiate athletes whereas Anderson and colleagues (2004) found no significant difference in attitudes between athletes 19 years or younger and athletes 20 years or older. However, given the low effect size $\left(\eta^{2}=.02\right)$, the difference found between high school and collegiate athletes may not be meaningful. Furthermore, the low effect size may suggest that Martin (2005) found significant differences given the large sample size of 793 athletes compared to Anderson and colleagues (2004) sample of 112 athletes. Although results did not reach significance, Anderson and colleagues descriptive statistics show that athletes 19 years or younger reported greater stigma associated with SP consulting compared to athletes 20 years or older. With regards to competitive level, Anderson and colleagues (2004) did not find a difference in attitudes between World Class, 
International, Developmental, or Junior athletes. Although athletes were of different classification levels, athletes included in the sample were all considered at the elite level. Elite level athletes, regardless of classification, may have more opportunity to work with a SP consultant or have been exposed to SP consulting in the past and; therefore, may have more favorable attitudes toward SP. Since previous experience is related to more favorable attitudes, it would make sense that athletes at the high school level may stigmatize SP consulting more given the less opportunity for SP exposure. Further research is warranted before firm conclusions can be made regarding the impact that age and competitive level may have on attitudes. Since previous research has focused attention on elite level athletes, future research may want to consider understanding attitudes of athletes at various competitive levels with various degrees of access to SP (e.g. youth, high school, collegiate, professional, etc.).

From the results of the SPA-R literature, it is suggested athlete characteristics may influence how SP consultants introduce mental skills training and work with different groups, especially with those early in the stages of change. Martin et al. (2004) suggested that SP consultants may want to approach mental skills training differently with male athletes, especially those from physical contact sports that emphasize masculinity. For instance, researchers suggested introducing the concepts of mental training as "mental toughness strategies” or "performance enhancement” because these phrases may be more attractive to male athletes compared to "sport psychology skills." This is consistent with Maniar et al. (2001), in which student-athletes preferred consulting with professionals that had no reference to psychology (e.g. performance enhancement consultant). Additionally, Martin (2005) suggested targeting athletes by 
reframing services as educational or as performance enhancement and providing information on what SP is, how SP consulting works, what is expected from the client, and what should be expected from the SP consultant.

Using theory to predict athletes' intention to use sport psychology. To further our insight into the meaningfulness of athletes' attitudes, researchers have taken steps toward using theory to link attitudes with intention to use SP services. Greaser (1992) utilized Fishbeing and Ajzen’s (1973; as cited in Greaser, 1992) expectancy value model which argues that a person's behavioral actions are considered to be related to the expectations the person holds and the subjective consequences that might occur following the action. Therefore, the more favorable an athletes' attitude and subjective norm (e.g. perceived social pressure to perform the activity) the stronger the intention is thought to be to practice and use mental skills. Using this approach to predict behavior, 76 collegiate athletes completed a 22-item questionnaire developed to assess the effect that attitude and subjective values have upon the decision to practice mental skills. A multiple regression analyses revealed that athletes’ attitudes and beliefs about SP influenced their behavioral intentions to practice mental skills. Compared to athletes with low intentions, athletes possessing high intentions to practice mental skills believed more strongly that SP would positively impact performance. When examining the normative considerations, athletes with higher intentions believed there was strong approval for using SP skills by significant others (e.g. coach, teammates). In addition, the attitudinal predictor contributed more to the regression equation compared to the subjective norm factor. Some caution must be noted as to the meaning of these results given the small sample size with a multiple regression analysis. However, results do provide some initial insight 
into the impact of attitudes in SP, in which providing information regarding the benefits of mental skills training may prove beneficial toward increasing confidence and intentions to use SP skills. Because coaches may have an impact toward athletes’ intentions to use SP skills (e.g. approval; perceived normative expectations), providing coaches with the benefits of mental skills training may also prove beneficial toward increasing SP service use with athletes.

Anderson, Hodge, Lavallee, and Martin (2004) used the SPA-R to investigate the relationship between elite athletes' attitudes toward SP and intentions to use SP services within the Theory of Reasoned Action and Theory of Planned Behavior. The Theory of Reasoned action suggests that attitudes toward a behavior and subjective norm influence intentions to engage in a specific behavior. With regards to attitudes, the Theory of Reasoned action postulates that the attitudes held about SP will subsequently affect intentions to use SP services. For instance, someone with a more positive attitude (e.g. believe that working with a SP consultant will lead to a positive outcome) will have stronger intentions to seek assistance form a SP consultant. Subjective norm can be described as an individual's perception regarding the social pressures to engage in a behavior, which involves considering the normative expectations of important others (Ajzen, 2002). Therefore, it is suggested that if an athlete values the coaches' opinion and the coach approves of SP service use, then the athlete would have higher intentions toward using services. The Theory of Planned Behavior incorporates perceived behavioral control, which includes beliefs about factors that may help or hurt performing the behavior and the belief in ability and control in executing a behavior (Ajzen, 2002). For instance, intentions and actual use of SP services may be impacted by the perceived 
ability to access and use SP services as well as the perception or belief that mental skills can or cannot be changed.

Anderson and colleagues (2004) surveyed 112 elite athletes from New Zealand using the SPA-R and measures of subjective norm, perceived behavioral control, and intentions to use SP services within the next 12 months. Results of a regression analysis revealed that confidence in SP consulting, subjective norm, and perceived behavior control independently predicted intentions and accounted for $39.7 \%$ of the variance in athletes' intentions to use SP services. Subjective norm was found to be the strongest predictor, followed by confidence in SP consulting, and perceived behavioral control. From an applied standpoint, it appears that measuring attitudes can provide practitioners with useful information toward intentions to use services, with specific attention toward subjective norm and confidence in SP consulting. Because athletes’ perceived access and confidence in overcoming barriers to SP service use were influential in predicting intentions, Anderson and colleagues (2004) suggested that practitioners should address barriers such as time, money, and access to SP consultants. Similar to Greaser, the findings in this study also appear to support that important others and the belief in SP contributed significantly to athletes’ decisions and intentions to use SP services. Coaches’ Attitudes and Intentions to Use Sport Psychology

Research with coaches and attitudes is not as well developed as that with athletes, in which research has primarily involved qualitative approaches in gauging coaches’ perceptions and attitudes toward SP services. Although qualitative approaches are useful, Zakrajsek and Zizzi (2007) were interested in developing a quantitative means of understanding coaches' attitudes toward SP consulting. Because it makes sense that 
tapping into coaches' attitudes would be developed from a similar theoretical framework as athletes’ attitudes, Zakrajsek and Zizzi modified the SPA-R for coaches. No items were deleted from the SPA-R and revisions included keeping 13 items and modifying 12 items in order to more accurately tap into coaches' attitudes instead of athletes. For instance, “I think a sport psychology consultant would help me perform better under pressure” was modified to "I think a sport psychology consultant would help my team perform better under pressure.” With the purpose of improving reliability of responses (Dillman, 2000; Gilljam \& Granberg, 1993), the researchers omitted the neutral option and modified the 7-pont scales to a 6-point scale. When measuring attitudes, Gilljam and Granberg (1993) found that the “don’t know” category included responses by individuals that really have attitudes but avoid expressing them.

Exploratory factor analysis with the 25 items was performed with 374 track and swimming coaches to identify item clusters that correspond to specific attitudes of coaches toward SP consulting. Results revealed a three-factor solution of coaches’ attitudes accounting for $45 \%$ of the total response variance: stigma tolerance (7 items); confidence in SP consultation (8 items); and personal openness (6 items). All items were assigned to the same scales as used by Martin et al. (2002) with the SPA-R. The four cultural preference items of the SPA-R did not uphold in the exploratory factor analysis procedures with swimming and track coaches. Coefficient alphas of .84 (stigma tolerance), .80 (confidence), and .63 (personal openness) showed similar estimates as those found in the SPA-R. In sum, validity and reliability estimates demonstrated initial support for the questionnaire with the exception of less than desirable internal consistency in the personal openness subscale. The Sport Psychology Attitudes-Revised 
Coaches (SPA-RC; Zakrajsek \& Zizzi, 2007) form is a 21-item questionnaire assessing coaches' attitudes toward SP consulting on three subscales: stigma tolerance, confidence in SP consulting, and personal openness. Higher scores on the subscales (closer to 6) indicate a more negative attitude toward seeking consultation (stigma tolerance), a stronger belief that mental training is useful (confidence), and an unwillingness to be involved in SP consultation and mental training (personal openness)

Using the SPA-RC, track and swimming coaches were found to have relatively favorable attitudes toward SP consulting. On a scale from 1 (strongly disagree) to 6 (strongly agree), track and swimming coaches reported low stigma associated with SP consulting $(M=1.62 ; S D=.66)$, were slightly to moderately confident in SP consulting $(M=4.40 ; S D=.73)$, and were slightly open to using SP service and mental training ( $M$ $=3.15 ; S D=.83)$. With regards to gender, female coaches $(n=74)$ reported less stigma toward SP consultation and were more open and willing to work with SP consultants compared to male coaches $(n=278)$. Although differences were not explored between those with and without previous experience, small correlations were found between previous experience and stigma tolerance, confidence in SP consulting, and personal openness, all in the expected directions. Though conclusions cannot be drawn, this provides some initial speculation that differences may exist with previous experience and coaches' attitudes.

Although the effect size with gender differences and attitude were small, this is consistent with previous literature with athletes (Anderson et al., 2004; Martin, 2005; Martin et al., 2004) and provided some evidence that gender differences in coaches’ attitudes may exist. Perhaps male and female coaches experience the same gender role 
socialization found with athletes and nonathletes. While consulting with a football coach of a Division I intercollegiate football program, Anshel (1989) explored the coach’s acceptance of SP. Statements such as “these guys don’t need this stuff” imply the "macho" dimension of the sport and the perception that SP is for the weak and vulnerable. On the other hand, a female head coach, Pat Summit, sought out the expertise of a SP consultant to mentally prepare her female basketball team prior to big games (Wrisberg, 1990). Caution must be noted to generalizing such reports to other coaches and it is evident that research regarding gender differences in coaches’ attitudes toward SP consultation is limited. As the first study to assess gender differences in coaches, Zakrajsek and Zizzi (2007) provided some initial insight into male and female coaches’ attitudes toward SP consulting. A more balanced sample of female and male coaches would also be helpful toward drawing conclusions regarding gender differences in coaches' attitudes and its impact on service use.

Literature is rather limited in terms of understanding the impact of coaches’ previous experience on attitudes and has often involved qualitative studies with elite level coaches who may have more access to SP services. Out of 17 Canadian Olympic Coaches surveyed, Partington and Orlick (1987) found that those who felt most negative toward SP services were the two coaches with no prior experience. Conversely, the 15 coaches with previous experience had a favorable perception toward, and valued the work of a SP consultant. Gould and colleagues (1991) found that coaches who worked with a U.S. Olympic SP consultant rated the consultant favorably and most coaches would retain the consultant for future work. Although research with previous experience has its 
limitations, there appears to be some support that coaches who have worked with a SP consultant may hold favorable attitudes toward SP consulting.

Zakrajsek and Zizzi (2007) did not explore differences between coaches with and without previous SP experience; however, the researchers did find small correlations between previous experience and the SPA-RC subscales. In order to draw better conclusions, future researchers should consider directly assessing the impact of coaches' previous experience on attitudes toward SP consulting. Furthermore, future researchers need to consider how to define previous experience. Zakrajsek and Zizzi defined previous experience differently than previous literature with athletes. Research with athletes assessed previous experiences with regards to if athletes had seen a SP consultant at least once before. Zakrajsek and Zizzi defined previous experience more broadly to include coaches who have previously worked with a SP consultant at least once, attended a workshop on SP, read literature on SP, or actually implemented psychological training into practice. Perhaps limiting previous experience only to those coaches who have used SP services in the past would provide different results. With the limited amount of research available future researchers need to continue assessing, through quantitative means, how previous experience impacts coaches’ attitudes towards SP and subsequent service use.

Cultural preference was the only factor not upheld in the exploratory factor analysis of the SPA-RC. This result is not consistent with previous literature with athletes that suggests an individual's identity to his or her own nationality, ethnicity, culture, or race may influence perceptions and attitudes toward seeking SP consulting (Anderson et al., 2004; Martin, 2005; Martin et al., 2002; 2004). Compared to those who identified 
with the broader American culture, those who held strong cultural affiliations were found to be less favorable toward seeking professional help (Atkinson \& Gim, 1989).

Furthermore, some individuals have been found to prefer working with instructors, counselors, and coaches that are ethnically and racially similar (Anshel, 1990; Atkinson \& Lowe, 1995; Kennedy, 1994). What may be different with coaches is that they work with athletes from a variety of backgrounds and may not hold a strong preference for the SP consultant to be more similar to him or herself (Zakrsjek \& Zizzi, 2007). If this is true, measuring a coaches' cultural preference may not be necessary as one of the primary aspects of assessing attitudes toward SP consulting. However, Zakrajsek and Zizzi also suggest that cultural preference items may not have upheld because a coach may be more likely to take the athletes' cultural preference into consideration rather than his or her own. Perhaps asking coaches questions related to hiring a SP consultant more closely related to their athletes would be beneficial. Further exploration is needed before firm conclusions can be made regarding the impact that a coaches’ cultural, ethnic, or racial identity has on attitudes and subsequent use of SP services.

In conclusion, it appears that the SPA-RC has the potential to provide useful information toward understanding coaches' interest in mental skills training, openness to use SP services, and confidence in the abilities of a SP consultant. The SPA-RC may also be a tool to further understand if coach characteristics, such as gender, previous experience, and sport type influence attitudes toward SP service use. Clearly, more research is needed regarding coaches' attitudes toward SP consultation, especially with coaches from a range of sports. 
With the central role that coaches hold in the athletic environment, Zakrajsek and Zizzi (2007) were interested in developing an exploratory model of service use to understand coaches’ intentions. Based on previous literature with athletes and coaches, Zakrajsek and Zizzi took a multidimensional approach to studying the impact that various variables (e.g. attitudes, expectations, previous experience, and gender) may have in predicting coaches' intentions to use SP services. The same sample of 374 track and swimming coaches’ mentioned earlier completed measures on attitudes (SPA-RC), expectations, previous experience, intentions, and demographics. Results of a regression analysis provided initial support for an exploratory model of service use in which confidence in SP consulting, stigma tolerance, and expectations significantly predicted intentions and accounted for 38\% of the variance in coaches' intentions to use SP services. Confidence in SP consulting was found to be the most significant predictor and controlled for substantially more variance (34\%) in predicting coaches’ intentions as compared to stigma tolerance (3\%) and expectations (1\%). The researchers suggested that a more holistic approach should be taken by applied SP consultants during initial meetings with coaches or when providing educational workshops for coaches. More specifically, the researchers suggested practitioners to spend most of their efforts toward increasing coaches' confidence in SP consulting.

In addition, SP consultants may want to spend some time addressing misperceptions about SP, especially to male coaches in physical contact sports. Believing that SP would have a positive impact on performance has been linked to higher intentions to use SP services (Greaser, 1992). Some coaches may be reluctant to using SP because 
the benefits of SP, in terms of actual performance, may be difficult to prove (Pain \& Harwood, 2004). Other coaches have expressed a fear that SP won't work and their athletes would perform badly because they were thinking too much about their game (Haslam, 2004). Some coaches and universities may not consider SP essential, beneficial, or a top priority (Voight \& Callaghan, 2001, Haslam, 2004). This lack of trust and skepticism on the usefulness of SP, and not prioritizing SP into training, clearly relates to the perceived value of SP services and is a barrier that continues to contribute to coaches' resistance to service use. Addressing perceptions, such as confidence, stigma, and expectations may help to decrease the skepticism and increase the value of SP. Using the TTM as Framework for Addressing Coaches' Attitudes

Previous research has linked athletes and coaches stage of motivational readiness with intentions and actual behaviors with SP service use (Leffingwell et al., 2001; Zakrajsek \& Zizzi, 2005). Furthermore, coaches and athletes with more positive attitudes have been found to have stronger intentions to use SP services. Therefore, it would make sense to apply the attitude research reviewed above toward tailoring services and educational programs to target attitude change and thus attempt to increase intentions and motivational readiness to use SP services.

From the literature, attitudinal variables that SP practitioners may want to address with coaches earlier in their motivational readiness to use SP services include building confidence (e.g. benefits) and decreasing the stigma associated with SP consulting. Attitudes such as subjective norm and control beliefs may also be applied to coaches' readiness to use SP services. With regards to subjective norm, coaches may be more likely to hire a SP consultant if they perceived positive social pressure from others (e.g. 
athletic director, other coaches, institution, national governing body). Furthermore, coaches’ belief that other, similar coaches, use SP services may also be a contributing factor. Support and encouragement from others and the belief that other coaches utilize SP services may be beneficial given that SP and mental skills training are not a traditional aspect of coaching.

Perceived behavioral control has also been found to predict athletes' intentions (Anderson et al., 2004) and may be another area that influences coaches' readiness to use SP services. Lack of funding, access, and time constraints are consistently reported in the literature as some of most common reasons why coaches and universities do not utilize mental skills training or SP services (Anshel, 1989; Gould et al., 1999; Gould, Tammen, Murphy, \& May, 1989; Haslam, 2004; Kremer \& Marchant, 2001; Pain \& Harwood, 2004; Rice, 1996; Voight \& Callaghan, 2001). Addressing access and availability of a SP consultant, as well as other barriers such as time and money, may help to target areas related to perceived behavioral control and increase service use.

Previous literature has found that a large percentage of coaches (approximately 80\%) surveyed do not use SP services (Rice, 1996; Zakrajsek \& Zizzi, 2007). Access may play a role in this; however, previous literature has found that only about half of the coaches who have access use some form of SP service (Zakrajsek \& Zizzi). Therefore, standard educational programs and interventions that are geared toward coaches in action may not be as useful for the majority of coaches. If we are attempting to increase service use in SP then there needs to be educational programs that target attitudinal change and geared toward those coaches earlier in the stages of change.

Coach Education 


\section{Current State of Coach Education}

Currently, there are at least 179 colleges and universities that offer coaching education programs (148 undergraduate minors, 10 undergraduate majors, and 21 master's degree programs) in the United States; however, these programs have yet to be standardized (McMillin \& Reffner, 1999). This lack of standardization has left the authority up to each college and university for developing the content of their program, in which requirements may vary by institution making it difficult to determine the quality of current coach education programs. For instance, the 21 master's degree programs that are offered are so varied in their requirements that McMillan and Reffner were unable to provide general observations regarding the status of the programs. The limited number of programs that offer undergraduate majors or graduate degrees in coach education further enhances the fact that having a four year degree or graduate degree in coach education is not necessary to pursue a professional career as a coach.

Gould, Giannini, Krane, and Hodge (1990) studied the educational backgrounds and perceived educational needs of elite level coaches. A total of 130 Olympic, Pan American, and national team coaches participated in the study. Approximately $80 \%$ of coaches had at least a 4-year degree. More specifically, 15\% of coaches indicated that they had a high school diploma, 6\% had a junior college degree, 32\% had a bachelors degree, 38\% had a masters degree, and 8\% had a doctorate degree. Out of the 101 coaches with a college degree, 47 had a degree in physical education and/or recreation, 23 had a minor in coaching, and 56 coaches reported having a college course in coaching. It is evident that, even at the elite level, coaches’ educational background is varied and often does not include a degree in coaching. 
The issue of coaching standards and education has been in existence for well over 20 years (Cohen, 1992). To increase awareness in the importance of proper training of coaches, the American Coaching Effectiveness Program (ACEP) was developed and has been recognized as one of the major coaching education programs in the U.S. (Partlow, 1992). The ACEP curriculum is a multilevel program that defines coaching education as more comprehensive than just techniques and tactics to include other areas such as SP, sport physiology, sport management, and sports medicine. Other coaching education programs, such as the Program for Athletic Coaches’ Education (PACE) and those created by the National Youth Sports Coaches Association (NYSCA), have also been developed as a comprehensive program to prepare qualified coaches. Although the efforts of ACEP, PACE and the NYSCA are encouraging, these programs have been around for some time and the country has yet to come to a consensus as to what exactly are the minimum standards for various levels of coaches. For instance, states and sport organizations may recommend or require coach certification; however, these requirements differ between states and sport organizations, resulting in a lack of consistency on what standards or program should be followed.

Because coach education is so scattered in the U.S., the National Association for Sport and Physical Education (NASPE) recently developed the National Standards for Sport Coaches (NSSC, 2006) which standardizes the skills and knowledge that can be expected of coaches at various levels of competition. Experts from the national governing bodies of sport, the United States Olympic Committee (USOC), National Federation of State High School Associations (NFSHSA), and NASPE leadership all worked together to review and revise the standards for coaching. Applicable across all sports and levels, 
these standards will help to ensure that coaches have the qualifications necessary to coach athletes and it is hoped that coaching education programs will construct curriculum for training based on these accreditation standards of practice. The NSSC encompasses 40 standards grouped into 8 domains: philosophy an ethics; safety and injury prevention; physical conditioning; growth and development; teaching and communication; sport skills and tactics; organization and administration; and evaluation. Principles within SP are weaved throughout the domains rather than identified as separate, showing that the mental and physical aspects of sport are integrated.

The coaching literature has recognized the need to develop coach education programs that balance technical and tactical knowledge with other areas such as SP (Cale \& Crisfield, 1994; Cassidy, Potrac, \& McKenzie, 2006). Currently, the SP training across coach education programs at colleges and universities is not clear. The colleges and universities that do follow the National Standards for athletic coaching (e.g. NASPE) do integrate SP principles and concepts within their curriculum. However, we cannot assume that SP is integrated into those programs that do not follow the National Standards for athletic coaching. In addition, some sport organizations may offer the opportunity for coaches' to learn SP skills; however, SP development is not a mandatory requirement in all certification programs. Because education in SP is, in some cases, a voluntary aspect of coach development, we cannot assume that organizational value has been placed on the usefulness of SP services within sport. With the continued attention and efforts toward developing standards and comprehensive education programs, it appears that coaching education is moving in a positive direction. However, SP professionals cannot 
assume that coaches place value on SP and see SP as an integral part of training because it may not be happening during their educational development.

A New Approach to Coach Education in Sport Psychology

Because the majority of coaches do not receive formal training (e.g.

undergraduate or graduate degree) in coaching education, providing workshops, clinics, or seminars may be an effective means for SP professionals to reach a larger population of coaches. Out of 130 elite level coaches, Gould et al. (1990) found that $97 \%$ of the coaches indicated that attending clinics, lectures, and seminars contributed to their knowledge about coaching. Furthermore, coaches are interested in attending courses and workshops about SP. Sullivan and Hodge (1991) found that out of 46 national coaches surveyed, 56.5\% had attended clinics/courses in SP. Out of 20 junior tennis coaches, Gould, Damarjian, and Medbery (1999) found that 13 had taken a SP course. It is clear that coaches are interested; however, despite taking a course or workshop in SP, 73 percent of coaches reported that they did not feel they had adequate knowledge of SP (Sullivan \& Hodge, 1991) and feel most knowledgeable in the skills and strategies of their sport (Gould et al., 1990).

Working within a cognitive-behavioral framework, Smith, Smoll, and Curtis (1979) designed workshops to impact coaching behaviors and create a healthy psychological environment for young athletes. Coaching Effectiveness Training (CET) is an intervention program that is geared toward making cognitive changes (e.g. awareness of coach behaviors) in efforts to promote positive changes in behavior (e.g. comply with coaching guidelines). Thirty one little league baseball coaches were randomly assigned to an experimental or no treatment group. Coaches in the experimental group went through 
a CET workshop regarding behavioral guidelines that promote a socially supportive environment for young athletes. Results revealed that coach behaviors in the experimental group were more consistent with the behavioral guidelines and they were evaluated more positively by their players as compared to the control group. Results of this study provide evidence toward the effectiveness of cognitive-behavioral interventions leading to overt behavioral changes. Few programs are evidence based and future research should continue to examine the effectiveness of workshops with cognitive interventions in creating future positive behavior changes in SP service use.

Working within the TTM may be useful for developing coach education programs, which supports the use of cognitive strategies focusing on attitude change that lay the groundwork for future action. Only about 20\% of coaches surveyed in the literature reported using some form of SP services (Zakrajsek \& Zizzi, 2007); however double (approximately 40\%) had access. Perhaps the majority of coaches are not yet ready to regularly use SP services and SP professionals may benefit from concentrating more on cognitive and affective strategies (e.g. impacting attitudes) in order to impact forward movement toward readiness to use SP services. From the literature, several attitudinal variables have been identified that may impact coaches' use of SP services. Specifically, practitioners may want to focus on anecdotal and empirical evidence of the value and benefits of SP consulting. In addition, it may prove beneficial to address coaches' concerns of the stigma associated with SP and misperceptions of SP consulting. Decreasing barriers (e.g. time), increasing perceived behavioral control (e.g. perceived access), and identifying the perception that SP services are used by coaches they respect may also warrant attention. Impacting attitudes through educational workshops may 
subsequently impact readiness to use and integrate SP services into the coach's program. Measuring coaches’ attitudes, perceived barriers, and readiness to use SP services may also be a useful tool toward understanding the impact of an educational workshop. Stage of change allows practitioners to distinguish between coaches who are not thinking of using SP services, intending to use SP services in the near future, have made some attempts to using SP services, and have actively integrated SP services into the program. Therefore, it may also be useful to apply follow-up intervention strategies with coaches tailored toward their stage of change in order to maximize impact of the intervention. Often coaches may receive information about the "menu" of SP services that can be offered to their program. However, this “action” oriented approach may be less effective with the majority of coaches. Literature with exercise behavior provides evidence toward written self-help material as a cost-effective means of stage of change interventions.

It may be worthwhile to assess if self-help material could be a cost-effective means of reaching coaches at different stages of readiness to use SP services. The ability to reach a large number of coaches and potentially make an impact could be particularly useful with the current number of AASP certified consultants. Self-help material tailored toward coaches in precontemplation and contemplation may devote more attention toward the importance of mental skills training and increasing the pros of using SP services by providing anecdotal or empirical accounts of the benefits of SP consultation. Additionally, it would be worthwhile to work on decreasing barriers by addressing the misperceptions about SP and concerns of the stigma associated with SP. Other barriers such as time, funding, and access could also be addressed as well as techniques to increase the coach’s self-efficacy to access and use SP services with the program. 
Coaches in preparation and action may benefit from spending more time on information regarding how the process of SP consulting works and expectations about the role of the coach and SP consultant. Information regarding who is considered a qualified SP consultant and how to initiate or set up a program with a SP consultant may also be useful. Coaches in maintenance may benefit from transitioning between seasons and strategies used to evaluate the program with the SP consultant.

The TTM has yet to be applied to coach education programs. Measuring a change in attitudes, barriers to service use, and stage of change may provide a more useful evaluative tool of coach education programs. Furthermore, self-help strategies tailored toward coaches stage of change may maximize a follow-up intervention and create forward movement toward regular use of SP services. Using the TTM as a framework for coach education through workshops and self-help material shows promise toward impacting coaches’ attitudes and possible service use, and thus, warrants further investigation.

\section{Summary and Future Directions}

Although coaches recognize the importance of mental skills to athletic success, the majority of coaches have yet to integrate SP services into training. Several factors may be contributing to coaches' reluctance toward using SP services. Variables identified in the literature include attitudes and perceptions, in which some coaches may associate negative connotations with the discipline and may not be confident in the usefulness of SP services. Other variables such as funding, time constraints, and access have been reported by coaches as barriers to service use. Because SP if often not viewed as a traditional aspect of sport, some coaches may not consider SP services as essential. More 
recently, quantitative data has linked coaches’ attitudes (e.g. confidence, stigma tolerance, expectations) with intentions to use SP services. In order to impact coach behaviors and increase service use, researchers need to quantitatively explore the effectiveness of addressing attitudes, perceptions, and barriers within a theoretical framework.

The TTM applied to SP is still in its infancy but shows promise as an effective means of stimulating readiness to use SP services. Although coaches' stage of change has been linked with intentions to use SP services, literature has linked athletes’ readiness with subsequent initiation of SP consultation. Athletes’ perceived gains and losses for initiating SP consultation have also been found to shift before action is taken. In addition, mental skills training workshops have been found to impact athletes’ perceived pros and cons and stage of change profiles. It appears that more subtle changes (e.g. changes in attitudes and pros and cons) will occur before more obvious ones (e.g. regular use of SP services); therefore, measuring attitudinal change and readiness to use SP services may be a useful measure of program effectiveness. The TTM has yet to be applied to coach education and future researchers should consider measuring changes in attitudes, readiness, and use of SP services following a tailored educational workshop.

Literature within SP has yet to apply the TTM toward developing stage-matched interventions with athletes and coaches. However, several researchers have suggested that SP professionals should maximize the impact of interventions by differentiating coaches and athletes' readiness to use SP services and tailoring interventions toward their stage of change. Research with the TTM and physical activity has found stage-matched self-help material to be an effective and inexpensive means toward helping individuals move 
forward in their readiness to change, especially for those in preconemtplation and contemplation. Since the majority of coaches have yet to integrate SP services into training, it would be worthwhile for future research to explore the effectiveness of stagematched material facilitating forward movement toward readiness to use SP services. It would also be useful to assess differences in SP usage behaviors of coaches who receive tailored information compared to those who do not. In addition, stage-matched material may be a cost effective means of reaching a large number of coaches who may not yet be ready to integrate SP services into training. It is hoped that matching interventions with coaches' stage of motivational readiness will lead to an increase in the percentage of coaches who initiate and regularly integrate SP services into training. 


\section{References}

Ajzen, I. (2002). Constructing a TPB questionnaire: Conceptual and methodological considerations. Retrieved October 3, 2006, from http://wwwunix.oit.umass.edu/ ajzen/tpb.html

Anderson, A. G., Hodge, K. P., Lavallee, D., \& Martin, S. (2004). New Zealand athletes’ attitudes towards seeking sport psychology consultation. New Zealand Journal of Psychology, 33, 129-136.

Anshel, M. H. (1989). Examination of a college football coach’s receptivity to sport psychology consulting: A three-year case study. Journal of Applied Research in Coaching and Athletics, 4(3), 139-149.

Anshel, M. H. (1990). Perceptions of black intercollegiate football players: Implications for the sport psychology consultant. The Sport Psychologist, 4, 235-284.

Atkinson, D. R., \& Gim, R. H. (1989). Asian-American cultural identity and attitudes toward mental health services. Journal of Counseling Psychology, 36, 209-212.

Atkinson, D. R., \& Lowe, S. M. (1995). The role of ethnicity, cultural knowledge, and conventional techniques in counseling and psychotherapy. In J. G. Ponterotto, J. M. Casas, L. A. Suzuki, \& C. M. Alexander (Eds.), Handbook of multicultural counseling (pp. 387-414). Thousand Oaks, CA: Sage.

Cale, A., \& Crisfield, P. (1994). Advances in British coach education: A sports psychology perspective. In F. I. Bell \& G. H. Van Gyn (Eds.), Proceedings for the $10^{\text {th }}$ Commonwealth \& International Scientific Congress: access to active living, University of Victoria, 560-564. 
Cardinal, B. J. (1997). Construct validity of stage of change for exercise behavior. American Journal of Health Promotion, 12, 68-74.

Cardinal, B. J., \& Sachs, M. L. (1995). Prospective analysis of stage-of-exercise movement following mail-delivered, self-instructional exercise packets. American Journal of Health Promotion, 9, 430-432.

Cassidy, T., Potrac, P., \& McKenzie, A. (2006). Evaluating and reflecting upon a coach education initiative: The CoDe of rugby. The Sport Psychologist, 20, 145-161.

Cohen, A. (1992). Standard time. A new effort is underway to develop a national coaching education system assuming, that is, that one doesn't already exist. Athletic Business, 16, 23-26; 28.

Curry, T., \& Strauss, R. H. (1994). A little pain never hurt anyone: Athletic career socialization and the normalization of sport injury. Symbolic Interaction, 16, 273290.

Dillman, D. A. (2000). Mail and internet surveys: The tailored design method ( $2^{\text {nd }}$ ed.). New York: John Wiley \& Sons.

Gilljam, M., \& Granberg, D. (1993). Should we take the don't know for an answer? Public Opinion Quarterly, 57, 348-357.

Good, G. E., \& Wood, P. K. (1995). Male gender role conflict, depression, and help seeking: Do college men face double jeopardy? Journal of Counseling Development, 74, 70-75.

Gould, D., Damarjian, N., \& Medbery, R. (1999). An examination of mental skills training in junior tennis coaches. The Sport Psychologist, 13, 127-143. 
Gould, D., Giannini, J., Krane, V., \& Hodge, K. (1990). Educational needs of elite U.S. national team, pan American, and Olympic coaches. Journal of Teaching in Physical Education, 9, 332-344.

Gould, D., Medberry, R., Damarjian, N., \& Lauer, L. (1999). A survey of mental skills training knowledge, opinion, and practices of junior tennis coaches. Journal of Applied Sport Psychology, 11, 28-50.

Gould, D., Murphy, S., Tammen, V., \& May, J. (1991). An evaluation of U.S. Olympic sport psychology consultant effectiveness. The Sport Psychologist, 5, 111-127.

Gould, D., Tammen, V., Murphy, S., \& May, J. (1989). An examination of U.S. Olympic sport psychology consultants and the services they provide. The Sport Psychologist, 3, 300-312.

Greaser, J. R. (1992). Motivational determinants of a sport specific behavior: The effects of attitudes and expectations upon the intentions of sport competitors to practice sport psychology skills. Unpublished doctoral dissertation, University of Connecticut, Storrs.

Grove, J. R., Norton, P. J., Van Raalte, J. L., \& Brewer, B. W. (1999). Stage of change as an outcome measure in the evaluation of mental skills training programs. The Sport Psychologist, 13, 107-116.

Haslam, I. R. (2004). Psychological skills training: A qualitative study of Singapore coaches. Journal of Physical Education \& Recreation, 10, 37-47.

Janis, I. L., \& Mann, L. (1977). Decision making: A psychological analysis of conflict, choice, and commitment. London: Cassel \& Collier Macmillan. 
Keeler, L. A. (2006). The transtheoretical model and psychological skills training: Application and implications with elite female athletes. Unpublished doctoral dissertation, West Virginia University, Morgantown.

Kennedy, G. E. (1994). Multicultural investigation of counseling expectations and preferences. Journal of College Student Psychotherapy, 9, 21-39.

Kimiecik, J., \& Gould, D. (1987). Coaching psychology: The case of James “Doc” Counsilman. The Sport Psychologist, 1, 350-358.

Kremer, P. J., \& Marchant, D. B. (2002). Reflections and considerations of providing sport psychology services with professional football players. In W. Spinks (Ed.), Science and Football IV (pp.294-299). London: Routledge.

Leffingwell, T. R., Rider, S. P., \& Williams, J. M. (2001). Applications of the Transtheoretical model to psychological skills training. The Sport Psychologist, 15, 168-187.

Linder, D. E., Brewer, B. W., Van Raalte, J. L., \& DeLange, N. (1991). A negative halo for athletes who consult sport psychologists: replication and extension. Journal of Sport \& Exercise Psychology, 13, 133-148.

Linder, D. E., Pillow, D. R., \& Reno, R. R. (1989). Shrinking jocks: Derogation of athletes who consult a sport psychologist. Journal of Sport \& Exercise Psychology, 11, 270-280.

Maniar, S. D., Curry, L. A., Sommers-Flanagan, J., \& Walsh, J. A. (2001). Studentathlete preferences in seeking help when confronted with sport performance problems. The Sport Psychologist, 15, 205-223. 
Marcus, B. H., Banspach, S. W., Lefebvre, R. C., Rossi, J. S., Carleton, R. A., \& Abrams, D. B. (1992). Using the stages of change model to increase the adoption of physical activity among community participants. American Journal of Health Promotion, 6, 424- 429.

Marcus, B. H., Emmons, K. M., Simikin-Silverman, L. R., Linnan, L. A., Taylor, E. R., Bock, B. C., et al. (1998). Evaluation of motivationally tailored vs. standard selfhelp physical activity interventions at the workplace. American Journal of Health Promotion, 12, 246-253.

Marcus, B., \& Forsyth, L. (2003). Motivating people to be physically active. Champaign, IL: Human Kinetics.

Marcus, B. H., Selby, V. C., Niarua, R. S., \& Rossi, J. S. (1992). Self-efficacy and the stages of exercise behavior change. Research Quarterly for Exercise and Sport, 63, 60-66.

Martin, S. B. (2005). High school and college athletes’ attitudes toward sport psychology consulting. Journal of Applied Sport Psychology, 17, 127-139.

Martin, S. B., Kellmann, M. Lavallee, D., \& Page, S. J. (2002). Development and psychometric evaluation of the sport psychology attitudes- Revised form: A multiple group investigation. The Sport Psychologist, 16, 272-290.

Martin, S. B., Lavallee, D., Kellman, M., \& Page, S. J. (2004). Attitudes toward sport psychology consulting of adult athletes from the United States, United Kingdom, and Germany. International Journal of Sport and Exercise Psychology, 2, 146160. 
Martin, S. B., Wrisberg, C. A., Beitel, P. A., \& Lounsbury, J. (1997). NCAA Division I athletes’ attitudes toward seeking sport psychology consultation: The development of an objective instrument. The Sport Psychologist, 11, 201-218.

McMillin, C. J., \& Reffner, C. (Eds.). (1999). Directory of college and university coaching education programs. Morgantown: Fitness Information Technology.

Messner, M. A. (1992). Power at play: Sports and the problem of masculinity. Boston. Beacon Press.

Murstein, B. I., \& Fontaine, P. A. (1993). The public's knowledge about psychologists and other mental health professionals. American Psychologist, 48, 839-845.

National Association for Sport and Physical Education (NASPE). (2006). National Standards for Athletic coaches. Reston, VA: Author.

Nixon, H. L. (1996). Explaining pain and injury attitudes and experiences in sport in terms of gender, race, and sports status factors. Journal of Sport \& Social Issues, 20, 33-44.

Pain, M. A., \& Harwood, C. G. (2004). Knowledge and perceptions of sport psychology within English soccer. Journal of Sports Sciences, 22, 813-826.

Partington, J., \& Orlick, T. (1987). The sport psychology consultant: Olympic coaches’ views. The Sport Psychologist, 1, 95-102.

Partlow, K. (1992). American Coaching Effectiveness Program (ACEP)- educating America’s coaches. The Journal of Physical Education, Recreation, and Dance, 63, 36-39. 
Perz, C. A., DiClemente, C. C., \& Carbonari, J. P. (1996). Doing the right thing at the right time? The interaction of stages and processes of change in successful smoking cessation. Health Psychology, 15, 462-468.

Prochaska, J. O., \& DiClemente, C. C. (1983). Stages and processes of self-change of smoking: toward an integrative model of change. Journal of Consulting and Clinical Psychology, 51, 390-395.

Prochaska, J. O., Velicer, W. F., DiClemente, C. C., \& Fava, J. (1988). Measuring processes of change: Applications to the cessation of smoking. Journal of Consulting and Clinical Psychology, 4, 520-528.

Prochaska, J. O., Velicer, W. F., Rossi, J. S., Goldstein, M. G., Marcus, B. H., Rakowski, W., Fiore, C., Harlow, L. L. et al. (1994). Stages of change and decisional balance for 12 problem behaviors. Health Psychology, 13, 39-46.

Ravizza, K. (1988). Gaining entry with athletic personnel for season-long consulting. The Sport Psychologist, 2, 243-254.

Rice, T. S. (1996). Should coaches administer psychological interventions to their athletes? Unpublished doctoral dissertation, West Virginia University, Morgantown.

Scully, D., \& Hume, A. (1995). Sport psychology: Status, knowledge and use among elite level coaches and performers in Ireland. The Irish Journal of Psychology, 16, 5266.

Silva, J. (1984). The status of sport psychology: A national survey of coaches. Journal of Physical Education, Recreation, and Dance, 55(7), 46-49. 
Smith, R. E., Smoll, F. L., \& Curtis, B. (1979). Coaching effectiveness training: A cognitive-behavioral approach to enhancing relationship skills in youth sport coaches. Journal of Sport Psychology, 1, 59-75.

Sullivan, J., \& Hodge, K. P. (1991). A survey of coaches and athletes about sport psychology in New Zealand. The Sport Psychologist, 5, 140-151.

Van Raalte, J. L., Brewer, B. W., Brewer, D. D., \& Linder, D. E. (1992). NCAA division II college football players’ perceptions of an athlete who consults a sport psychologist. Journal of Sport \& Exercise Psychology, 14, 273-282.

Van Raalte, J. L., Brewer, D. D., Brewer, B. W., \& Linder, D. E. (1993). Sport psychologists’ perceptions of sport and mental health practitioners. Journal of Applied Sport Psychology, 5, 222-233.

Van Raalte, J. L., Brewer, B. W., Linder, D. E., \& DeLange, N. (1990). Perceptions of sport-oriented professional: A multidimensional scaling analysis. The Sport Psychologist, 4, 228-234.

Van Raalte, J. L., Brewer, D. D., Matheson, H., \& Brewer, B. W. (1996). British athletes perceptions of sport and mental health practitioners. Journal of Applied Sport Psychology, 8, 102-108.

Velicer, W. F., DiClemente, C. C., Prochaska, J. O., \& Brandenburg, N. (1985). A decisional balance measure for predicting smoking cessation. Journal of Personality and Social Psychology, 48, 1279-1289.

Voight, M., \& Callaghan, J. (2001). The use of sport psychology services at NCAA Division I Universities. The Sport Psychologist, 15, 91-102. 
Weinberg, R. S., \& Gould, D. (1999). Foundations of sport and exercise psychology $\left(2^{\text {nd }}\right.$ ed.). Champaign, IL: Human Kinetics.

Wrisberg, C. A. (1990). An interview with Pat Head Summit. The Sport Psychologist, 4, 180-191.

Yambor, J., \& Connelly, D. (1991). Issues confronting female sport psychology consultants working with male student-athletes. The Sport Psychologist, 5, 304312.

Zakrajsek, R. A., \& Zizzi, S. J. (2007). Factors influencing track and swimming coaches’ intentions to use sport psychology services. Athletic Insight: The Online Journal of Sport Psychology, 9(2). Retrieved September 29, 2007, from http://www.athleticinsight.com/Vol9Iss2/CoachesIntentions.htm

Zakrajsek, R. A., \& Zizzi, S. J. (2005, October). Coaches’ intentions to use sport psychology services and their preferences for different contact methods. Poster session presented at the annual meeting of the Association of the Advancement of Applied Sport Psychology, Vancouver, BC.

Zizzi, S., Blom, L., Watson, J., Downey, V., \& Geer, J. (2005). Establishing a hierarchy of psychological skills: Coaches, athletic trainers, and psychologists' uses and perceptions of psychological skills training. International Sport Journal.

Zizzi, S. J., \& Perna. F. M. (2002). Integrating web pages and e-mail into sport psychology consultations. The Sport Psychologist, 16, 416-431. 
Zizzi, S. J., \& Perna, F. M. (2003). Impact of a brief workshop on stages of change profiles in athletes. Athletic Insight: The Online Journal of Sport Psychology, 5(4). Retrieved October, 24, 2004, from http://www.athleticinsight.com/Vol5Iss4/ImpactofBriefWorkshop.htm 